\title{
MODELING SENSIBLE HEAT DRIVEN DIRECT CONTACT MEMBRANE DISTILLATION TREATMENT OF OILFIELD PRODUCED WATER
}

\author{
A Thesis \\ presented to \\ the Faculty of California Polytechnic State University, \\ San Luis Obispo
}

\author{
In Partial Fulfillment \\ of the Requirements for the Degree \\ Master of Science in Civil and Environmental Engineering
}

by

Tyler Gregory Dery

June 2019 
(C) 2019

Tyler Gregory Dery

ALL RIGHTS RESERVED 


\section{COMMITTEE MEMBERSHIP}

TITLE: Modeling Sensible Heat Driven Direct Contact Membrane Distillation Treatment of Oilfield Produced Water

AUTHOR: $\quad$ Tyler Gregory Dery

DATE SUBMITTED: June 2019

COMMITTEE CHAIR: Yarrow Nelson, Ph.D.

Professor of Environmental Engineering

COMMITTEE MEMBER: Rebekah Oulton, Ph.D.

Assistant Professor of Civil \& Environmental Engineering

COMMITTEE MEMBER: Amro El Badawy, Ph.D.

Assistant Professor of Environmental

Engineering 


\begin{abstract}
Modeling Sensible Heat Driven Direct Contact Membrane Distillation Treatment of Oilfield Produced Water

Tyler Gregory Dery
\end{abstract}

A model was developed for predicting the performance of direct contact membrane distillation (DCMD) to evaluate the feasibility of using sensible heat to drive DCMD treatment of oilfield produced water. Algorithms for performance prediction of instantaneous and counter-current DCMD flow were developed. These algorithms used equation-based models of heat transfer, mass transfer, concentration polarization, and counter-current flow to predict performance of DCMD systems. The performance prediction model was validated against experimental data from the literature, and limitations to the accuracy of predictions were identified. The model was applied to evaluate performance sensitivity to nine operational parameters. The model was applied to evaluate the feasibility of sensible heat driven DCMD treatment of produced water using DCMD alone and using a reverse osmosis-DCMD hybrid system. The largest water recoveries that were energetically favorable (lower energy demand than reverse osmosis) for sensible heat driven DCMD produced water treatment were $0.5 \%$ and $0.75 \%$ for $1 \%$ and $3.5 \% \mathrm{NaCl}$ feeds, respectively. As feed $\mathrm{NaCl}$ concentration increased, higher recoveries were energetically favorable over RO. A bulk $\mathrm{NaCl}$ concentration of $6 \%$ was evaluated to simulate the feasibility of further treatment of reverse osmosis retentate using sensible heat driven DCMD. Compared to treatment alternatives of multiple-stage flash distillation (MSF) and multiple-effect distillation (MED), recoveries up to $2.5 \%$ were favorable and up to $4.0 \%$ were competitive. Due to model limitations, the performance of optimal conditions for sensible heat driven DCMD produced water treatment could not be predicted, so the recoveries presented in this work are likely lower than the expected recoveries for optimal field conditions. Water recovery of produced water using sensible heat driven DCMD is limited thermodynamically to low recoveries, but any treatment using sensible heat that is energetically favorable reflects the utilization of two waste streams (produced water and waste heat) to produce high quality water. Using sensible heat to drive produced water treatment could be useful for providing small quantities of usable water, but would only result in a very small reduction of the volume of produced water needing to be disposed. 


\section{TABLE OF CONTENTS}

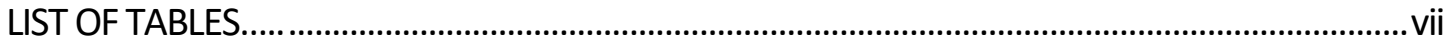

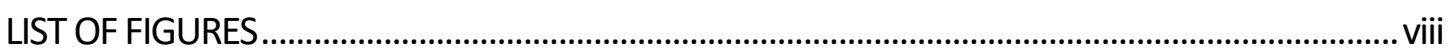

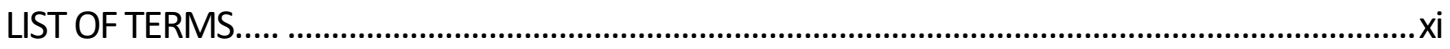

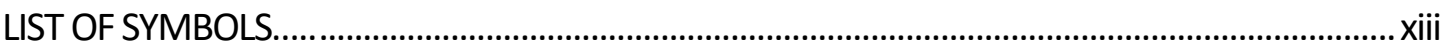

CHAPTER

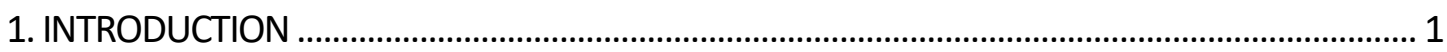

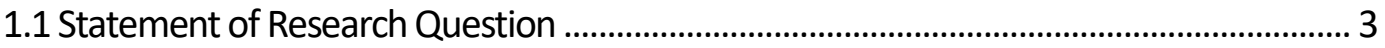

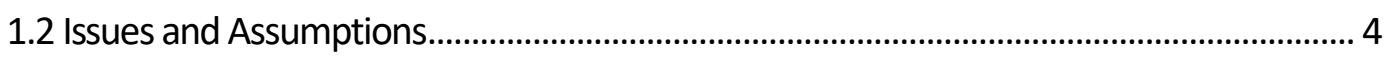

1.3 General Approach ..................................................................................................... 5

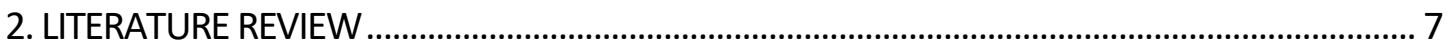

2.1 Membrane Distillation Background ............................................................................. 7

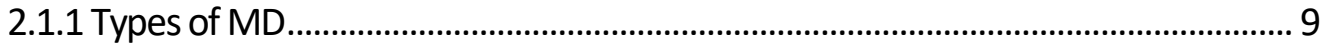

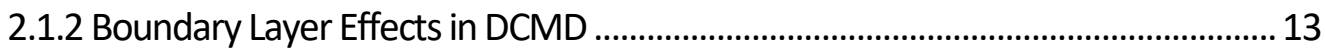

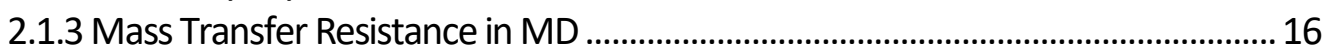

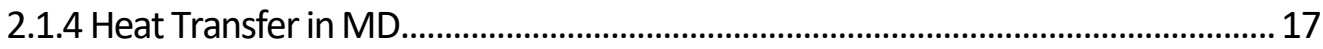

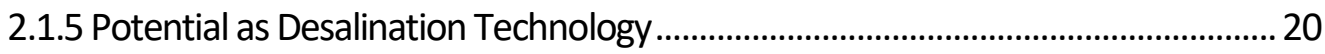

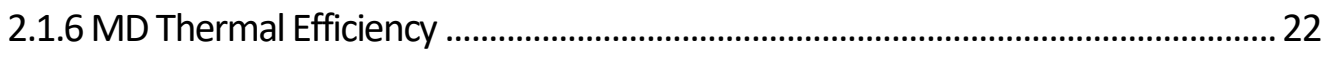

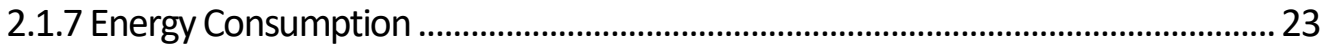

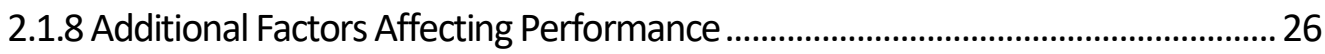

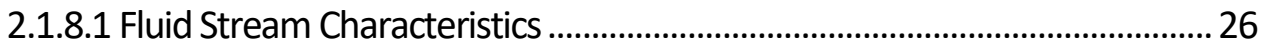

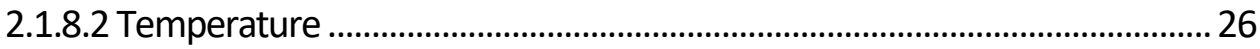

2.1.8.3 Membrane Composition ............................................................................. 27

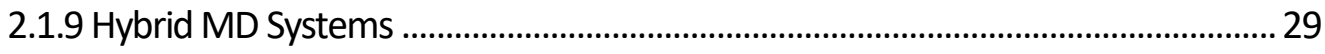

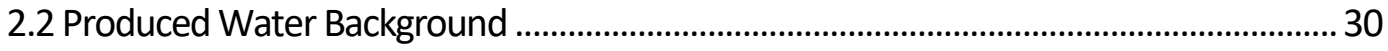

2.2.1 Produced Water Viability for MD Treatment ....................................................... 32

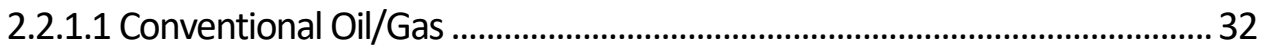

2.2.1.2 Hydraulic Fracturing ...................................................................................... 35

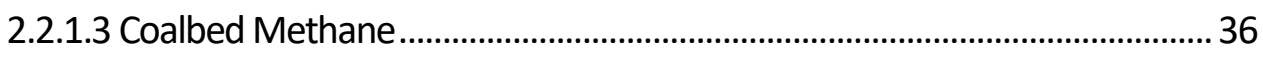

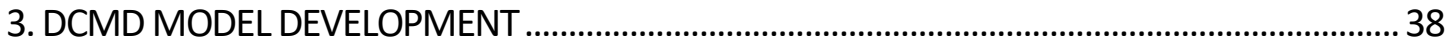

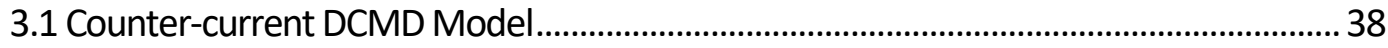

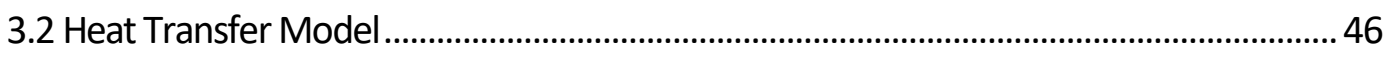

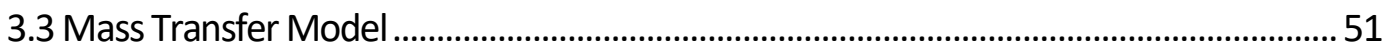

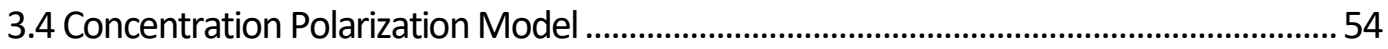

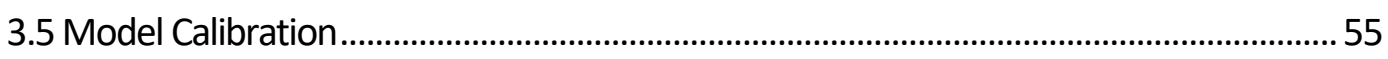

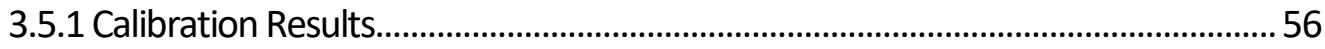

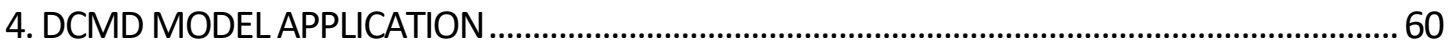

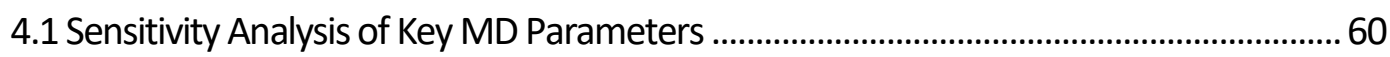

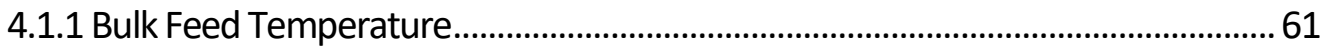

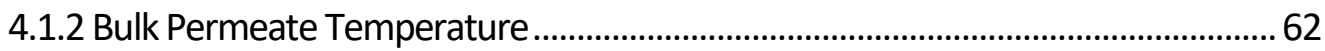




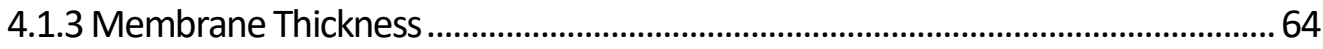

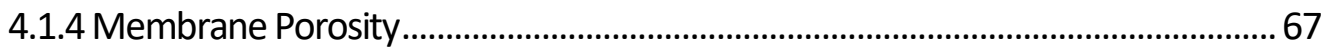

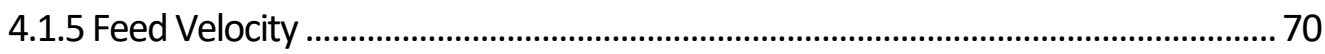

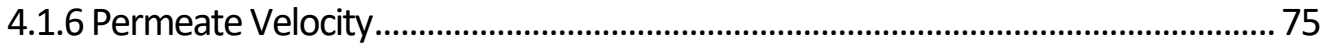

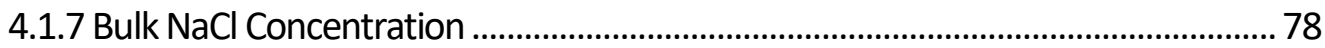

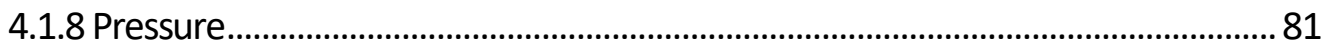

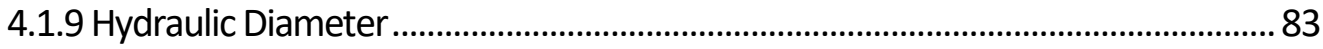

4.2 DCMD Desalination Potential Using Sensible Heat ............................................................ 87

4.2.1 Selection of Operational Parameters for DCMD Produced Water Treatment.... 88

4.2.2 Evaluation of Sensible Heat Driven DCMD Produced Water Treatment ............. 92

4.2.3 Hybrid RO-DCMD Produced Water Treatment Using Sensible Heat .................. 103

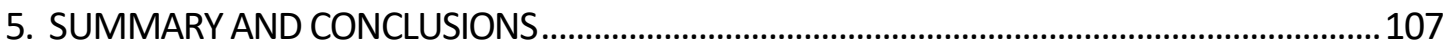

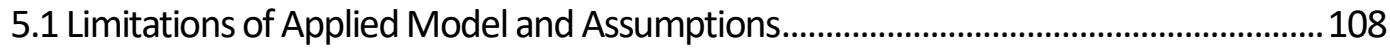

5.2 DCMD Operational Parameter Sensitivity...................................................................109

5.3 Feasibility of DCMD Produced Water Treatment Using Sensible Heat .........................112

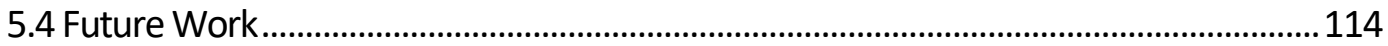

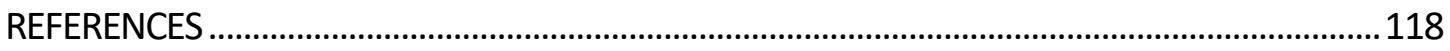

APPENDICES

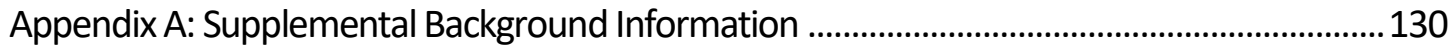

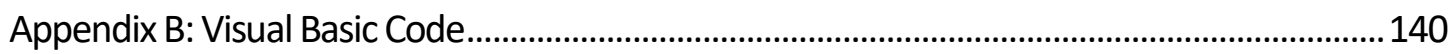

Appendix C: Instantaneous Algorithm Spreadsheet............................................................ 148 


\section{LIST OF TABLES}

Table

Page

1. Cath et al Experimental Parameters Applied for Calibration ................................. 56

2. Parameters for Produced Water Recovery Analysis......................................... 89 


\section{LIST OF FIGURES}

$\begin{array}{ll}\text { Figure } & \text { Page }\end{array}$

1. Diagram of membrane distillation process operating in counter-current

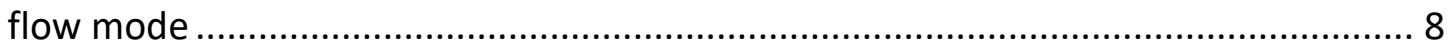

2. Schematic diagram of the four most common MD configurations ........................... 10

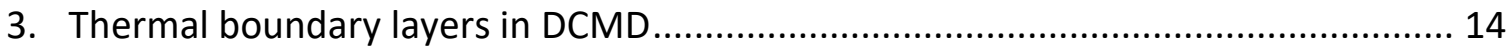

4. Concentration boundary layers in DCMD that lead to concentration polarization ... 15

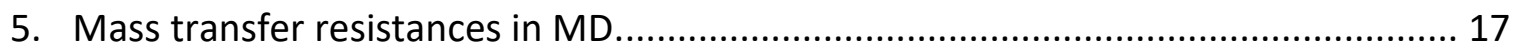

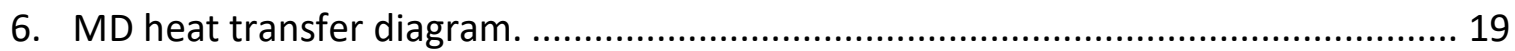

7. Schematic of hybrid RO-MD treatment process.................................................... 30

8. Produced water TDS distribution for conventional oil/gas extraction ...................... 34

9. Coalbed methane TDS distribution in the western United States.......................... 37

10. Counter-current DCMD incremental volume analysis schematic diagram ............... 40

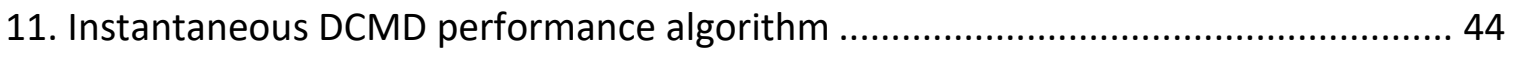

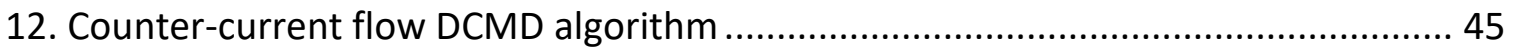

13. Comparison of predicted flux vs feed temperature values to experimental results

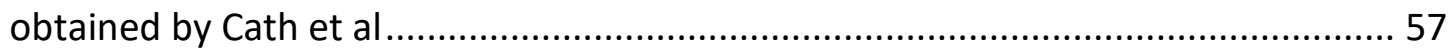

14. Comparison of predicted flux vs feed velocity values to experimental results

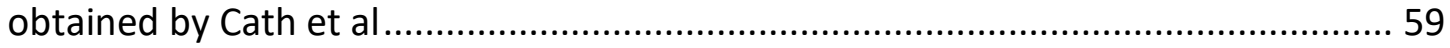

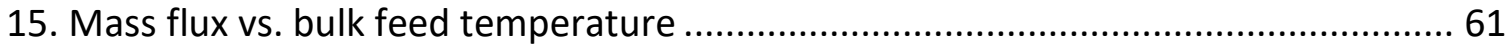

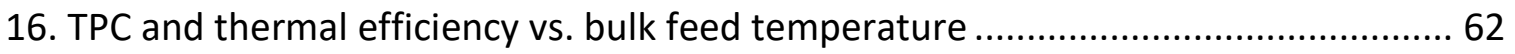

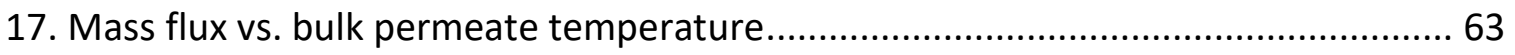

18. TPC and thermal efficiency vs. bulk permeate temperature ................................. 64

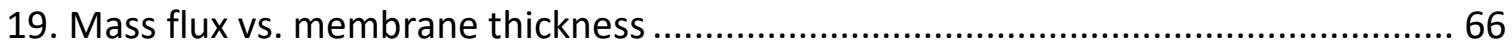

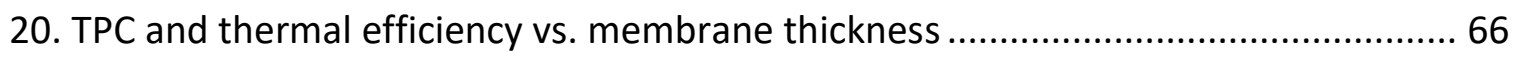

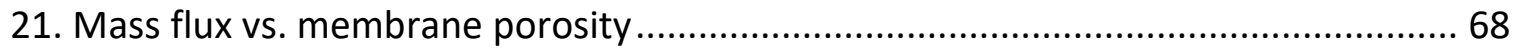


22. TPC and thermal efficiency vs. membrane porosity.

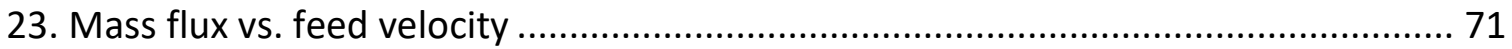

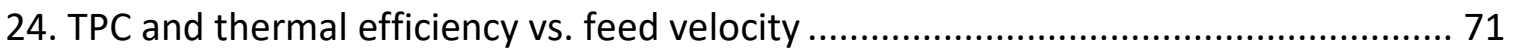

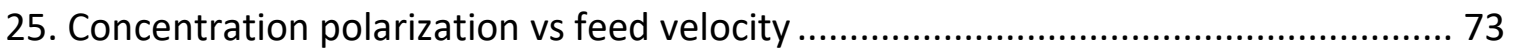

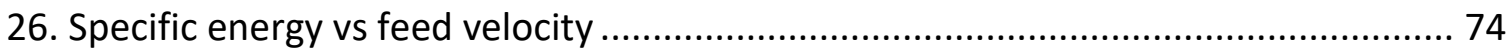

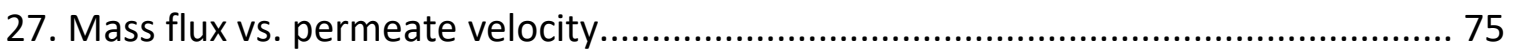

28. TPC and thermal efficiency vs. permeate velocity............................................ 76

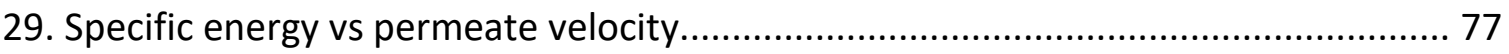

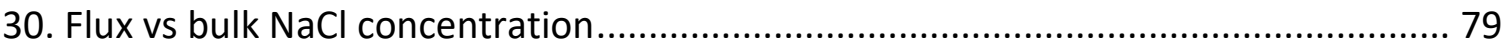

31. Temperature polarization and thermal efficiency vs $\mathrm{NaCl}$ concentration ................ 80

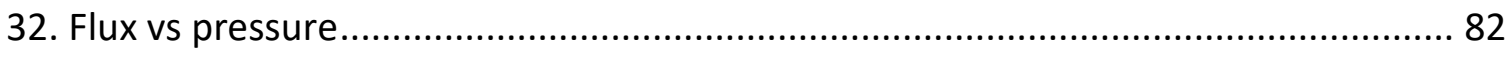

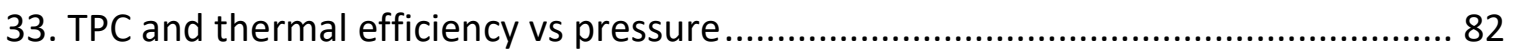

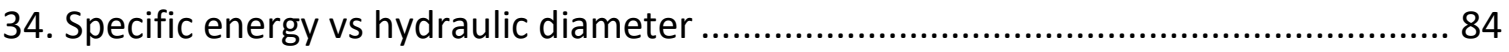

35. Hydraulic energy consumption and flux vs hydraulic diameter from

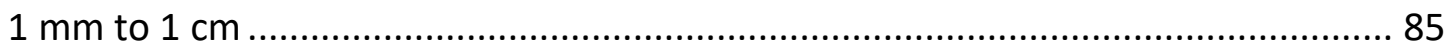

36. Hydraulic energy consumption and flux vs hydraulic diameter from

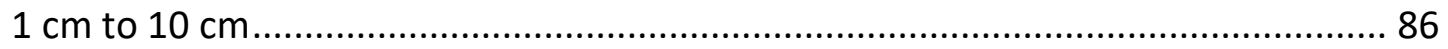

37. Concentration polarization vs hydraulic diameter from $1 \mathrm{~mm}$ to $10 \mathrm{~cm}$................. 87

38. Results of counter-current DCMD algorithm showing bulk temperatures and flux vs the length along the membrane channel ............................................................ 94

39. Percent recovery from sensible heat vs counter-current DCMD module length for feed inlet temperatures ranging from $50^{\circ} \mathrm{C}$ to $94^{\circ} \mathrm{C}$

40. Hydraulic energy consumption vs counter-current DCMD module length for feed inlet temperatures ranging from $50^{\circ} \mathrm{C}$ to $94^{\circ} \mathrm{C}$

41. Percent recovery from sensible heat and hydraulic energy consumption vs countercurrent DCMD module length for feed inlet temperatures of $90^{\circ} \mathrm{C}$ and $94^{\circ} \mathrm{C}$ 
42. Counter-current simulation of recovery and specific hydraulic energy consumption vs module length for $1 \%$ and $3.5 \%$ by weight $\mathrm{NaCl}$ feeds

43. Counter-current simulation of recovery and specific hydraulic energy consumption vs bulk $\mathrm{NaCl}$ concentration

44. Counter-current simulation of recovery and specific hydraulic energy consumption vs module length for $6 \%$ by weight $\mathrm{NaCl}$ feed 
LIST OF TERMS

AGMD - Air gap membrane distillation

bbl - Barrel, 1 bbl = 42 gallons

CBM - Coal-bed methane

$\mathrm{CP}$ - Concentration polarization

CPC - Concentration polarization coefficient

DCMD - Direct contact membrane distillation

GOR - Gained output ratio

$\mathrm{HF}$ - Hydraulic fracturing

MD - Membrane Distillation

MED - Multiple-effect distillation

MSF - Multiple-stage flash distillation

$\mathrm{Nu}-$ Nusselt number

Pr - Prandtl number

PP - Polypropylene

PTFE - polytetrafluoroethylene

PVDF - Polyvinylidene fluoride

Re - Reynold's number 
RO - Reverse osmosis

Sc - Schmidt number

SEC - Specific energy consumption $\left(\mathrm{kWh} / \mathrm{m}^{3}\right)$

SGMD - Sweeping gas membrane distillation

Sh - Sherwood number

SHEC - Specific hydraulic energy consumption $\left(\mathrm{kWh} / \mathrm{m}^{3}\right)$

STEC - Specific thermal energy consumption $\left(\mathrm{kWh} / \mathrm{m}^{3}\right)$

TDS - Total Dissolved Solids

TP - Temperature polarization

TPC - Temperature polarization coefficient

UF - Ultrafiltration

VMD - Vacuum membrane distillation

WGR - Water-to-gas ratio

WOR - Water-to-oil ratio 


\section{LIST OF SYMBOLS}

$C=$ Concentration of $\mathrm{NaCl}(\%)$

$C p=$ Heat capacity $(\mathrm{J} / \mathrm{kg} . \mathrm{K})$

$d=$ Hydraulic diameter $(\mathrm{m})$

$d x=$ Incremental length $(\mathrm{m})$

$d m=$ Incremental mass flow rate $(\mathrm{kg} / \mathrm{s})$

$d Q=$ Incremental heat rate $(\mathrm{W})$

$D_{N a C l}=$ Diffusivity of $\mathrm{NaCl}$ in water $\left(\mathrm{m}^{2} / \mathrm{s}\right)$

$D_{w}=$ Diffusion coefficient $\left(\mathrm{m}^{2} / \mathrm{s}\right)$

$D_{w, \text { eff }}=$ Effective diffusion coefficient $\left(\mathrm{m}^{2} / \mathrm{s}\right)$

$g=$ Acceleration due to gravity, $9.81 \mathrm{~m} / \mathrm{s}^{2}$

$H=$ Membrane channel Height (m)

$h=$ Heat transfer coefficient $\left(\mathrm{W} / \mathrm{m}^{2} . \mathrm{K}\right)$

$h_{l}=$ Head loss due to friction (m)

$H_{v}=$ Heat of vaporization of water $(\mathrm{J} / \mathrm{mole})$

$k=$ Thermal conductivity $(\mathrm{W} / \mathrm{m} . \mathrm{K})$

$k_{c}=$ Convective mass transfer coefficient of the feed stream $(\mathrm{m} / \mathrm{s})$

$m=$ Mass flow rate $(\mathrm{kg} / \mathrm{s})$

$M_{w}=$ Molecular weight of water $(\mathrm{kg} / \mathrm{mole})$

$N=$ Molar flux of water vapor $\left(\mathrm{mol} / \mathrm{m}^{2} . \mathrm{s}\right)$ 
$p(T)=$ Saturation vapor pressure of water $(\mathrm{Pa})$

$P=$ Pressure $(\mathrm{Pa})$

$Q_{c}=$ Conductive heat transfer across the membrane (W)

$Q_{v}=$ Vaporization heat transfer across the membrane (W)

$R=$ Gas constant, $8.314(\mathrm{~J} / \mathrm{mole} . \mathrm{K})$

$S=$ Salinity $(\% \mathrm{NaCl})$

$T=$ Temperature $(\mathrm{K})$

$T_{m}=$ Mean membrane temperature $(\mathrm{K})$

$v=$ Flow velocity $(\mathrm{m} / \mathrm{s})$

$V_{t}=$ Volume of water treated $\left(\mathrm{m}^{3}\right)$

$W=$ Module width $(\mathrm{m})$

$x_{w}=$ Mole fraction of water in feed solution

$\Delta T_{m}=$ Membrane temperature difference $(\mathrm{K})$

$\epsilon=$ Membrane porosity

$\rho=$ Fluid density $\left(\mathrm{kg} / \mathrm{m}^{3}\right)$

$\eta_{T}=$ Thermal efficiency

$\mu=$ Dynamic viscosity (Pa.s)

$\delta=$ Membrane thickness $(\mathrm{m})$

$\beta=$ Intermediate factor for determining thermal conductivity

$\gamma_{m f}=$ Water vapor activity coefficient 
Subscripts:

ave $=$ Average

$b=$ Bulk fluid

$f=$ Feed

$g=$ Gas

$m=$ membrane

$p=$ Permeate

$S=$ Solid

$i=$ Current Iterative step

$i+1=$ Next Iterative step

$w=$ Water

wall $=$ At the membrane surface 


\section{Chapter 1}

\section{INTRODUCTION}

Produced water is a byproduct of oil and gas extraction and its disposal is a major concern. Costs for disposal of produced water using disposal wells can range from $\$ 0.07$ to $\$ 1.75$ per barrel (bbl) (USBR, 2014) Recycling can be an effective way to recover water and reduce disposal costs. In 2012, the United States extracted 21.2 billion bbl of produced water (GWPC, 2015). Produced water is often more saline than seawater, and can contain other constituents that include oil \& grease, production chemicals, and heavy metals (Ray \& Engelhardt, 1992)(Alkhudhiri et al, 2013)(Han et al, 2017). Treatment of produced water for reuse can help to ease existing water scarcity in oil and gas well locations (USBR, 2016).

Membrane distillation (MD) technology can help expand the ways that we can recycle water and utilize waste energy streams. MD is a thermal separation process that transfers water vapor from a feed solution across a hydrophobic membrane into a distillate stream (Lawson \& Lloyd, 1997). The temperature difference between the feed solution and permeate stream causes a vapor pressure gradient that drives the formation and movement of water vapor across the membrane (Colorado School of Mines, 2009) (Martinez, 2004). MD can operate at a temperature difference as low as $10^{\circ} \mathrm{C}$ allowing it to operate at lower temperatures than other thermal desalination processes. The most common configuration of MD is direct contact membrane distillation ( $D C M D)$, where the feed and permeate streams contact the membrane. MD has low flux variation with increased salt concentration, so it can treat high total dissolved solids (TDS) concentrations (Zhang et al, 2015a) (Martinez, 2004). The ability 
of MD to treat high concentration solutions distinguishes MD from other membrane desalination technologies such as reverse osmosis (RO).

MD is most economically feasible when utilizing waste heat from an existing process. Typical feed temperatures range from 60 to $90^{\circ} \mathrm{C}$ (Lawson \& Lloyd, 1997). These sub-boiling temperature allow MD to use heat sources such as solar and geothermal, and low-grade waste heat. The use of waste heat can allow MD to operate at similar costs to reverse osmosis (RO) (Alklaibi \& Lior, 2004).

MD has been demonstrated to be effective for treating produced water or produced water brines to high water recovery rates (Duong et al, 2015a) (Lokare et al, 2017) (Kim et al, 2017) (Kim et al, 2018) (Cho et al, 2016) (Chew et al, 2017) (CSM, 2009) (Alkhudhiri et al, 2012). High salinity RO systems have recoveries that are limited to 4050\% (Duong et al, 2015c). Combined MD-RO hybrid processes can increase water recovery due to the ability of MD to operate at TDS concentrations much larger than RO. MD-RO hybrid systems use MD to treat high concentration RO retentate (Duong et al, 2015a).

Produced water temperatures can range from 50 to $94^{\circ} \mathrm{C}$ (Ray \& Engelhardt, 1992). The sensible heat from these high temperature produced waters could be used to drive MD treatment of produced waters at low recovery levels (thermodynamic limit of approximately $0.2 \% /{ }^{\circ} \mathrm{C}$ sensible heat utilized). Utilizing sensible heat to treat produced water represents the use of two waste streams to produce high quality treated water. Currently, there is no work specifically focused on utilizing sensible heat 
from produced water to drive DCMD produced water treatment. This work seeks to evaluate the feasibility of using sensible heat to drive DCMD produced water treatment.

Sensible heat driven treatment must be energetically favorable over treatment alternatives for the utilization of this waste heat source to be feasible. Both the extent of possible treatment and the extent to which the process is energetically favorable need to be known to evaluate the feasibility of utilizing sensible heat to drive MD. Additionally, the feasibility of using sensible heat is different for low $\mathrm{NaCl}$ concentration MD treatment and for high $\mathrm{NaCl}$ concentration MD treatment as would be found in an RO-MD hybrid system, so both scenarios must be considered. The ability of MD to treat high concentration solutions may allow MD to be more energetically competitive at high concentrations.

\subsection{Statement of Research Question}

This work seeks to add to the current knowledge of the factors that affect DCMD performance. Consequently, this work has two primary goals: to evaluate the feasibility of using sensible heat from high temperature produced water to drive DCMD treatment of the produced water stream, and to model and evaluate the sensitivity of DCMD performance based on key operational parameters.

Currently, there is little information available on the possibilities of treating produced water using sensible heat as an energy source for DCMD desalination. Though the thermodynamic extent of sensible heat distillation is limited to low recoveries, sensible heat could allow some treatment of a waste water source at low cost by using waste heat already present. Use of sensible heat can also be integrated with other 
waste heat sources to improve recovery. A way of predicting MD performance was necessary to evaluate the feasibility of sensible heat driven produced water treatment using MD. Using a model-based approach, this study evaluates the extent to which sensible heat driven DCMD is energetically feasible over alternative treatment technologies. This work considers sensible heat driven produced water treatment using DCMD alone and treatment using RO-DCMD hybrid systems where RO retentate is further treated by DCMD. Utilization of sensible heat to treat produced water has the possibility to produce low level recovery using waste streams or augment high recovery produced water treatment systems.

DCMD is a promising desalination technology whose performance is heavily dependent on the operational parameters selected. Fluid parameters, thermal parameters, and membrane module parameters all impact the performance of DCMD treatment, so an understanding of the effect each parameter has on performance is valuable in evaluating the extent to which DCMD can be applied to treat water. This work evaluates the effect of nine key operational parameters on DCMD performance and suggests conditions that can optimize performance. The nine parameters evaluated were bulk feed temperature, bulk permeate temperature, membrane thickness, membrane porosity, feed velocity, permeate velocity, bulk $\mathrm{NaCl}$ concentration, pressure, and hydraulic diameter.

\subsection{Issues and Assumptions}

The model was developed using assumptions that were contained within the applied equation-based models of heat transfer, mass transfer, concentration 
polarization, and counter-current flow. A description of the assumptions of the model can be found in Sections 3.1-3.4. There are also real-world limitations to some membrane parameters that can not be accurately described using a simulation. Where applicable, these limitations are discussed in the sensitivity analysis (see Section 4.1). There are also limitations to the extent to which the model algorithms can predict performance. These limitations are described in Sections 4.1 and 5.1. A further analysis of the life cycle costs and impacts of treatment using various technologies would be needed to fully consider the best available treatment method.

\subsection{General Approach}

A model for predicting performance of DCMD systems was created. The model is composed of two algorithms that can predict instantaneous DCMD performance and DCMD performance in a counter-current flow module. The algorithms utilize equationbased models for heat transfer, mass transfer, concentration polarization, and countercurrent flow. The model can predict the performance of a DCMD system based on nine operational parameters: bulk feed temperature, bulk permeate temperature, membrane thickness, membrane porosity, feed velocity, permeate velocity, bulk $\mathrm{NaCl}$ concentration, pressure, and hydraulic diameter. Using the instantaneous performance algorithm, the sensitivity of DCMD performance to variation in each of these parameters was evaluated.

A set of parameters that minimized DCMD energy consumption was selected for use in produced water sensible heat analysis. Not all parameters could be optimized to reduce energy consumption due to limitations in the model. The performance of DCMD 
modules was evaluated based on feed inlet temperature and module length using these operating parameters and the counter-current module algorithm. An energy-use comparison of hydraulic energy (from pumping) consumption and percent water recovery was conducted to determine the favorability of using sensible heat from high temperature produced water to drive DCMD treatment. The energy demands of a DCMD system using sensible heat were compared to RO energy demands to assess the feasibility of utilizing the waste heat. The performance of a DCMD-RO hybrid system was evaluated using a high $\mathrm{NaCl}$ feed concentration. This work only considers energy-use comparisons of DCMD to alternative treatment technologies. In reality, the energy demand of treatment technologies is only one factor in determining the most appropriate treatment technology. 


\section{Chapter 2}

\section{LITERATURE REVIEW}

An evaluation of current knowledge and application of membrane distillation is needed to effectively evaluate performance and predict the feasibility of sensible heat driven membrane distillation treatment of produced water. Background on oilfield produced water is needed to understand the challenges and opportunities of treatment.

\subsection{Membrane Distillation Background}

Membrane distillation (MD) is a thermal separation process where a temperature difference across a hydrophobic membrane causes a vapor pressure gradient that drives water vapor across the membrane (Lawson \& Lloyd, 1997). The membrane lies between a hot channel that contains the feed solution and a cold channel that contains permeate or a coolant. Water vapor forms at the interface of the warm channel and the membrane surface and travels across the membrane where it is condensed by a cold stream or a cooling surface (Figure 1). The driving force of MD is the vapor pressure gradient between the hot and cold streams that can be measured by a bulk temperature difference of the two streams. Typical bulk feed temperatures for MD are 60 to $90^{\circ} \mathrm{C}$ (Lawson \& Lloyd, 1997). MD flux is typically much lower than RO flux, meaning that MD requires a larger membrane surface area for similar treatment capacity. Permeate flux can be as high as $75 \mathrm{~kg} / \mathrm{m}^{2}-\mathrm{hr}$, but various factors can affect permeate flux including temperature, fluid characteristics, and membrane composition (see Section 2.1.8) (Lawson \& Lloyd, 1997). 


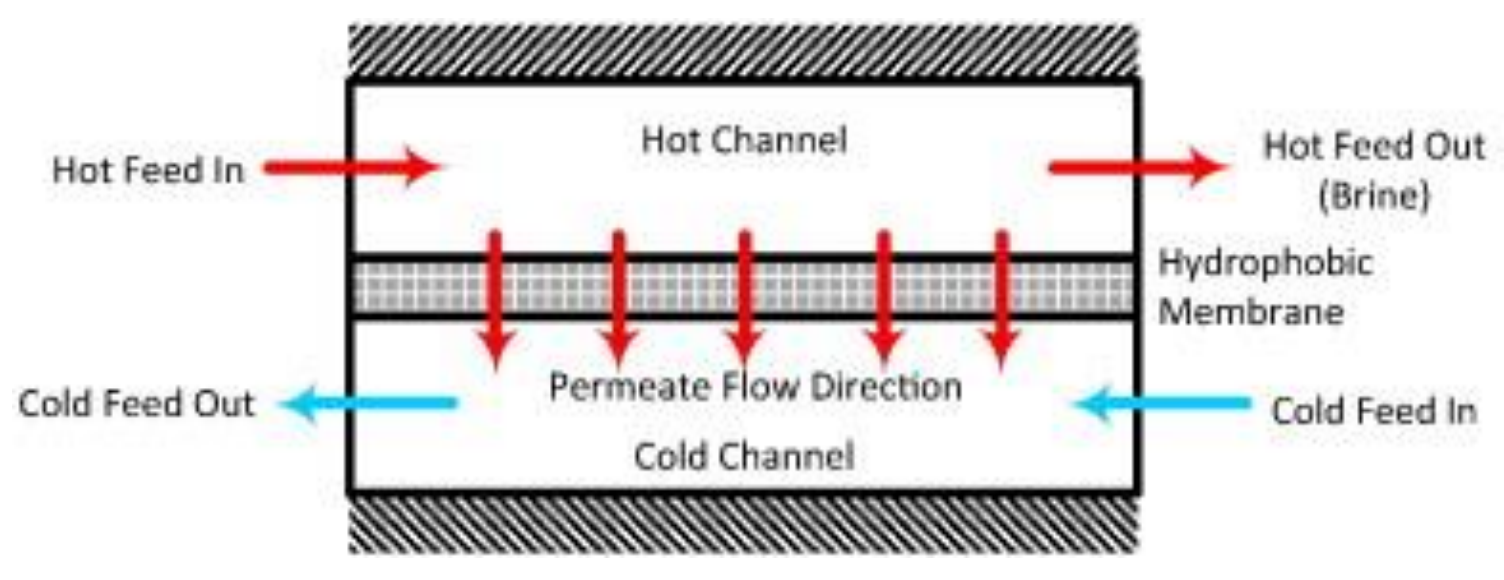

Figure 1: Diagram of membrane distillation process operating in counter-current flow mode (Kayvani Fard et al, 2015).

MD is a distillation process with a theoretical salt rejection of $100 \%$ which can remove all non-volatile constituents (Bush, Vanneste \& Cath, 2016). The permeate produced is high quality and can maintain $99.9 \%$ salt rejection at concentrations as high as $330,000 \mathrm{mg} / \mathrm{L} \mathrm{NaCl}$ (Bush, Vanneste \& Cath, 2016). In contrast to RO, MD energy consumption and production rate do not vary greatly with salt concentration. At $\mathrm{NaCl}$ concentrations approaching saturation, a 30\% decrease in permeate flux is observed compared to distilled water with MD (Zhang et al, 2015a)(Martinez, 2004). This is a 30\% flux reduction at nearly ten times the salinity of seawater. This allows MD to treat much higher salt concentrations than RO with less variation in energy usage. MD can achieve high recovery rates that are only limited by membrane fouling.

Problems associated with MD membranes are fouling and wetting. Membrane fouling is caused by adhesion or deposition of feed constituents onto the membrane which results in decreases in membrane flux, membrane hydrophobicity, or a combination thereof. A reduction of membrane hydrophobicity can lead to membrane 
wetting, in which liquid feed solution is able to cross the membrane. Membrane wetting can result in a drastic reduction of permeate quality. Permeate quality can be measured by the stream's conductivity, and conductivity spikes in permeate solutions are usually indicative of wetting.

\subsubsection{Types of MD}

There are four common MD configurations used for water separation. These configurations include: sweeping gas membrane distillation (SGMD), vacuum membrane distillation (VMD), direct contact membrane distillation (DCMD), and air gap membrane

distillation (AGMD)(Figure 2). Each configuration has a hot feed solution in contact with the membrane that produces vapor at the feed side vapor-liquid interface of the membrane. Then, vapor is transported across the membrane (Lawson \& Lloyd, 1997). The configurations differ in the movement of water vapor after being transported across the membrane. DCMD and AGMD are the configurations typically used for desalination as explained below (Lawson \& Lloyd, 1997) (Kucera, 2014). 


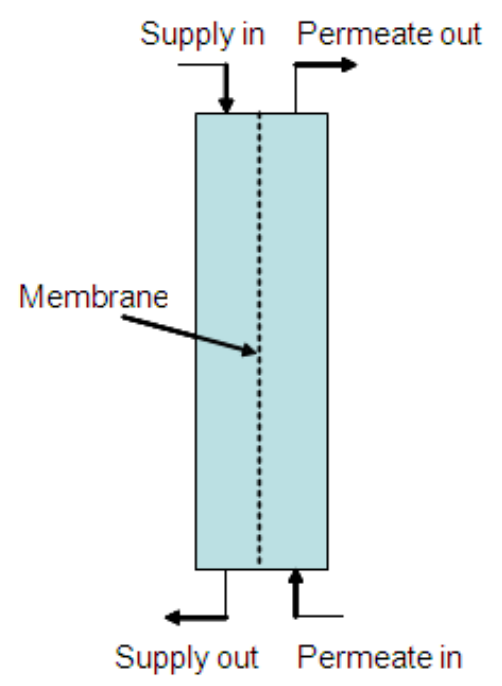

DCMD configuration

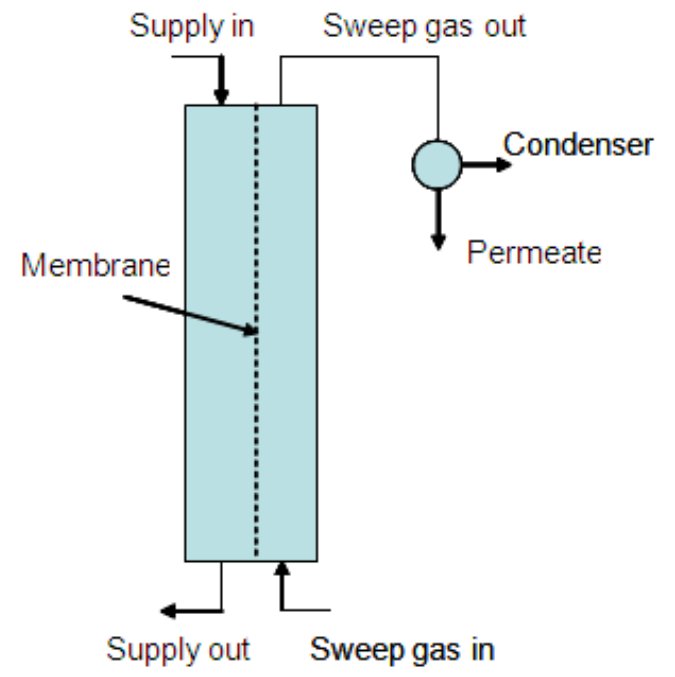

SGMD configuration

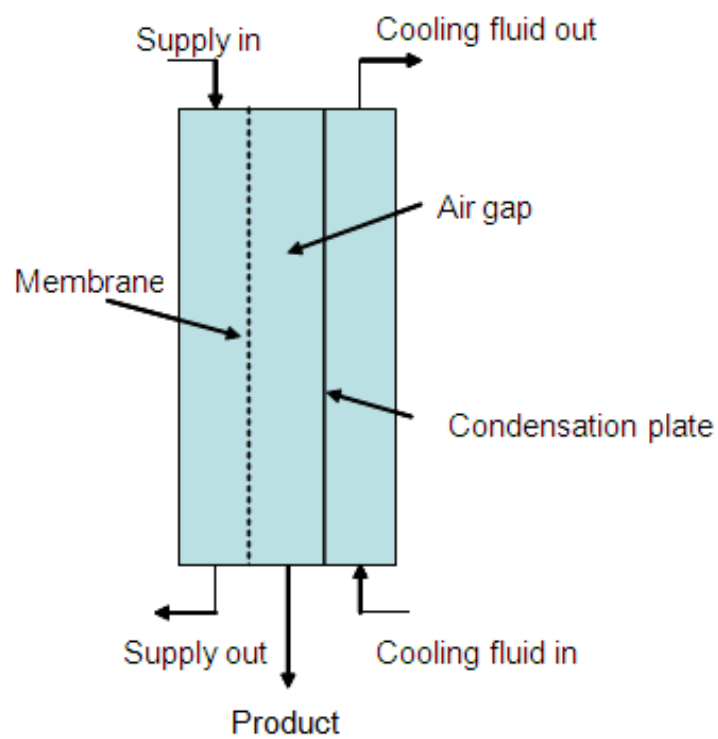

AGMD configuration

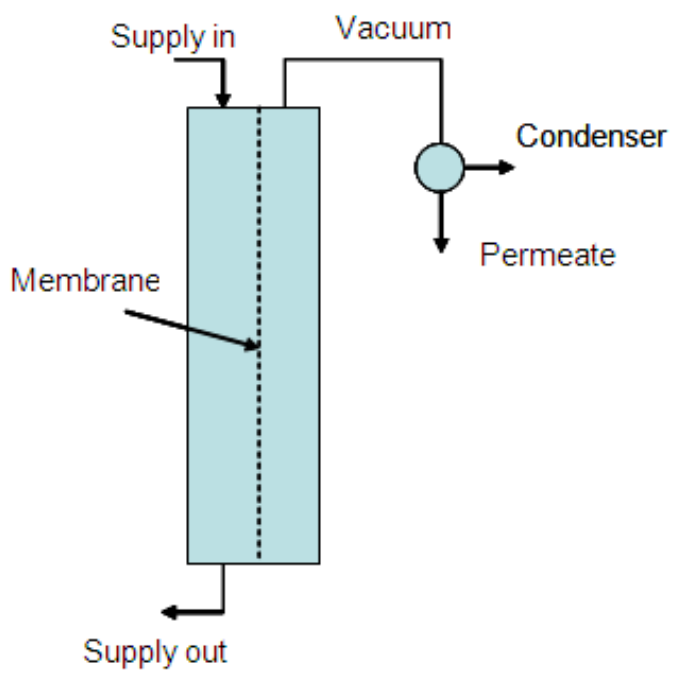

VMD configuration

Figure 2: Schematic diagram of the four most common MD configurations (El-Bourawi et al, 2006). 
Sweeping gas membrane distillation (SGMD) uses a moving stream of inert gas to sweep water vapor from the membrane (Figure 2). The water vapor diffuses into a large volume of sweep gas, which can make recovery of the vapor difficult. A large external condenser is required to separate the vapor from the sweep gas stream (Alkhudhiri et al, 2012). Since there is a larger load on the condenser due to the sweep gas volume, SGMD is not a common configuration (Lawson \& Lloyd, 1997). The most common application of SGMD is the removal of volatile compounds (Alkhudhiri et al, 2012). SGMD is not effective for desalination, so it will not be further discussed.

Vacuum membrane distillation (VMD) applies a vacuum to the permeate side of the membrane to impart the necessary partial pressure difference for vapor transfer (Figure 2). VMD lowers the resistance to mass transfer caused by air and increases the permeate flux (Kucera, 2014). The vacuum imparted on the permeate side results in negligible heat losses due to conduction (Alkhudhiri et al, 2012). Lower heat losses lead to higher thermal efficiencies than DCMD, but large membrane pressure differences can lead to liquid feed solution passing through the membrane, deteriorating permeate quality (Zhang et al, 2015a). The most common application for VMD is the separation of volatile contaminants (Lawson \& Lloyd, 1997). VMD is not effective for desalination due to the need for a large external condenser (Lawson \& Lloyd, 1997), so it will not be further discussed.

Direct contact membrane distillation (DCMD) consists of a hot feed stream and a cold permeate stream contacting opposing sides of the membrane (Figure 2). The direct contact of the two streams across the membrane lowers resistance, producing high 
mass transfer, but at the cost of high heat losses. DCMD has the lowest thermal efficiency of the four configurations, ranging from 17\% to 65\% (Zhang et al, 2015a). DCMD is the most well researched MD configuration due to its simplicity (Kucera, 2014). DCMD is typically used for desalination or aqueous concentration processes (Alkhudhiri, Darwish, \& Hilal, 2012) and will be the primary focus of this study.

In air gap membrane distillation (AGMD), water vapor passes through the membrane and into a stagnant air gap before condensing on a plate that is cooled by a "cold" stream (Figure 2). The thermal efficiency of AGMD is typically $70 \%$ to $98 \%$ (Zhang et al, 2015a). The air gap increases the thermal resistance between the hot and cold streams and lowers heat losses (Kucera, 2014). The mass transfer resistance is also increased, which results in lower permeate flux when compared to DCMD (Zhang et al, 2015a). The reduction in conductive heat transfer reduces wasted heat at the cost of a lower permeate flux (Kucera, 2014).

AGMD has the lowest permeate flux of the four common MD configurations with flux eight-times lower than DCMD for the same conditions (Lawson \& Lloyd, 1997) (Alklaibi \& Lior, 2004). Mass transfer resistance is related to the thickness of the air gap. Reducing the air gap thickness can reduce mass transfer resistance and improve flux (Alklaibi \& Lior, 2004). AGMD uses less thermal energy than DCMD due to lower losses, but $A G M D$ requires a larger membrane surface area for a given flow rate. The most common applications of AGMD are desalination and removal of volatile compounds, but AGMD also has a largest range of applications (Alkhudhiri et al, 2012)(Lawson \& Lloyd, 1997). This work does not consider AGMD evaluate the performance of AGMD systems 
for modeling simplicity and because DCMD is a more thoroughly researched configuration.

\subsubsection{Boundary Layer Effects in DCMD}

In DCMD operation, the role of thermal and concentration boundary layers has a significant effect on performance. Boundary layers in fluid flow arise from interactions between the fluid and solid surfaces; in the case of DCMD, the solid surface is the membrane itself. Thermal boundary layers are caused by temperature differences between the bulk fluid and the solid surface with which the fluid is interacting (Bird, Stewart, \& Lightfoot, 2007)(Bergman et al, 2011). At the solid surface, the fluid temperature is equal to the solid surface temperature. The thermal boundary layer is the transition region between the surface temperature and the temperature of the bulk fluid (Bird, Stewart, \& Lightfoot, 2007). The concentration boundary layer develops from a concentration difference between the bulk fluid and solid surface. With a concentration difference, there will be convective mass transfer that transfers solute from the solid surface to the bulk stream (Bergman et al, 2011).

In DCMD, thermal and fluid conditions at the membrane surface determine the driving force for mass transfer. As the temperatures at the membrane surfaces determine the mass flux, conditions that create large thermal boundary layers results in a phenomenon known as temperature polarization (TP), where the membrane surface temperature difference is lower than the bulk fluid temperature difference (Figure 3). TP lowers mass flux as the trans-membrane vapor pressure is lower due to boundary conditions. Increasing convective heat transfer and mixing can decrease the thickness of 
the thermal boundary layer and decrease TP (Patil and Shirsat, 2017). Often over $50 \%$ and up to $80 \%$ of the driving force from bulk temperature differences can be lost from effects of TP (Kucera et al, 2014). Increasing temperature is associated with increased TP effect (Kucera, 2014). Small thermal boundary layers reflect high convective heat transfer and a membrane surface temperature that is similar in temperature to the bulk fluid temperature (Bergman et al, 2011). This can be achieved through high mixing of the fluid stream (Patil and Shirsat, 2017).

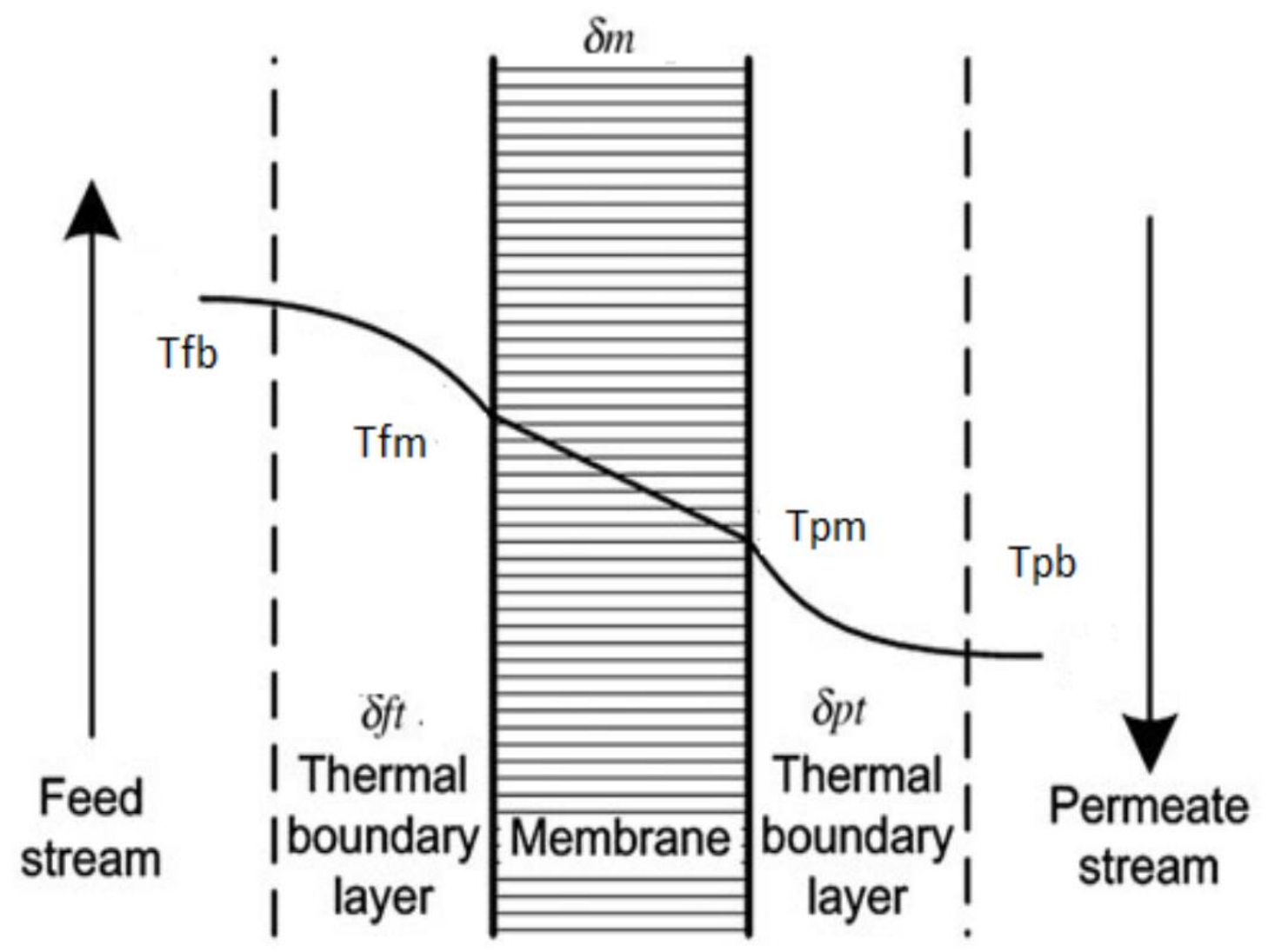

Figure 3: Thermal boundary layers in DCMD (Patil and Shirsat, 2017). Thermal boundary layers in DCMD cause a reduced temperature difference at the membrane surface. 
As water vapor is transferred from the feed side to the permeate sides, solutes are left behind at the membrane surface leading to elevated concentrations of solutes at the membrane surface. With a larger concentration at the membrane surface, a concentration boundary layer develops (Figure 4). This phenomenon is known as concentration polarization (CP). With low hydrodynamic boundary layer thicknesses, there is increased mixing that reduces the extent of CP. Higher mixing results in less solute buildup at the surface of the membrane (Patil and Shirsat, 2017).

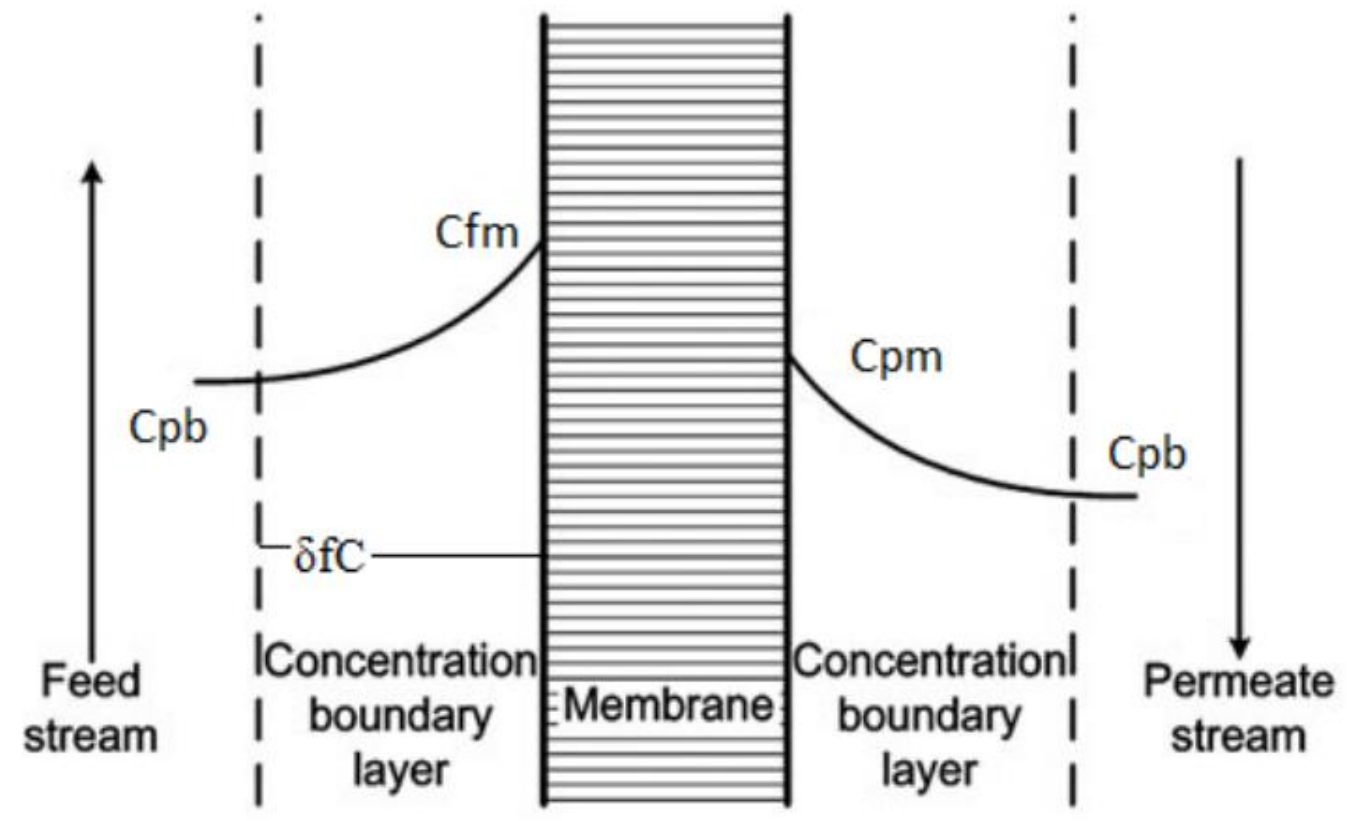

Figure 4: Concentration boundary layers in DCMD that lead to concentration polarization (Patil and Shirsat, 2017).

The Prandtl number $(P r)$ is the ratio of mass diffusivity to thermal diffusivity, so Pr can be used as a relative comparison of a fluid's hydrodynamic boundary layer and its thermal boundary layer (Equation 1) (Bird, Stewart, \& Lightfoot, 2007). Generally for 
liquids, $\operatorname{Pr}>1$, meaning that the thickness of the thermal boundary layer is less than the thickness of the hydrodynamic boundary layer (Bird, Stewart, \& Lightfoot, 2007).

$$
\operatorname{Pr}=\frac{\mu C_{p}}{k}
$$

where: $\operatorname{Pr}=$ Prandtl number

$$
\begin{aligned}
& C_{p}=\text { Heat capacity }(\mathrm{J} / \mathrm{kg} . \mathrm{K}) \\
& \mu=\text { Dynamic viscosity (Pa.s) } \\
& k=\text { Thermal conductivity }(\mathrm{W} / \mathrm{m} . \mathrm{K})
\end{aligned}
$$

\subsubsection{Mass Transfer Resistance in MD}

Resistances to mass transfer occur from the feed solution to the membrane surface, through the pores of the membrane, and from the membrane surface to the permeate solution (Figure 5) (Kucera, 2014). In both the permeate and feed solutions, transport by molecular diffusion across hydrodynamic boundary layers to the membrane surface is the highest resistance (Kucera et al, 2014). Vapor formed the vapor-liquid interface of the membrane surface moves across the membrane by diffusion or in some circumstances through convection (Schofield, Fane, \& Fell, 1986) (Lawson \& Lloyd, 1997). All substances that are not able to evaporate at the vapor-liquid interface are rejected (Lawson \& Lloyd, 1997)(Kucera, 2014). Inside the membrane pores, significant mass transfer resistance can occur from molecular, Knudsen, and viscous resistances. Molecular and Knudsen resistances are caused by collisions of molecules with other molecules and with the membrane, respectively (Lawson \& Lloyd, 
1997). Momentum transfer from the molecules to the membrane causes viscous

resistance (Figure 5). Resistances to mass transfer vary with membrane composition, feed constituents, and configuration (Kucera, 2014)(Lawson \& Lloyd, 1997). For DCMD, stagnant air trapped in the membrane pores generally provide the largest mass transfer resistances.

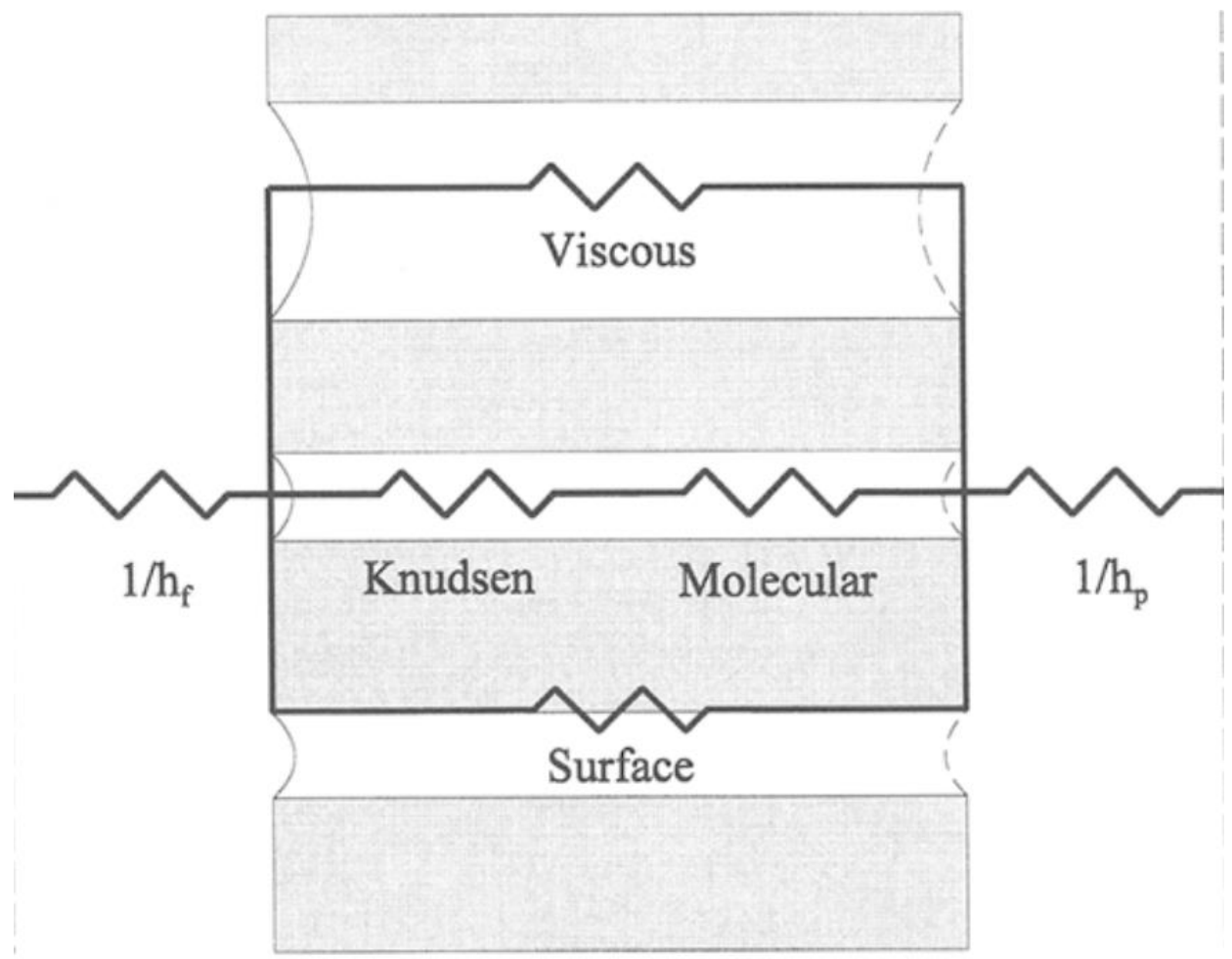

Figure 5: Mass transfer resistances in MD. Vapor flows from left to right (Lawson \& Lloyd, 1997).

\subsubsection{Heat Transfer in MD}

MD heat transfer consists of heat transfer from the feed solution to the membrane surface $\left(h_{f}\right)$, across the membrane, and from the membrane surface to the permeate $\left(h_{p}\right)$ (Figure 6). The MD feed solution transfers heat to the membrane surface by convection (Lawson \& Lloyd, 1997). Heat transfer across MD membranes consists of 
two primary mechanisms, vaporization $\left(h_{v}\right)$ and conduction $\left(h_{m}\right)$ (Equations 2 and 3).

Heat transferred by vaporization is the product of permeate flux and the heat of vaporization (Equation 3) (Lawson \& Lloyd, 1997). Heat transferred by vaporization is referred to as the effective heat as it is being used to drive permeate across the membrane. The rate of heat transfer towards vaporization is the largest factor in the mass transfer rate. The large amount of energy required to vaporize water limits permeate production to the rate of heat transfer across thermal boundary layers at the membrane surface (Lawson \& Lloyd, 1997).

$$
Q_{c}=h_{m} \Delta T_{m}
$$

where: $Q_{c}=$ Conductive heat transfer across the membrane (W)

$\Delta T_{m}=$ Membrane temperature difference $(\mathrm{K})$

$h_{m}=$ Conductive heat transfer coefficient of the membrane $\left(\mathrm{W} / \mathrm{m}^{2} . \mathrm{K}\right)$

$$
Q_{v}=N \Delta H_{v}
$$

where: $Q_{v}=$ Vaporization heat transfer across the membrane (W)

$$
\begin{aligned}
& N=\text { Molar flux of water vapor }\left(\mathrm{mol} / \mathrm{m}^{2} . \mathrm{s}\right) \\
& \mathrm{H}_{\mathrm{v}}=\text { Heat of vaporization of water }(\mathrm{J} / \mathrm{mole})
\end{aligned}
$$




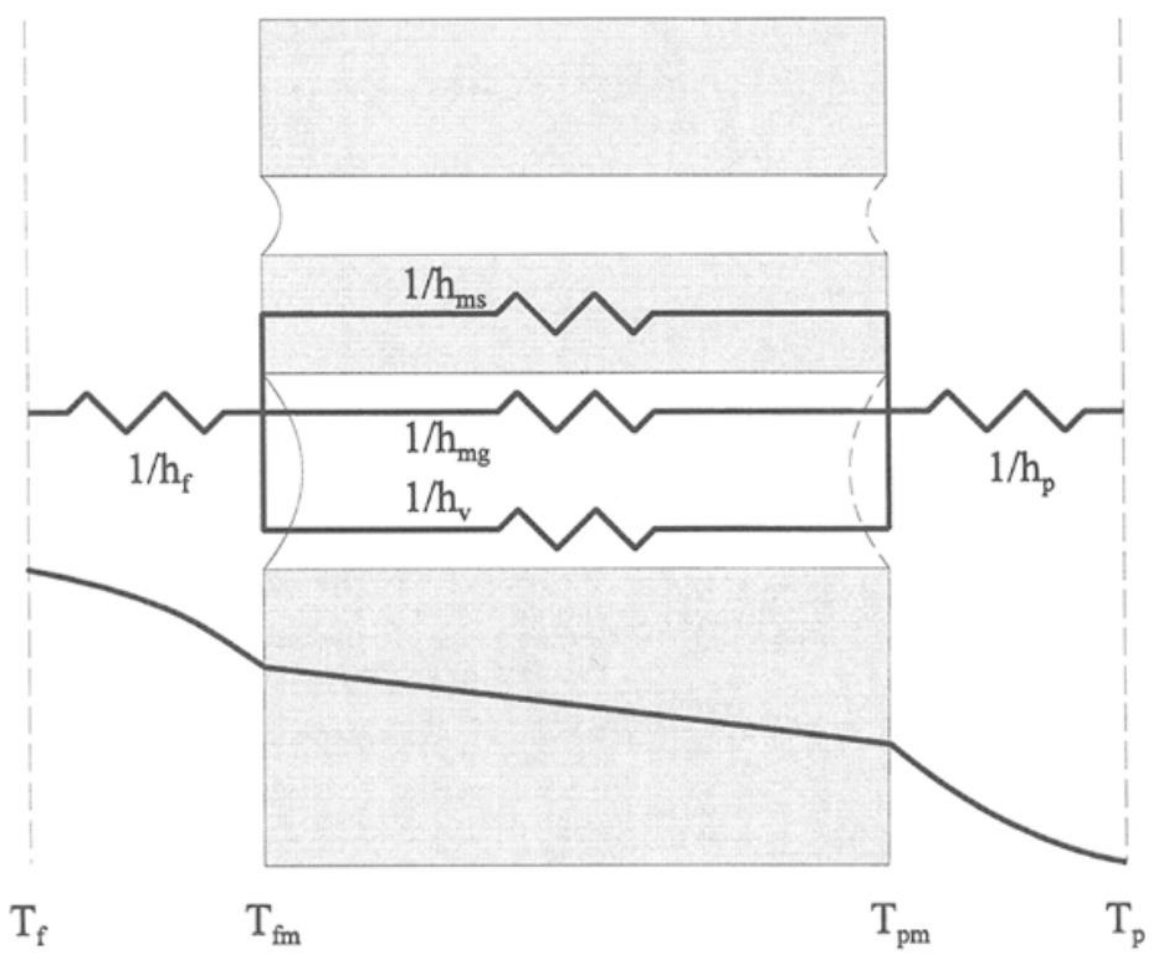

Figure 6: MD heat transfer diagram. Vapor flow is from left to right (Lawson \& Lloyd, 1997).

Unlike vaporization, conductive heat transfer across the membrane $\left(h_{m}\right)$ and conductive heat transfer through the vapor $\left(h_{m g}\right)$ are considered losses (Figure 6). Thermal energy transferred through conduction is not used for transfer of vapor, so it is wasted energy in the MD process. Heat can conduct through the membrane itself or through vapor in the membrane pores (Lawson \& Lloyd, 1997). While the bulk temperatures ( $T_{f}$ and $T_{p}$ ) can be measured, vapor pressure gradient and conductive heat loss are caused by the temperature difference at the membrane surfaces ( $T_{f m}$ and $\left.T_{p m}\right)$ (Figure 6). An increased interfacial temperature difference results in higher mass transfer and higher conductive heat losses. 


\subsubsection{Potential as Desalination Technology}

As mentioned above, MD flux does not greatly vary with $\mathrm{NaCl}$ concentration. $\mathrm{NaCl}$ concentrations near saturation decrease flux approximately $30 \%$ for the same driving force when compared to distilled water (Zhang et al, 2015a) (Martinez, 2004). Compared to other membrane technologies, this relative stability makes MD well suited to maintain similar energy consumption and performance while treating high concentration brines.

Hypersaline MD feed can have increased viscosity and vapor suppression that reduces the driving force of the MD process. Vapor suppression refers to the reduction in effective vapor pressure that drives the MD treatment process. The concentration polarization and temperature polarization phenomena that lower flux are increased due to increased viscosity and decreased mixing. This increases the thickness of the thermal boundary layer (Tun et al, 2005).

As $\mathrm{NaCl}$ concentration increases above $25 \%$ by weight, concentration polarization causes saturation levels to be reached at the membrane surface. As the bulk solution approaches saturation, heavy precipitation may be observed (Yun et al, 2006). Precipitation on the membrane surface can block pores leading to lowered flux and increased risk of wetting. Concentrations higher than saturation have been found to deteriorate the flux to zero (Yun et al, 2006).

Low variation in distillate flux with salt concentration allows for greater potential recovery than can be achieved with $\mathrm{RO}$. The theoretical maximum water recovery of $\mathrm{MD}$ is $100 \%$, but as high recovery is achieved, feed properties may lower MD flux and 
increase the risk of fouling (Colorado School of Mines, 2009). As recovery approaches $100 \%$, solids are much more likely to deposit on the membrane rather than be retained in the feed retentate stream. This phenomenon creates the practical limit to recovery. To ensure proper operation and solids disposal, recovery should be at or below this practical limit where precipitation of solutes occurs at the membrane surface.

As $\mathrm{MD}$ is not as sensitive to high salinity as other membrane processes, it is a good candidate for treatment of high salinity brines in excess of $65,000 \mathrm{mg} / \mathrm{L} \mathrm{TDS}$. MD can approach zero-liquid discharge (ZLD) and can greatly reduce brine volume compared to other membrane technologies. RO cannot be used for streams greater than 65,000 $\mathrm{mg} / \mathrm{L}$ due to increases in energy consumption and maintenance at these levels (Sanmartino et al, 2017). Concentration polarization in MD is a prevalent issue, but it is not as inhibiting to the driving force as it is for RO. Because of this, higher recovery than RO is possible using DCMD (Drioli et al, 2015).

One MD brine concentration application is desalination of RO retentate using MD (Sanmartino et al, 2017) (Duong et al, 2015a) (Duong et al, 2015b). MD has been combined with $\mathrm{RO}$ to achieve a higher water recovery than $\mathrm{RO}$ alone. RO retentate is used for the MD feed and high recoveries can be achieved with similar costs to RO. With reported costs of $\$ 1.25 / \mathrm{m}^{3}$ for both $\mathrm{RO}$ and $\mathrm{RO}+\mathrm{MD}$, over twice the water recovery as RO alone can be achieved at similar energy costs (Alklaibi \& Lior, 2004). 


\subsubsection{Thermal Efficiency}

Thermal efficiency is the ratio of heat of vaporization used for mass transfer to the total heat transferred (Zhang et al, 2015a). The thermal efficiency of MD is typically $20-30 \%$, which is low for thermal desalination technologies. Loss of thermal efficiency in MD is due to conductive heat losses (Zhang et al, 2015a). Conductive heat losses and polarization are the focus of many efficiency-increasing measures for MD. By utilizing heat recycling, heat used for mass transfer can be reused. Heat recycling can cause the ratio of heat used for mass transfer to be greater than the initial total heat, causing thermal efficiency to exceed $100 \%$ (Alsaadi et al, 2015).

Thermal efficiency is commonly referred to as the gained output ratio (GOR) (Zhang et al, 2015a). Without heat recovery, the GOR of a system is $<1$, whereas heat recovery can result in a GOR much greater than 1 . Multiple effect distillation (MED) and multi-stage flash distillation (MSF) have GOR values ranging from 2 to 15 while multiple stage MD ranges from 2 to 20 (Zhang et al, 2015a). For GOR<1, thermal efficiency increases with increased flux as less heat is wasted and more heat is used for vaporization. For MD systems operating at a $G O R>1$, recovered heat is used to partially drive the MD process As GOR increases above one, less energy is needed per $\mathrm{m}^{3}$, but more membrane surface area is required (Alsaadi et al, 2015).

Duong et al found that recycling hot MD brine into the feed solution to recover heat can be used to increase DCMD thermal efficiency. It was found that at $60 \%$ recovery, use of recycled brine doubled the thermal efficiency of the DCMD system (Duong et al, 2015c). 
As described above, recovery of latent heat of vaporization is necessary to achieve a GOR greater than one. External heat recovery uses external heat exchange with warm distillate streams to recover latent heat and is often used in DCMD configurations. Internal heat exchange uses a heat recovery mechanism built into the membrane module. The condensation plate of AGMD is an example of an internal recovery device (Zhang et al, 2015a).

\subsubsection{Energy Consumption}

In determining the energy demands of $M D$, it is helpful to normalize the energy demands against a volume of water treated. The specific energy consumption (SEC) is the total energy required to treat a volume of water. In MD, thermal and hydraulic energy are both needed to achieve treatment. Thermal energy represents the majority of energy demands accounting for over $90 \%$ of the total energy consumption in most cases (Kesieme et al, 2013). This thermal energy demand can be affected by operational parameters that change the process thermal efficiency. Increases in thermal efficiency result in lower process energy consumption (Kucera, 2014). The remaining energy usage comes from hydraulic energy consumption required to drive the feed and permeate fluid streams.

The SEC is the sum of the specific thermal energy consumption (STEC) and specific hydraulic energy consumption (SHEC). The STEC is a function of the heat of vaporization of water and the MD thermal efficiency (Equation 4). 


$$
S T E C=\frac{H_{v}}{3600 \cdot \eta_{T} M_{w}}
$$

where: $S T E C=$ Specific thermal energy consumption $\left(\mathrm{kWh} / \mathrm{m}^{3}\right)$

$$
\begin{aligned}
& H_{v}=\text { Heat of vaporization of water }(\mathrm{J} / \mathrm{mole}) \\
& \eta_{T}=\text { Thermal efficiency } \\
& M_{w}=\text { Molecular weight of water }(\mathrm{kg} / \mathrm{mole}) \\
& \text { Conversion factor }=3600 \mathrm{~J} / \mathrm{kg} \text { per } \mathrm{kWh} / \mathrm{m}^{3}
\end{aligned}
$$

The SHEC used in this work for DCMD is derived as function the head losses, flow rates, and mass treated (Equation 5).

$$
S H E C=\frac{\left(Q_{f}+Q_{p}\right)\left(h_{l, f}+h_{l, p}\right) g \rho_{w, a v e}}{3.6 \times 10^{6} V_{t}}
$$

where: $S H E C=$ Specific hydraulic energy consumption $\left(\mathrm{kWh} / \mathrm{m}^{3}\right)$

$$
\begin{aligned}
& Q_{f}=\text { Feed channel flow rate }\left(\mathrm{m}^{3} / \mathrm{s}\right) \\
& Q_{p}=\text { Permeate channel flow rate }\left(\mathrm{m}^{3} / \mathrm{s}\right) \\
& h_{l, f}=\text { Head loss due to friction of the feed channel }(\mathrm{m}) \\
& h_{l, p}=\text { Head loss due to friction of the permeate channel }(\mathrm{m}) \\
& g=\text { Acceleration due to gravity, } 9.81 \mathrm{~m} / \mathrm{s}^{2} \\
& \rho_{w, \text { ave }}=\text { Average density of the fluid streams }\left(\mathrm{kg} / \mathrm{m}^{3}\right) \\
& V_{t}=\text { Volume of water treated }\left(\mathrm{m}^{3}\right) \\
& \text { Conversion factor }=3.6 \times 10^{6} \mathrm{~J} / \mathrm{kWh}
\end{aligned}
$$


MD energy consumption differs based on configuration and use of heat recovery. MD SEC can range from $120 \mathrm{kWh} / \mathrm{m}^{3}$ to $1700 \mathrm{kWh} / \mathrm{m}^{3}$ (Camacho et al, 2013). This is much greater than RO desalination, where energy consumption ranges from 3-4 $\mathrm{kWh} / \mathrm{m}^{3}$ (Ali et al, 2018).Configuration, energy source, module design, feed constituents, and other factors can result in greatly differing energy consumption (Kucera, 2014).

MD can operate with a temperature difference as low as $10^{\circ} \mathrm{C}$ and low operating temperatures (Drioli et al, 2015)(Lawson \& Lloyd, 1997). MD allows for the use of lowgrade waste heat to drive the treatment of contaminated water, which can lower the operational costs of MD. With thermal energy accounting for $90 \%$ of the energy needed in MD, waste energy usage drastically lowers MD energy costs (Kesieme et al, 2013). When utilizing low-grade waste heat, costs estimates for MD treatment range from $\$ 0.26-\$ 1.17 / \mathrm{m}^{3}$ (Kucera, 2014). Kesieme et al estimated MD costs to be $\$ 1.72 / \mathrm{m}^{3}$ without waste heat and $\$ 0.61 / \mathrm{m}^{3}$ when utilizing waste heat (Kesieme et al, 2013). These costs are competitive with reverse osmosis costs that range from $\$ 0.53-\$ 1.58 / \mathrm{m}^{3}$ (Mishra, 2018). Alklaibi et al estimated that the use of waste heat can result in nonwaste energy consumption as low as $1.25 \mathrm{kWh} / \mathrm{m}^{3}$ (Alklaibi \& Lior, 2004). Low-grade waste heat is an attractive option as it allows the high energy demands of distillation to be met in part by a source that has little to no cost. Low grade heat from power plants, process equipment, solar, or geothermal can be cost-efficient MD energy sources (Lawson \& Lloyd, 1997) (Kucera, 2014). 


\subsubsection{Additional Factors Affecting Performance}

In MD systems, various parameter involved with the treatment process have an effect on performance. Fluid stream characteristics, temperature, and membrane composition may significantly alter performance characteristics such as flux, thermal efficiency, temperature polarization, and concentration polarization.

\subsubsection{Fluid Stream Characteristics}

Typically, laminar flows are observed in MD systems leading to unfavorable mixing and more signifcant boundary condition effects (Eykens et al, 2016). High TP can be mitigated by increasing mixing through module flow path and increased flow rate (Kucera, 2014). For instance, flow spacers have been employed to increase mixing (Kucera, 2014). Increased flow rate increases membrane flux, but membrane wetting may also increase (Zhang et al, 2015)(Alkhudhiri, Darwish, \& Hilal, 2013). Increasing feed flow rate also increases electrical energy consumption (Kucera, 2014). Both mitigation strategies increase mixing of the feed solution leading to decreased TP. TP generally increases as concentration of TDS increases as viscosity increases (Martinez, 2004). Increasing viscosity decreases mixing leading to thicker thermal boundary layers and larger TP.

\subsubsection{Temperature}

Vapor flux across the membrane and thermal efficiency increases exponentially with increased temperatures (Zhang et al, 2015a) (Karakulski \& Gryta, 2005) (Alkhudhiri et al, 2013). As interfacial temperature difference drives MD, TP can cause interfacial feed temperatures to be much lower than bulk temperatures. Feed temperatures 
typically range from $60-90^{\circ} \mathrm{C}$ (Lawson \& Lloyd, 1997). The driving force increases with increased bulk temperature, but feed temperatures greater that $85^{\circ} \mathrm{C}$ have been seen to increase wetting of the membrane (Tun et al, 2005). For DCMD, both feed and coolant temperature affect the permeate flux, but increasing feed temperature has a much larger impact (Alklaibi \& Lior, 2004) (Alkhudhiri et al, 2013). Duong et al found that flux decline at high salinity was lower at higher temperatures (Duong et al, 2015c).

\subsubsection{Membrane Composition}

Membrane materials, structure, and dimensions play a role in determining the effectiveness of MD operation. Hydrophobic polymers are often selected for MD membranes to prevent feed solution from crossing the membrane. In addition to the need for hydrophobicity, there is a need for materials to have low thermal conductivity (Zhang et al, 2015a). As thermal conductivity of the membrane $\left(k_{m}\right)$ directly relates to the conductive waste heat, a low thermal conductivity is required for a high thermal efficiency. Polyvinylidene fluoride (PVDF), polypropylene (PP), and polytetrafluoroethylene (PTFE) are the most common materials and exhibit high hydrophobicity. The thermal conductivities of these materials range from 0.11 to 0.27 $\mathrm{W} / \mathrm{m}-\mathrm{K}$. When commercial microfiltration membranes are used, overall membrane thermal conductivities range from 0.04 to $0.06 \mathrm{~W} / \mathrm{m}-\mathrm{k}$ (Schofield et al, 1986). As the membrane heat transfer resistance is dominant in DCMD, the high thermal conductivity of these materials leads to high heat losses and low thermal efficiencies. Hydrophobicity varies with membrane materials, and more hydrophobic materials can better resist membrane wetting (Peng et al, 2015). 
Thickness of the membrane affects mass transfer resistance and the conductive heat loss. As membrane thickness increases, mass and heat transfer resistance increase. Thin membranes have high conductive heat losses resulting in high TP. Effective membrane thickness balances mass transfer resistance and heat losses (Zhang et al, 2015a). Optimal membrane thickness ranges from 10-700 $\mu$ m (Eykens et al, 2016). In AGMD, membrane thickness does not affect flux as the additional mass transfer resistance is negligible when compared to the resistance of the air gap (Eykens et al, 2016). Thicker membranes and membranes with lower thermal conductivity decrease conductive heat transfer across the membrane and increase the temperature difference across the membrane.

MD membrane porosity is the ratio of pore volume to total volume. Increasing membrane porosity reduces the conductive heat transfer resulting in higher flux and thermal efficiency (Zhang et al, 2015a) (Schofield et al, 1986). The decrease of conductive heat transfer is from an increase in void space filled with air that has much lower thermal conductivity than the membrane itself, leading to a reduction in wasted heat (Kucera, 2014). However, greater porosity may also result in higher membrane wetting. Membrane porosity ranges from 0.6 to 0.9 for various MD membranes (Zhang et al, 2015a). Porosity exceeding 0.75 is recommended for MD membranes to ensure high flux (Eykens et al, 2016). This exceeds the porosity for other membrane technologies with similar pore sizes, such as microfiltration and UF that range from 0.3 to 0.7 (Sagle \& Freeman, 2004). 
Mean pore size typically ranges from 0.1 to $1.0 \mu \mathrm{m}$, and the ideal pore sizes are 0.3 to $0.4 \mu \mathrm{m}$ to reduce wetting and increase flux (Zhang et al, 2015a). Although flux increases with increased pore size, Alkhudhiri et al found that pore size has a negligible effect on energy consumption (2013). Pore size should not vary much throughout a membrane and there should be a tight distribution to reduce the chance of wetting from pores larger than the mean pore size. This is one of the disadvantages to repurposing MF and ultrafiltration (UF) membranes for MD as they typically have larger pore size distributions that can lead to greater wetting (Kucera, 2014).

A MD membrane must also have high chemical and thermal resistance. Highly acidic gases can corrode MD membranes, so membrane materials must be resistant to chemical interaction over time. A membrane must also be resistant to high temperatures over long periods of time to be effective. Generally, a larger glass transition/melting temperature results in a more thermally stable membrane (Drioli, et al, 2015).

\subsubsection{Hybrid MD Systems}

Hybrid systems that combine MD with other treatment technologies have been found in some cases to improve cost effectiveness and water recovery of MD treatment. Hybrid MD systems have been tested with RO, ultrafiltration, nanofiltration, and crystallization (Kucera, 2014).

RO-MD hybrid systems are among the most evaluated MD hybrid systems. ROMD hybrid systems use MD to treat RO retentate (Figure 7). This results in higher water recovery and lower overall energy use than MD alone (Kucera, 2014). These hybrid 
systems can have over twice the water recovery as RO while taking advantage of the low energy usage of RO at appropriate concentrations.

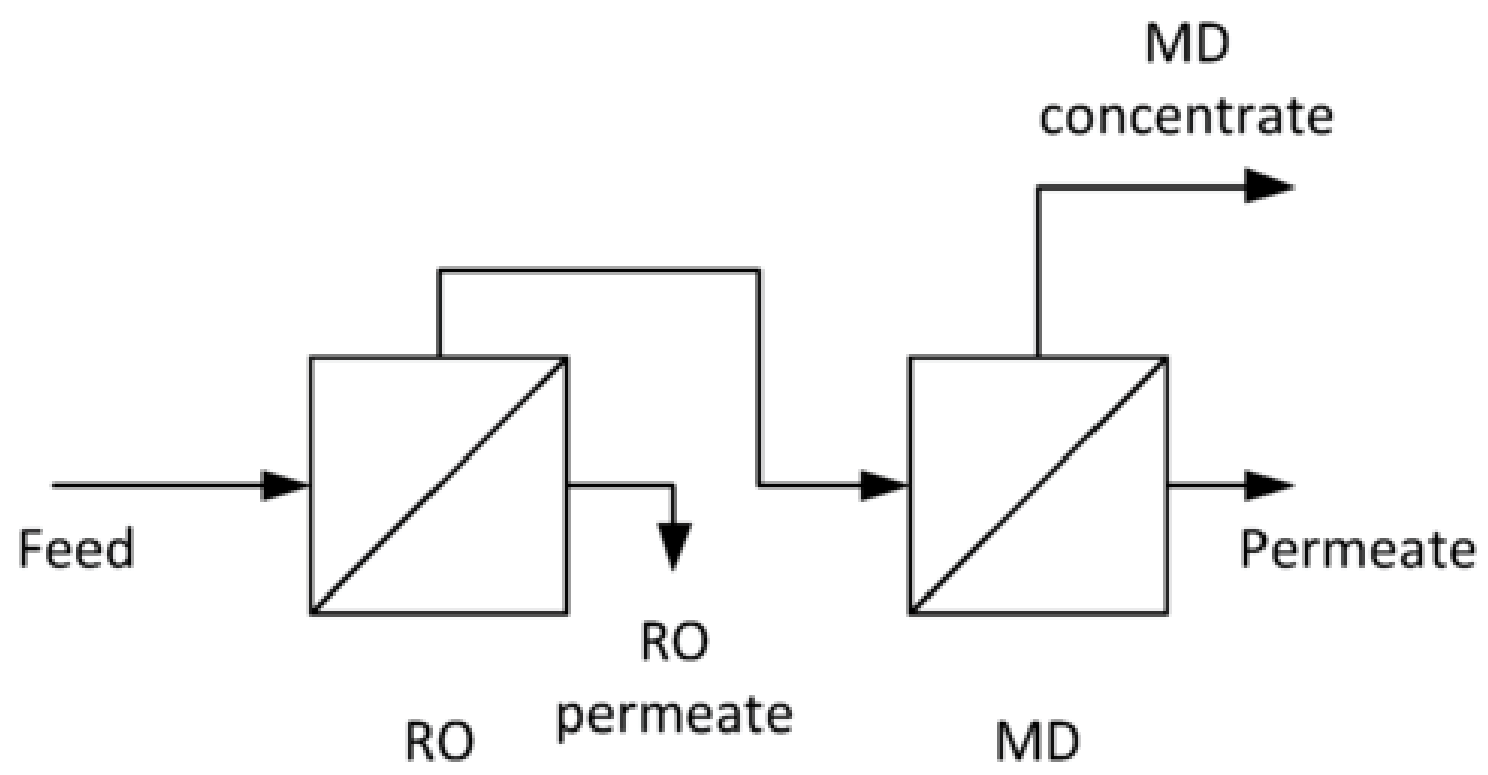

Figure 7: Schematic of hybrid RO-MD treatment process (Camacho et al, 2013). RO retentate is used as the influent for MD treatment.

The $\mathrm{RO}$ retentate that is most advantageous for treatment by MD is at TDS concentrations in excess of the typical operating limit of RO (approximately 60,000 $\mathrm{mg} / \mathrm{L})($ IAEA, 2013). Above the operating range of $\mathrm{RO}$, increased recovery from MD have more comparable energy consumptions with treatment alternatives.

\subsection{Produced Water Background}

Produced water is water that is generated as a byproduct of oil and gas production. Produced water is the largest waste generated by volume in oil and gas operations (Alkhudhiri et al, 2013). In 2012, the United States national average waterto-oil ratio (WOR) and water-to-gas ratio (WGR) were 9.2 and 97, respectively (GWPC, 
2015). Over the lifetime of conventional wells, the WOR increases (Ray \& Engelhardt, 1992). In 2012, the total volume of produced water in the United States was 21.2 billion bbl (890 billion gallons) (GWPC, 2015).

Produced water constituents include dispersed oils, soluble and insoluble organics, heavy metals, radionuclides, production chemicals, salts, dissolved oxygen, inorganic compounds, and formation minerals (Ray \& Engelhardt, 1992) (Alkhudhiri et al, 2013) (Han et al, 2017). One of the primary challenges with produced water management is high TDS $(1,000-400,000 \mathrm{mg} / \mathrm{L}$ TDS) (USBR, 2011). Produced water composition varies greatly based on geological formation and type of extraction (USBR, 2016). High temperatures are often associated with produced water, typically ranging from 50 to $94^{\circ} \mathrm{C}$ (Ray \& Engelhardt, 1992).

Management of produced water is primarily conducted through re-injection, which accounted for $96.3 \%$ of produced water disposal in 2007 and $84 \%$ of disposal in 2012 (GWPC, 2015). In 2012, 45.1\% of produced water was used for enhanced oil recovery (EOR). EOR is a method of using produced water to assist in the extraction of oil in a well. Injection into disposal wells accounted for $38.9 \%$ of produced water disposal in 2012 (GWPC, 2015). Other produced water management methods used are offsite commercial disposal, surface discharge, evaporation, and beneficial reuse. Beneficial reuse was the fate of $0.6 \%$ of the total produced water volume in 2012 (GWPC, 2012). Many of the locations that produce large amounts of oil and gas are experiencing water scarcity, so additional use of treated produced water may be able to offset other sources (USBR, 2016). 


\subsubsection{Produced Water Viability for MD Treatment}

The primary characteristic that determines the effectiveness of MD for treatment of produced water is total dissolved solids (TDS) content. MD is able to operate at TDS concentrations as high as $300,000 \mathrm{mg} / \mathrm{L}$ if proper pretreatment methods are used. RO has a much lower energy usage and cost than MD at lower TDS concentrations, but the effectiveness of RO is limited above TDS concentrations of 40,000 mg/L (Gregory, Vidic \& Dzombak, 2011). For most applications, an influent TDS concentration between $40,000 \mathrm{mg} / \mathrm{L}$ and $300,000 \mathrm{mg} / \mathrm{L}$ are best suited for MD treatment. High recovery and better cost-effectiveness may be achieved through hybrid RO-MD systems, so influent concentrations less than $40,000 \mathrm{mg} / \mathrm{L}$ may still be wellsuited for treatment using a MD system or an RO-MD hybrid system.

There is a large amount of variation in TDS concentration present in produced water from wells across the United States, varying from $<1000 \mathrm{mg} / \mathrm{L}$ to $>400,000 \mathrm{mg} / \mathrm{L}$ (USBR, 2011). There is also a significant variation in produced water TDS by the extraction method. Some extraction methods are likely to produce the optimal TDS range for MD treatment than others. Produced water from conventional oil/gas extraction is the best suited for MD desalination, while hydraulic fracturing (HF) produced water and coalbed methane (CBM) produced water are less suited for $M D$ treatment.

\subsubsection{Conventional Oil/Gas}

The sources of conventional oil and gas are typically found in traps associated with faults, traps associated with changing rock type, and dome formations created by 
movement of layers below (BCMNGD, n.d.). This is in contrast to the generally low permeability formations and/or additional processing that is needed for extraction of unconventional oil/gas resources. Conventional crude oil typically has the highest value per unit energy of any hydrocarbon, but the amount of available crude oil is decreasing with time (Gordon, 2012).

Over the lifetime of a conventional well, the amount of produced water increases and additional water may be needed to assist extraction (USBR, 2016). Near the end of a well's lifetime, produced water can account for up to $98 \%$ of extracted fluids (Ray \& Engelhardt, 1992). This increased volume of produced water over time presents additional challenges for treatment or disposal. MD is a modular technology so increasing the membrane surface area can increase the capacity. As produced water volume increases, MD can be suitable to increase treated volume due to its modular nature.

TDS in produced water from conventional extraction varies from 1,000 - 400,000 $\mathrm{mg} / \mathrm{L}$ in the western United States (USBR, 2011). Over half (53\%) of produced water from conventional extraction had a TDS between 50,000 mg/L and 200,000 mg/L (Figure 8). The remainder of the produced water was split between $<50,000 \mathrm{mg} / \mathrm{L}(29 \%)$ and $>200,000 \mathrm{mg} / \mathrm{L}(18 \%)(U S B R, 2011)$. 


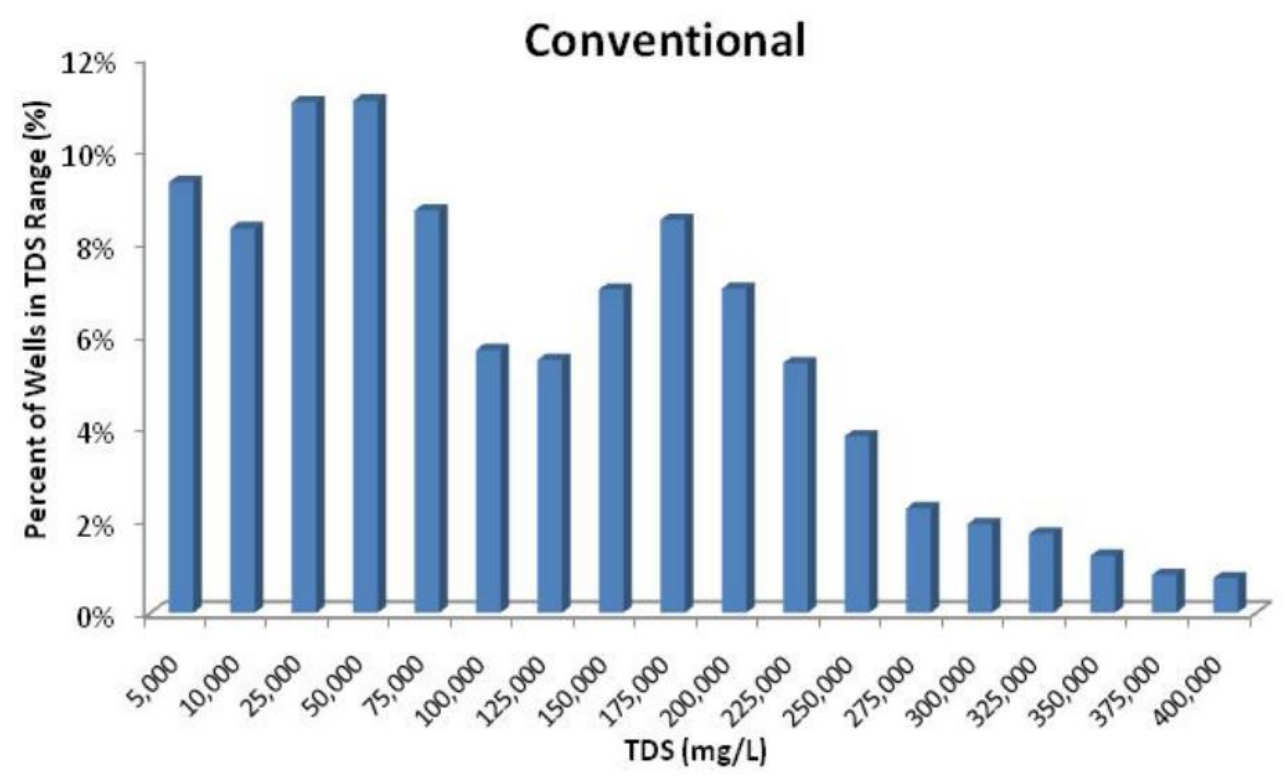

Figure 8: Produced water TDS distribution for conventional oil/gas extraction (USBR, 2011).

The large amount of conventional extracted produced water in the range between $40,000 \mathrm{mg} / \mathrm{L}$ and $300,000 \mathrm{mg} / \mathrm{L}$ makes this water source applicable of MD in many of conventional wells. With $29 \%$ of the wells having a TDS less than $50,000 \mathrm{mg} / \mathrm{L}$, there is also a proportion under $40,000 \mathrm{mg} / \mathrm{L}$ that may be well suited for high recovery desalination through RO-MD hybrid treatment or RO treatment alone. Because produced waters from conventional oil/gas extraction wells have a large proportion of the total TDS distribution in the TDS ranges that are well suited for MD and RO-MD and increasing produced water production over time is well suited for the modularity of MD, conventional oil/gas well produced water will be a focus of this evaluation. 


\subsubsection{Hydraulic Fracturing}

Hydraulic fracturing is a term that refers to the process of creating and expanding fissures in low permeability shale formations to allow extraction of natural gas (SPE, 2012). After the fracturing process, water and natural gas are extracted, but the entire extraction process is often referred to under the term "hydraulic fracturing" or "fracking." During the fracturing process, water, proppant (typically sand), and other production chemicals are injected into a horizontally drilled well at typical depths around $7000 \mathrm{ft}$, and the mixture expands fissures to release natural gas. After the fracturing process, the water used in the fracturing process flows back out of the well. This water is known as flowback water and makes up a majority of hydraulic fracturing produced water. The volume of flowback water is greatest initially and it decreases over the course of two to three weeks. After two to three weeks, the flow may be less than 1\% of the initial flow (SPE, 2012).

Produced water from hydraulic fracturing gas extraction is characterized by very high TDS. Flowback water increases in TDS over the lifetime of a well. Along with decreasing flow rate, the flowback water has a higher TDS concentration over time. Gregory et al found that for western Pennsylvania shale gas produced water sites, flowback TDS was $66,000 \mathrm{mg} / \mathrm{L}$ early in flowback and increased to $150,000 \mathrm{mg} / \mathrm{L}$ for late flowback waters. For these same wells, concentrations as high as $261,000 \mathrm{mg} / \mathrm{L}$ were observed for late flowback waters (Gregory et al, 2011).

Hydraulic fracturing produced water typically has a larger TDS than produced water from traditional oil/gas extraction. An evaluation of 630 hydraulic fracturing wells 
in California had an average TDS of $100,000 \mathrm{mg} / \mathrm{L}$ with a standard deviation of 190,000 $\mathrm{mg} / \mathrm{L}$ and a median value of $280,000 \mathrm{mg} / \mathrm{L}$ (Chitick \& Srebotnjak, 2017). This high median concentration shows a left skewed distribution with few very low concentrations. The majority of the wells are at a TDS level approaching the upper limiting concentration of effective MD operation. A much larger proportion of this distribution is above or approaching the upper limit for MD treatment of produced water than for conventional oil/gas extraction, so MD desalination of hydraulic fracturing produced water is less suited than for conventional extraction. While MD treatment is well-suited for high TDS concentrations, a median TDS concentration of $280,000 \mathrm{mg} / \mathrm{L}$ is close to the saturation point of the dissolved constituents, namely $\mathrm{NaCl}$ where MD treatment is no longer feasible. The declining flow rate over time makes treatment of produced water difficult. For these reasons, the focus of this evaluation does not include hydraulic fracturing produced water.

\subsubsection{Coalbed Methane}

Coalbed methane (CBM) refers to extraction of natural gas that is naturally present in coal formations. Removal of water in the coalbed is often a requirement to release methane in the coal formation, so produced water is generated in large amounts at the start of production. This stage is known as the dewatering stage. After the dewatering stage, the produced water flow rate greatly decreases (USGS, 2000).

CBM produced water is characterized by typically low relative TDS concentrations (Figure 9). In a USBR review of CBM produced water, $86 \%$ of wells had a TDS less than $5000 \mathrm{mg} / \mathrm{L}$ (USBR, 2011). This is in contrast to the conventional extraction 
TDS, where over $90 \%$ of produced water had a TDS greater than $5000 \mathrm{mg} / \mathrm{L}$ (USBR, 2011). This very low relative TDS makes CBM produced water desalination unnecessary in some circumstances. In Alabama, where $62 \%$ of generated produced water is from CBM, all CBM produced water is disposed through surface discharge under NPDES permits (GWPC, 2015). When desalination is necessary for treatment, brackish or seawater RO, or surface evaporation can be applied.

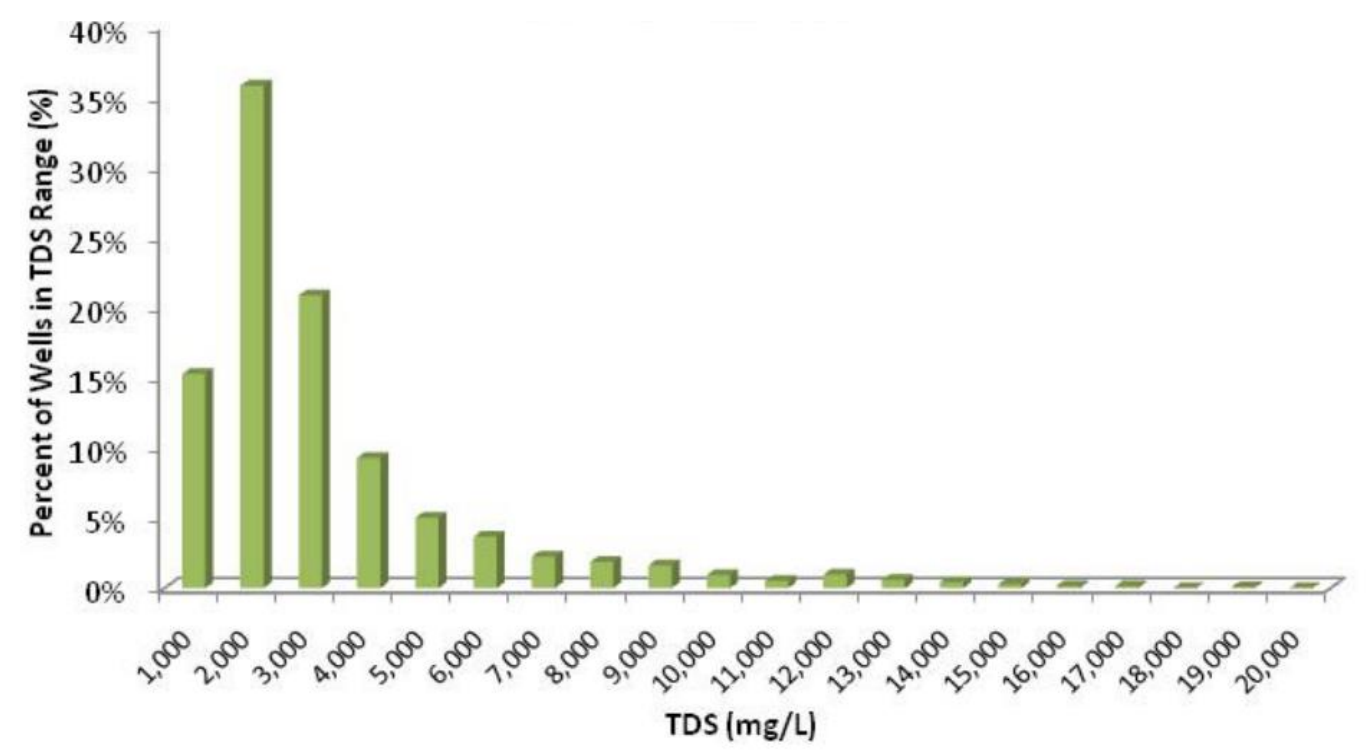

Figure 9: Coalbed methane TDS distribution in the western United States (USBR, 2011).

Since the vast majority of CBM produced water is below $40,000 \mathrm{mg} / \mathrm{L}$, it is not as well suited for desalination using MD as other desalination technologies such as RO. Some CBM produced water sources may be a fit for high recovery using a RO-MD hybrid, but the majority of CBM produced water has a TDS too low for RO-MD to be optimal. Additionally, the declining flow rate over time makes treatment of produced water difficult. For these reasons, the focus of this evaluation does not include CBM produced water. 


\section{Chapter 3}

\section{DCMD MODEL DEVELOPMENT}

Performance prediction can yield important information including treatment rate and thermal energy consumption. Additionally, the performance of a DCMD system can be evaluated under varied conditions to express the impact of changing key parameters to the overall performance of the system. In DCMD, both the module components and the feed and permeate conditions influence the overall performance of the treatment process. Therefore, it is necessary to predict the performance of a DCMD using these parameters. Using models for DCMD heat transfer, mass transfer, concentration polarization, and operation in a counter-current flow module, the performance of a DCMD system can be predicted. The model was developed using Microsoft Excel and Visual Basic. The model developed within this work is a synthesis of equation-based models and algorithms from the literature to create a new model for DCMD performance prediction.

\subsection{Counter-current DCMD Model}

Counter-current flow in DCMD is when the feed and permeate streams flow in opposite directions (Figure 10). This configuration allows for a larger average temperature difference than when the feed and permeate streams flow in the same direction (co-current flow). The introduction of a model for countercurrent flow allows prediction of DCMD performance along a user-specified module length given userspecified flow and temperature conditions of the two fluid streams. Along the length of a countercurrent flow system, the feed and permeate bulk temperatures and flow rates 
change, leading to changing performance along the length. It is necessary to model these changes to accurately determine average overall performance through a countercurrent DCMD system. Predicting performance changes over membrane length is necessary to determine the effectiveness of using sensible heat to operate the DCMD process.

Counter-current membrane distillation module modelling is conducted by taking control volumes of the feed and permeate flows over an incremental length, $d x$ (Figure 10). Over an initial incremental area $i$, the incremental heat transfer, $d Q$, and the incremental mass flow, $d m$, are calculated to determine the state of the next incremental volume $i+1$ (Figure 10) (Duong et al, 2017). The incremental mass flow, $d m$, is related to the mass flux and the area of the membrane in the incremental volume (Equation 6) (Duong et al, 2017). The incremental heat transfer is the sum of the heat transferred from vaporization and the conductive heat transfer lost through the membrane (Equation 7) (Duong et al, 2017). The model assumes steady state conditions with no external heat losses. 


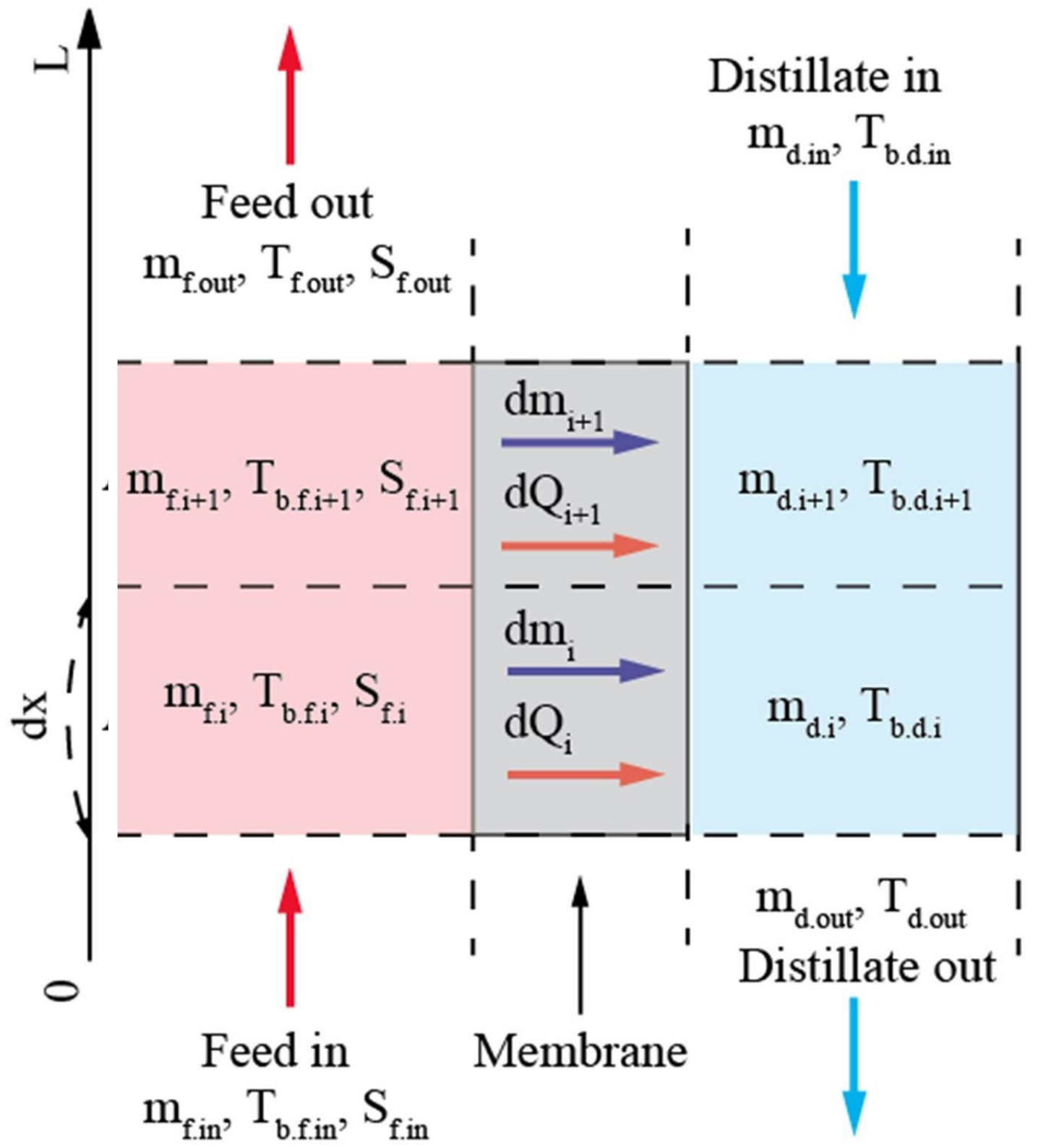

Counter-current

Figure 10: Counter-current DCMD incremental volume analysis schematic diagram (Duong et al, 2017). 


$$
d m_{i}=N_{i} W M_{w} d x
$$

(Equation 6)

where: $d m_{i}=$ Change in mass flow rate at step $i(\mathrm{~kg} / \mathrm{s})$

$$
\begin{aligned}
& N_{i}=\text { Molar flux at step } i\left(\mathrm{~mol} / \mathrm{m}^{2} . \mathrm{s}\right) \\
& W=\text { Module width }(\mathrm{m}) \\
& d x=\text { incremental length step }(\mathrm{m})
\end{aligned}
$$

$$
d Q_{i}=\left(N_{i} \Delta H_{v}+\frac{k_{m}}{\delta}\left(T_{m f}-T_{m p}\right)\right) W d x
$$

where: $\mathrm{dQ}_{\mathrm{i}}=$ Change in heat rate at step $i(\mathrm{~W})$

At each step $i+1$, the feed and permeate bulk temperatures change, the feed and permeate mass flows change, and the feed salinity can be predicted by using conditions at the previous step (Equations 8-10) (Duong et al, 2017). The salt rejection is assumed to be $100 \%$, so the salinity in the permeate solution is assumed to be zero.

$$
T_{b f . i+1}=\frac{m_{f . i} C p_{f . i} T_{b f . i}-d Q_{i}}{m_{f . i+1} C p_{f . i}}
$$

where: $T_{b f . i+1}=$ Bulk temperature at step $i+1(\mathrm{~K})$

$$
C p_{f . i}=\text { Fluid specific heat capacity at step } i(\mathrm{~J} / \mathrm{kg} . \mathrm{K})
$$




$$
m_{f . i+1}=m_{f . i}-d m_{i}
$$

where: $m_{f . i+1}=$ Mass flow rate at step $i+1(\mathrm{~kg} / \mathrm{s})$

$$
m_{f . i}=\text { Mass flow rate at step } i(\mathrm{~kg} / \mathrm{s})
$$

$$
S_{f . i+1}=\frac{m_{f . i} S_{f . i}}{m_{f . i+1}}
$$

where: $S_{f . i+1}=\mathrm{NaCl}$ concentration at step $i+1(\%)$

$$
S_{f . i}=\mathrm{NaCl} \text { concentration at step } i(\%)
$$

In the countercurrent arrangement, the flow of the permeate solution is counter to the flow of the feed solution, so $d m$ and $d Q$ are subtracted from the permeate mass flow and heat, respectively, for step i+1 (Equations 11 and 12) (Duong et al, 2017).

$$
\begin{gathered}
m_{p . i+1}=m_{p . i}-d m_{i} \\
T_{b p . i+1}=\frac{m_{p . i} C p_{p . i} T_{b p . i}-d Q_{i}}{m_{p . i+1} C p_{p . i}}
\end{gathered}
$$

The performance parameters (recovery, SEC, flux, bulk temperatures, TPC, and $\mathrm{CPC}$ ) of a DCMD operating in counter-current flow can be predicted using the module length, membrane conditions, temperature conditions, and flow conditions into the DCMD module. When predicting temperature and flux along the length of the module, the parameters that must be iteratively determined are the temperature $\left(T_{p, 0}\right)$ and mass 
flow rate $\left(m_{p, 0}\right)$ of the permeate at length $X=0$ (Duong et al, 2017). At each step of the iteration, the algorithm for instantaneous DCMD prediction (Figure 11) is applied. The algorithm for counter-current DCMD operation uses an iterative process to solve for $T_{p, 0}$ and $m_{p, 0}$ given known parameters (Figure 12). A specified length step $d x$ is used to predict the conditions along the length of the module. At length $X=L$, the temperature and mass flow of the permeate stream should be the same as the known permeate input values. If they are not equal, the process is iterated and a different guess for $T_{p, o}$ is made. This process is repeated until $T_{p, L}$ is equal to $T_{p, i n}$. After the temperature value is determined, a similar iterative process is applied to determine the value of $m_{p, 0}$.

Once the values for $T_{p, 0}$ and $m_{p, 0}$ are known, all of the known input values are used with the counter-current condition equations (Equations 6-12) and iterated along the length of the module.

At each incremental length, $d x$, heat transfer, mass transfer, and concentration polarization models are applied in an iterative algorithm to predict the performance of DCMD at an instantaneous state. The algorithm in Figure 11 assumes there is no change in bulk temperatures and no change in fluid stream mass flow rates. This algorithm is useful for determining performance trends that are independent of module length, while the full counter-current algorithm (Figure 12) can predict performance variation over the length of a DCMD module. The counter-current algorithm contains the instantaneous algorithm that is applied at each length step. The counter-current algorithm is used to iteratively determine the values for $T_{p, 0}$ and $m_{p, 0}$. 


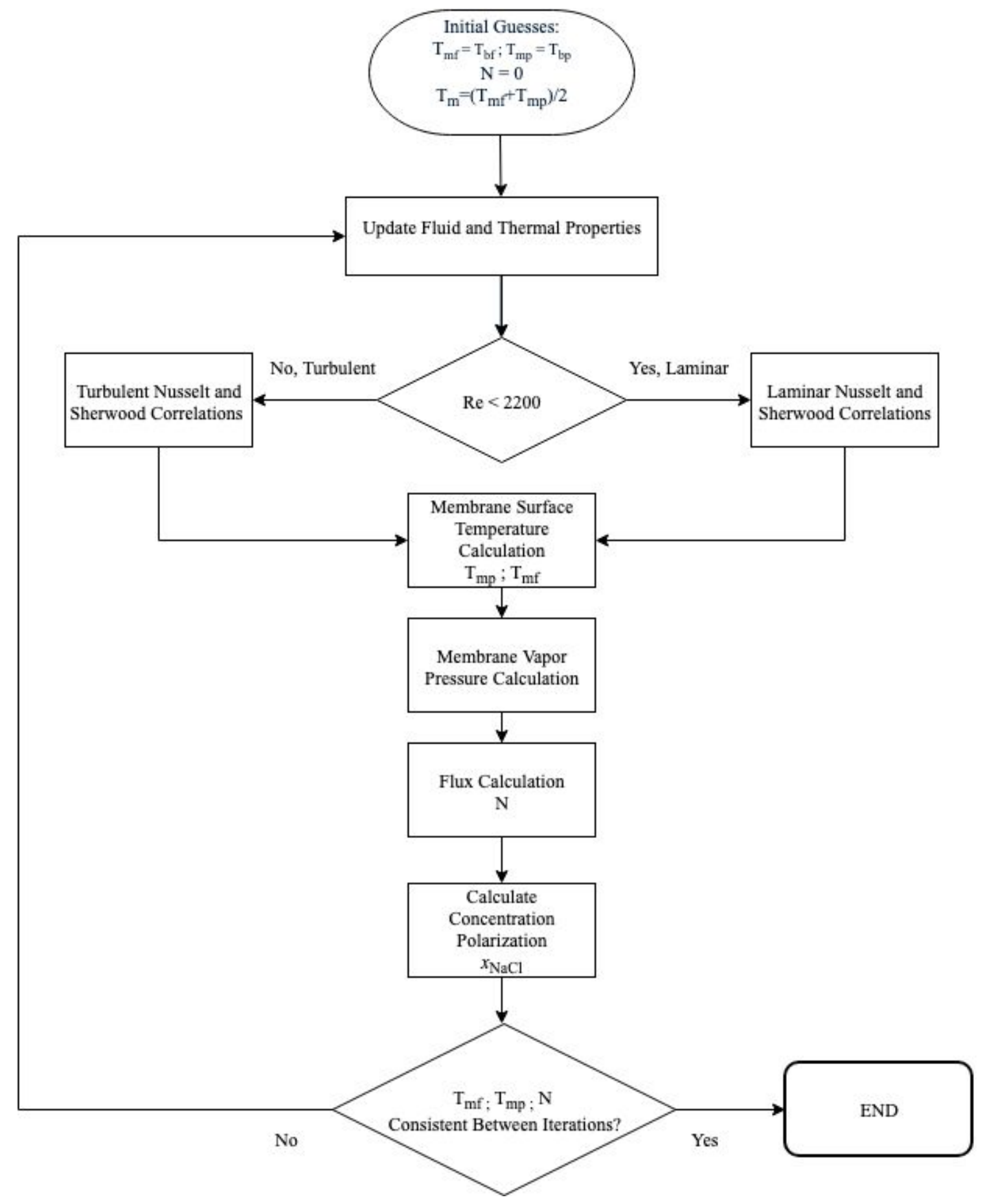

Figure 11: Instantaneous DCMD performance algorithm. The heat transfer, mass transfer, and concentration polarization models are applied in an iterative algorithm until convergence is reached for instantaneous performance predictions. 


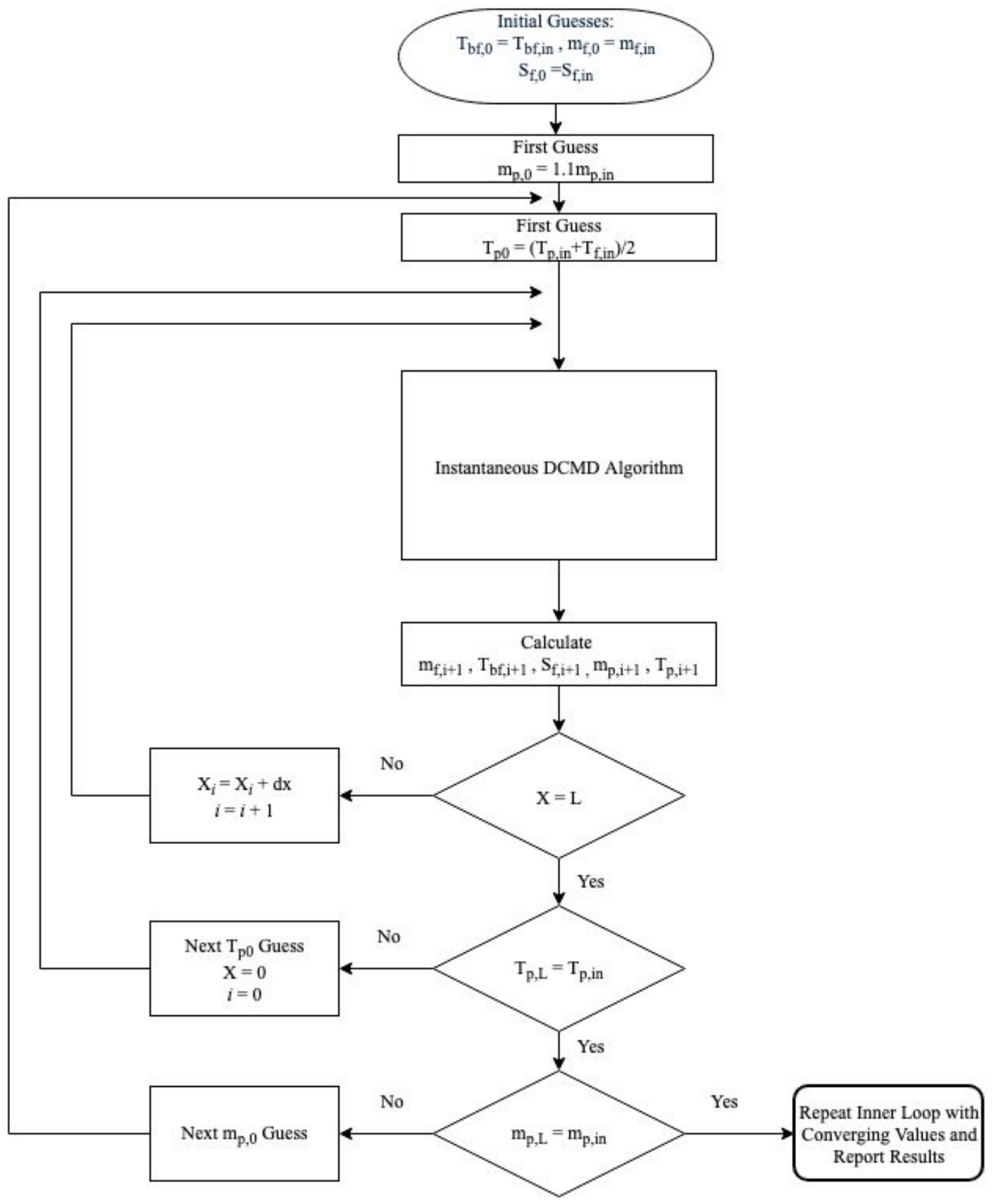

Figure 12: Counter-current flow DCMD algorithm. At each length iteration, the instantaneous algorithm is applied. The algorithm iteratively determines $T_{p, 0}$ and $m_{p, 0}$ to predict performance given input criteria. 


\subsection{Heat Transfer Model}

A heat transfer model to determine the MD membrane surface temperatures was adopted from Hitsov et al (2015). As MD operates from a vapor pressure difference at the membrane surfaces, the surface temperatures are needed to predict MD conditions. Bulk fluid temperatures, hydrodynamic conditions, flux, and membrane conditions are evaluated to predict the membrane surface temperatures.

Heat transfer to and from the bulk feed and permeate solutions to the membrane is governed by convective heat transfer (see Section 2.1.4). In determining convective heat transfer, the dimensionless Nusselt number $(\mathrm{Nu})$ is used. The Nusselt number is the ratio of convective heat transfer to conductive heat transfer for a fluidsurface interaction. Convective heat transfer computations rely on empirical Nusselt correlations that describe convective heat transfer for specific cases. The Reynolds number and Prandtl number are required to calculate the Nusselt number (Equations 13 and 1). The hydraulic diameter for a rectangular channel is defined as four times the area divided by the perimeter (Bergman et al, 2011). For a DCMD flow channel, this is given by equation 14 .

$$
R e=\frac{v d \rho}{\mu}
$$

where: $R e=$ Reynolds number

$$
\begin{aligned}
& d=\text { Hydraulic diameter }(\mathrm{m}) \\
& \rho=\text { Fluid density }\left(\mathrm{kg} / \mathrm{m}^{3}\right) \\
& v=\text { Flow velocity }(\mathrm{m} / \mathrm{s})
\end{aligned}
$$




$$
d=\frac{2 H W}{H+W}
$$

where: $H=$ Membrane channel Height (m)

$$
W=\text { Membrane channel width }(\mathrm{m})
$$

The dynamic viscosity and density properties both vary with temperature and salinity. Values used in the model range from $0 \%$ to $26 \% \mathrm{NaCl}$ and from $0^{\circ} \mathrm{C}$ to $100^{\circ} \mathrm{C}$ (using properties from Kestin et el, 1981). For thermal conductivity and specific heat, the properties used only varied with temperature. In reality, these parameters vary with salinity as well, but due to lack of available property data, an assumption was made that the variation with salinity was not significant.

The Nusselt correlations for both laminar and turbulent flow utilize the fluid conditions in the bulk fluid and at the membrane surface to predict convective heat transfer. The following Nusselt correlation was used for laminar flow conditions (Equation 15) (Hitsov et al, 2015).

$$
N u_{\text {laminar }}=0.097 \operatorname{Re}^{0.73} \operatorname{Pr}^{0.13}\left(\frac{P r_{b}}{P r_{\text {wall }}}\right)^{0.25}
$$

where: $N u=$ Nusselt number

$$
\begin{aligned}
& P r_{b}=\text { Prandtl number of the bulk fluid } \\
& P r_{\text {wall }}=\text { Prandtl number at the membrane surface }
\end{aligned}
$$


For turbulent flow conditions, the Nusselt correlation reflects an increased convective heat transfer found in turbulent flow conditions (Equation 16) (Lawal and Khalifa, 2014).

$$
N u_{\text {turbulent }}=0.023 \operatorname{Re}^{0.8} \operatorname{Pr}^{0.33}\left(\frac{\mu_{b}}{\mu_{\text {wall }}}\right)^{0.14}
$$

where: $\mu_{b}=$ Dynamic Viscosity of the bulk fluid

$$
\mu_{\text {wall }}=\text { Dynamic Viscosity at the membrane surface }
$$

The convective heat transfer coefficient $(h)$ can be calculated using the appropriate Nusselt number, fluid thermal conductivity, and hydraulic diameter (Equation 17).

$$
h=\frac{N u \cdot k}{d}
$$

where: $h=$ Convective heat transfer coefficient $\left(\mathrm{W} / \mathrm{m}^{2} . \mathrm{K}\right)$

The conductive heat transfer across the membrane can be described by the membrane thermal conductivity and the membrane thickness (Equation 18).

$$
h_{m}=\frac{k_{m}}{\delta}
$$

where: $h_{m}=$ Conductive heat transfer coefficient of the membrane $\left(\mathrm{W} / \mathrm{m}^{2} . \mathrm{K}\right)$

$k_{m}=$ Membrane composite thermal conductivity (W/m.K) $\delta=$ Membrane thickness (m) 
The membrane thermal conductivity $\left(k_{m}\right)$ is a composite thermal conductivity of the membrane material and the gases within the membrane pores. The thermal conductivity of the gases within the membrane pores $\left(k_{g}\right)$ is a function of the mean temperature of the membrane given by the empirical correlation reported by Hitsov et al (2015) (Equation 19).

$$
k_{g}=2.73 \times 10^{-3}+7.77 \times 10^{-5} T_{m}
$$

where: $k_{g}=$ Thermal conductivity of the gases within the membrane pores (W/m.K)

$$
T_{m}=\text { Mean membrane temperature }(\mathrm{K})
$$

The thermal conductivity of the membrane material varies with material type and mean membrane temperature. This work considers a PTFE membrane whose thermal conductivity can be approximated by Equation 20 (Hitsov et al, 2015).

$$
k_{s}=5.769 \times 10^{-4} T_{m}+8.914 \times 10^{-2}
$$

where: $k_{S}=$ Thermal conductivity of the membrane material (W/m.K)

The composite membrane thermal conductivity is related to the porosity and the component thermal conductivities. The equation used for $k_{m}$ was a best fit from a study performed by Garcia-Payo and Izquierdo-Gil, where $\beta$ is an intermediate value for determining composite thermal conductivity (Equation 21 and 22) (Hitsov et al, 2015). 


$$
k_{m}=\frac{k_{g}(1+2 \beta(1-\epsilon))}{1-\beta(1-\epsilon)}
$$

$$
\beta=\frac{\left(k_{s}-k_{g}\right)}{\left(k_{s}+2 k_{g}\right)}
$$

where: $\epsilon=$ Membrane porosity

$$
\beta=\text { Intermediate factor for determining thermal conductivity }
$$

The heat of vaporization varies with temperature and can be predicted by a correlation of heat of vaporization vs temperature values (Equation 23) (Bergman et al, 2011).

$$
H_{v}=-43.838 T_{m}+45078
$$

where: $\mathrm{H}_{\mathrm{v}}=$ Heat of vaporization of water $(\mathrm{J} / \mathrm{mole})$

The temperature at the membrane surfaces was calculated by re-arranging the heat transfer components from the overall heat transfer balance (Equations 24 and 25).

$$
\begin{gathered}
T_{m f}=\frac{T_{b f} h_{f}+h_{m}\left(T_{b p}+T_{b f} \frac{h_{f}}{h_{p}}\right)-N H_{v}}{h_{f}\left(1+\frac{h_{m}}{h_{p}}\right)+h_{m}} \\
T_{m p}=\frac{T_{b p} h_{p}+h_{m}\left(T_{b f}+T_{b p} \frac{h_{p}}{h_{f}}\right)+N H_{v}}{h_{p}\left(1+\frac{h_{m}}{h_{f}}\right)+h_{m}}
\end{gathered}
$$

where: $\mathrm{N}=$ Molar flux $\left(\mathrm{mol} / \mathrm{m}^{2} . \mathrm{s}\right)$ 
The temperature difference of the membrane surfaces determines the driving force for mass transfer and the driving force for convective heat loss. The temperatures at the membrane surfaces allow for prediction of performance parameters such as flux and STEC. The membrane temperatures can also be used to quantify the temperature polarization that is present. The temperature polarization coefficient (TPC) is the ratio of the membrane temperature difference to the bulk temperature difference (Equation 26) (Bahmanyar et al, 2012). A higher TPC reflects less temperature polarization as the membrane temperature difference is closer to the bulk temperature difference. A low TPC reflects temperature polarization that reduces the driving force of DCMD treatment.

$$
T P C=\frac{T_{m f}-T_{m p}}{T_{b f}-T_{b p}}
$$

\subsection{Mass Transfer Model}

Mass transfer in membrane distillation occurs through diffusion and convection (Lawal and Khalifa, 2014). The driving force of mass transfer in membrane distillation is transmembrane vapor pressure difference. The transmembrane vapor pressure difference $\left(\Delta P_{m}\right)$ is the difference in vapor pressure between the feed and permeate sides of the membrane (Equation 27). Permeate flux $(N)$ is proportional to the vapor pressure difference across the membrane (Equation 28) (Lawal and Khalifa, 2014). 


$$
\Delta P_{m}=P_{m f}-P_{m p}
$$

where: $P_{m f}=$ Water vapor pressure at the feed side of the membrane

$P_{m p}=$ Water vapor pressure at the permeate side of the membrane

$$
N \propto \Delta P_{m}
$$

(Equation 28)

The base membrane vapor pressures $\left(p_{m f 0}, p_{m p}\right)$ can be calculated using the Buck equation (Equation 29) (Buck, 1981). Salinity of the feed stream can reduce the activity of water vapor and lower the effective vapor pressure difference across the membrane. To account for this decrease in water vapor activity, the activity coefficient $\left(\gamma_{m f}\right)$ is used to find the effective feed vapor pressure, $p_{\mathrm{mf}}$ (Equations 30 and 31) (Hitsov et al, 2015). Since the permeate stream is assumed to be pure, the activity coefficient does not need to be calculated for the permeate stream.

$$
p(T)=611.21 \exp \left(\left(18.678-\frac{T}{234.5}\right)\left(\frac{T}{257.14+T}\right)\right)
$$

where: $p(T)=$ Saturation vapor pressure of water $(\mathrm{Pa})$

$$
\mathrm{T}=\text { Temperature of air }\left({ }^{\circ} \mathrm{C}\right)
$$

$$
p_{m f}=p_{m f 0} x_{w} \gamma_{m f}
$$

where: $x_{w}=$ Mole fraction of water in feed solution

$$
\gamma_{m f}=\text { Water vapor activity coefficient }
$$




$$
\gamma_{m f}=1-0.5 x_{N a C l}-10 x_{N a C l}^{2}
$$

where: $x_{\mathrm{NaCl}}=$ Mole fraction of $\mathrm{NaCl}$ in feed solution

In DCMD, Knudsen and molecular mass transfer resistances are typically mass transfer limiting (Lawson and Lloyd, 1997). The first mass transfer modeling approach that was attempted accounted for both of these resistances, but that method was removed due to low accuracy in corresponding with experimental data. Instead, the mass transfer was approximated as diffusion through a thin film and calibrated against experimental data. The molar flux can be calculated using Fick's law to approximate the membrane as a stagnant air film (Equation 32) (Bahmanyar et al, 2012). The product of the pressure and the diffusion coefficient of water vapor is given by Equation 33 (Lawal and Khalifa, 2014). The limitation of applying Fick's law to predict mass transfer is that it neglects the effects that membrane porosity, tortuosity, and pore size have in determining mass transfer. For that reason, a correction factor for the diffusion coefficient was applied using results from experimental data. The effective diffusion coefficient is found by using the ratio of experimental flux to predicted flux (Equation 34) (Bahmanyar et al, 2012). The effective diffusion coefficient was then used to predict flux using Equation 32.

$$
N=\frac{P_{t} D_{w}}{R T_{m} \delta} \ln \left(\frac{P_{t}-p_{m p}}{P_{t}-p_{m f}}\right)
$$

where: $D_{w}=$ Diffusion coefficient $\left(\mathrm{m}^{2} / \mathrm{s}\right)$ 


$$
\begin{gathered}
P_{t}=\text { Total pressure in the membrane pore }(\mathrm{Pa}) \\
R=\text { Gas constant, } 8.314(\mathrm{~J} / \text { mole.K) } \\
\qquad \begin{array}{c}
P_{t} D_{w}=4.46 \times 10^{-6} T_{m}{ }^{2.334} \\
D_{w, \text { eff }}=\frac{N_{\text {exp }}}{N_{\text {calc }}} D_{w}
\end{array}
\end{gathered}
$$

where: $D_{w, e f f}=$ Effective diffusion coefficient $\left(\mathrm{m}^{2} / \mathrm{s}\right)$

$$
\begin{aligned}
& N_{\text {exp }}=\text { Experimental molar flux }\left(\mathrm{mol} / \mathrm{m}^{2} . \mathrm{s}\right) \\
& N_{\text {calc }}=\text { Molar flux predicted by model }\left(\mathrm{mol} / \mathrm{m}^{2} . \mathrm{s}\right)
\end{aligned}
$$

\subsection{Concentration Polarization Model}

Concentration polarization coefficient (CPC) is the ratio of the concentration of $\mathrm{NaCl}$ at the membrane surface of the feed stream to the concentration of $\mathrm{NaCl}$ in the bulk feed solution (Equation 35) (Bahmanyar et al, 2012). The concentration of $\mathrm{NaCl}$ at the membrane surface can be calculated using Equation 36 (Bahmanyar et al, 2012).

$$
C P C=\frac{C_{m f}}{C_{b f}}
$$

where: $C_{m f}=$ Concentration of solute at the membrane surface

$$
C_{b f}=\text { Concentration of solute in the bulk solution }
$$

$$
C_{m f}=C_{b f} \exp \left(\frac{N M_{w}}{\rho k_{c}}\right)
$$

where: $k_{c}=$ Convective mass transfer coefficient of the feed stream $(\mathrm{m} / \mathrm{s})$ 
The convective mass transfer coefficient $\left(k_{c}\right)$ can be found using the Sherwood number (Equation 37) (Bahmanyar et al, 2012). The Sherwood number (Sh) can be approximated using empirical correlations for the laminar and turbulent regimes (Equations 38 and 39) (Bahmanyar et al, 2012). The Schmidt number (Sc) can be found using Equation 40 (Bahmanyar et al, 2012). The Schmidt number is applied in Equations 38 and 39 to approximate the Sherwood numbers.

$$
S h=\frac{k_{c} d}{D_{N a C l}}
$$

where: $S h=$ Sherwood number

$$
\begin{aligned}
& D_{\mathrm{NaCl}}=\text { Diffusivity of } \mathrm{NaCl} \text { in water }\left(\mathrm{m}^{2} / \mathrm{s}\right) \\
& \qquad h=0.13 R e^{0.64} S c^{0.38}, R e<2300 \\
& S h=0.023 R e^{0.8} S c^{0.33}, R e>2300
\end{aligned}
$$

where: $S c=$ Schmidt number

$$
S c=\frac{\mu}{\rho D_{\text {NaCl }}}
$$

\subsection{Model Calibration}

The applied model for DCMD was compared to experimental data to calibrate and validate the model predictions. The results from the Cath et al (2003) study were compared to the model results given the same operational parameters. The operational parameters of the experiment are listed in Table 1. Two membranes were used in the 
Cath et al study under these parameters, TS45 and TS22. These two membranes both had a porosity of 0.7 and a membrane thickness of $175 \mu \mathrm{m}$. These two membranes varied only in their nominal pore size $(0.45 \mu \mathrm{m}$ and $0.22 \mu \mathrm{m}$ respectively).

Table 1: Cath et al Experimental Parameters Applied for Calibration (Cath et al, 2003)

\begin{tabular}{|c|c|}
\hline Parameter & Value \\
\hline Membrane thickness & $175 \mu \mathrm{m}$ \\
\hline Feed Velocity & $1.75 \mathrm{~m} / \mathrm{s}$ \\
\hline Permeate Velocity & $1.75 \mathrm{~m} / \mathrm{s}$ \\
\hline Hydraulic Diameter & $0.0024 \mathrm{~m}$ \\
\hline Permeate Temperature & $20^{\circ} \mathrm{C}$ \\
\hline Porosity & 0.7 \\
\hline Membrane Channel Height & $0.003 \mathrm{~m}$ \\
\hline Membrane Channel Width & $0.002 \mathrm{~m}$ \\
\hline Bulk NaCl Concentration & $0.06 \%$ \\
\hline
\end{tabular}

The mass transfer model does not use pore size to predict mass transfer. In reality, pore size is a factor that affects which mass transfer resistance mechanism is dominant and affects the overall mass transfer resistance (Lawal and Khalifa, 2014). This limitation of not incorporating pore size is accounted for by calibrating the model against experimental data, but there may be operational parameters that have dependence on pore size that are not accounted for solely by calibration against experimental data.

\subsubsection{Calibration Results}

The experimental results from two membranes under the operating conditions in Table 1 were used to obtain a corrected diffusion coefficient using Equation 34. The average flux of the two membranes at a feed temperature of $40^{\circ} \mathrm{C}$ and a feed velocity of 
$1.75 \mathrm{~m} / \mathrm{s}$ was used to calibrate the model to find an effective diffusion (See Equation 34). With this calibrated diffusion, the model predictions were compared to experimental data.

When comparing mass flux and feed temperature, the predicted values were similar to the experimental results for both the TS45 and TS22 membranes (Figure 13). The similarity of the predicted values to the experimental data demonstrates the ability of the model to accurately predict performance of DCMD systems with regard to feed temperature.

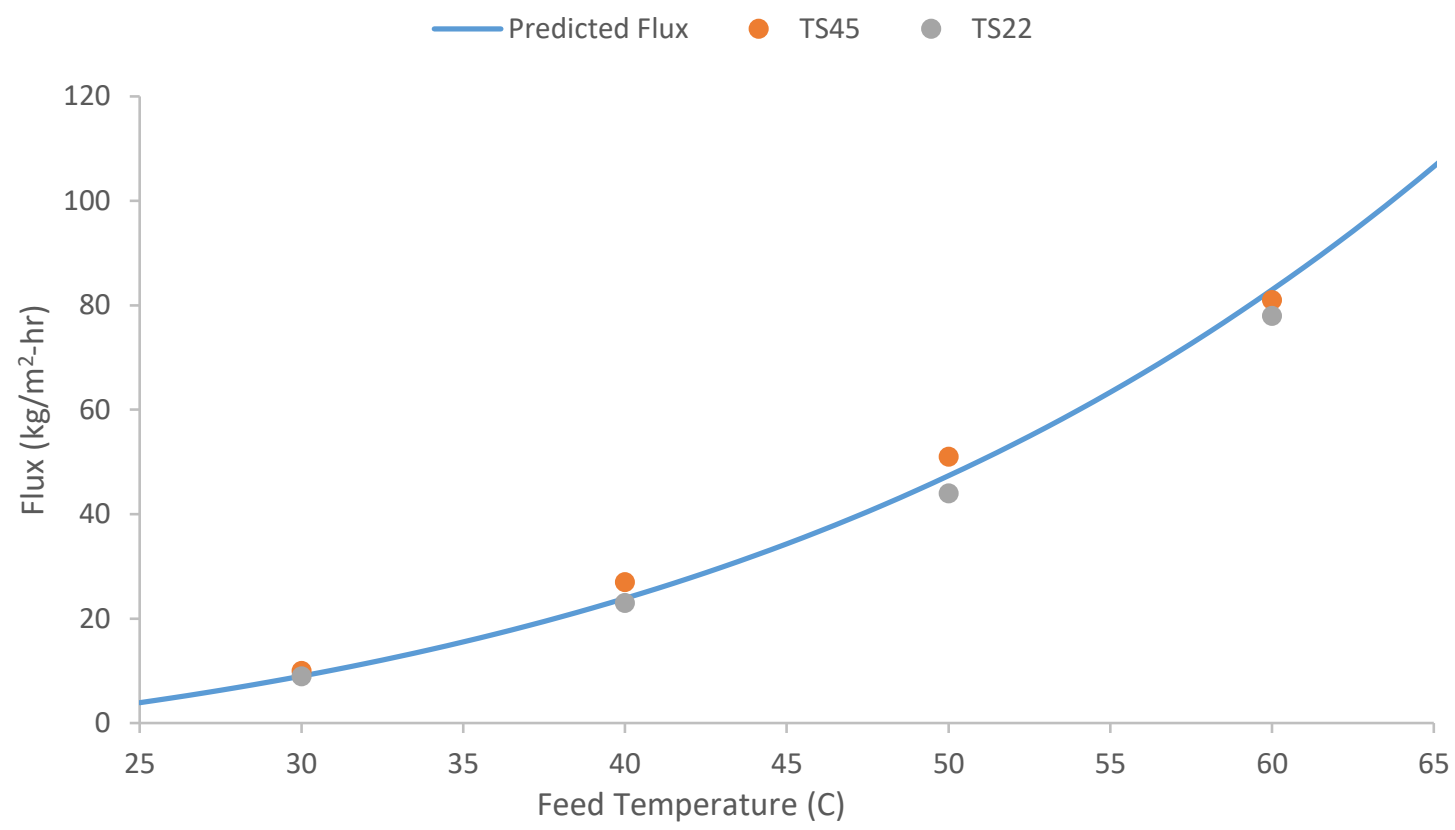

Figure 13: Comparison of predicted flux vs feed temperature values to experimental results obtained by Cath et al. Permeate temperature is $20^{\circ} \mathrm{C}$. Feed and Permeate velocities are $1.75 \mathrm{~m} / \mathrm{s}$. NaCl concentration is $0.06 \%$ by weight (Cath et al, 2003).

When comparing the predicted flux vs feed velocity to the experimental results, a weaker fit was found (Figure 14). The predicted values for flux level off at a lower velocity than the trend suggested by the experimental data. The model was calibrated 
at $40^{\circ} \mathrm{C}$ and $1.75 \mathrm{~m} / \mathrm{s}$, so the predicted flux at the $1.75 \mathrm{~m} / \mathrm{s}$ point being close to the experimental flux is reasonable. The predicted flux vs feed velocity displayed a similar trend to the experimental data, where the flux increase from increasing feed velocity begins to level off at high velocities. The discrepancy in the predicted flux trend may be due to the applied convective heat transfer correlations used in the turbulent regime underestimating the impact of increased feed velocity. The experimental values for the TS45 and TS22 membranes also showed substantial variation, suggesting that for feed velocity, pore size may have a larger impact on flux. Not incorporating pore size when applying a thin film diffusion mass transfer prediction may provide a greater limitation to the ability of the model to accurately predict flux based on feed velocity compared to predicting flux based on feed temperature. The ability of the model to accurately predict flux with changing feed velocity is limited. 


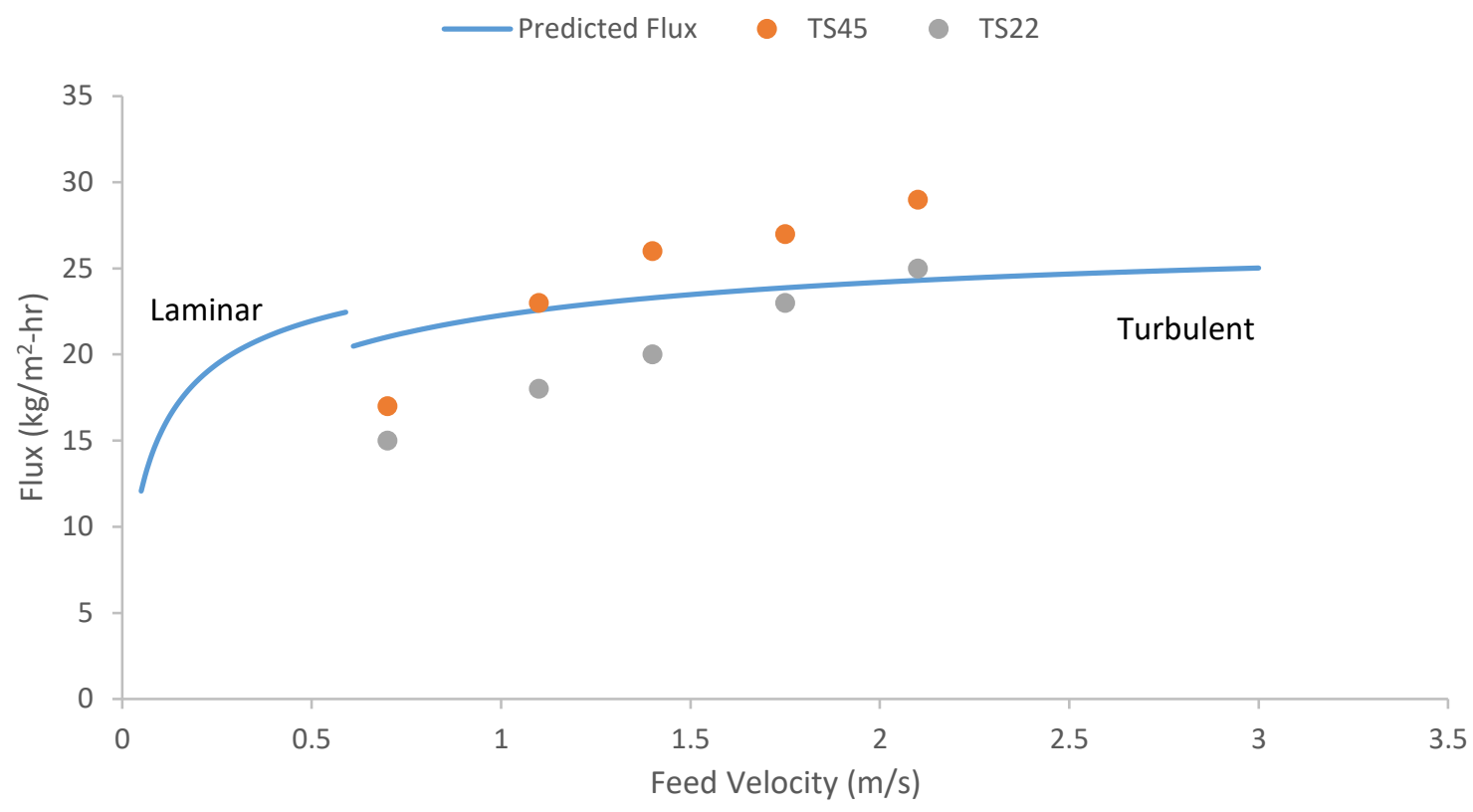

Figure 14: Comparison of predicted flux vs feed velocity values to experimental results obtained by Cath et al. Feed temperature is $40^{\circ} \mathrm{C}$. Permeate temperature is $20^{\circ} \mathrm{C}$. Permeate velocity is $1.75 \mathrm{~m} / \mathrm{s}$. NaCl concentration is $0.06 \%$ by weight (Cath et al, 2003). 


\section{Chapter 4}

\section{DCMD MODEL APPLICATION}

The model and algorithms were applied to evaluate the sensitivity of DCMD performance to key parameters and to evaluate the feasibility of treating high temperature produced water using sensible heat. For the sensitivity analysis, nine key parameters were varied individually while the remaining parameters were held constant.

A feasible set of parameters that minimized DCMD energy consumption was selected for use in the analysis of sensible heat-driven treatment of produced water. Using the models and the counter-current module algorithm, the performance of DCMD modules based on feed inlet temperature and module length was evaluated. From this evaluation of counter-current DCMD performance, a comparison of hydraulic energy consumption and percent recovery was conducted to determine the feasibility of using sensible heat from high temperature produced water to drive DCMD treatment. The energy demands of a DCMD system using sensible heat were compared to RO energy demands to assess the feasibility of utilizing the waste heat. The performance of a hypothetical DCMD-RO hybrid system was then evaluated using a high $\mathrm{NaCl}$ concentration.

\subsection{Sensitivity Analysis of Key MD Parameters}

Using results from the applied models, one parameter was varied at a time while all of the other parameters were held constant. For each parameter, the parameter in question was varied, and the other eight parameters were held constant. The variables 
that were held constant were operated at the same parameters as in the Cath et al study (see Table 1).

\subsubsection{Bulk Feed Temperature}

The membrane vapor pressure difference is the driving force in MD, and is directly proportional to the temperature of the vapor-liquid interfaces. As the bulk temperature of the feed solution increases, the vapor pressure difference increases at a similar rate to the increase in bulk temperature (Figure 15). As bulk feed temperature increases, there is an exponential increase in the permeate flux due to the increasing vapor pressure. Thermal efficiency also increases as the bulk temperature increases due to the increase in heat transferred by vaporization relative to the increase in heat transferred by conduction (Figure 16). A larger bulk temperature difference leads to more significant temperature polarization and a decrease in TPC (Figure 16).

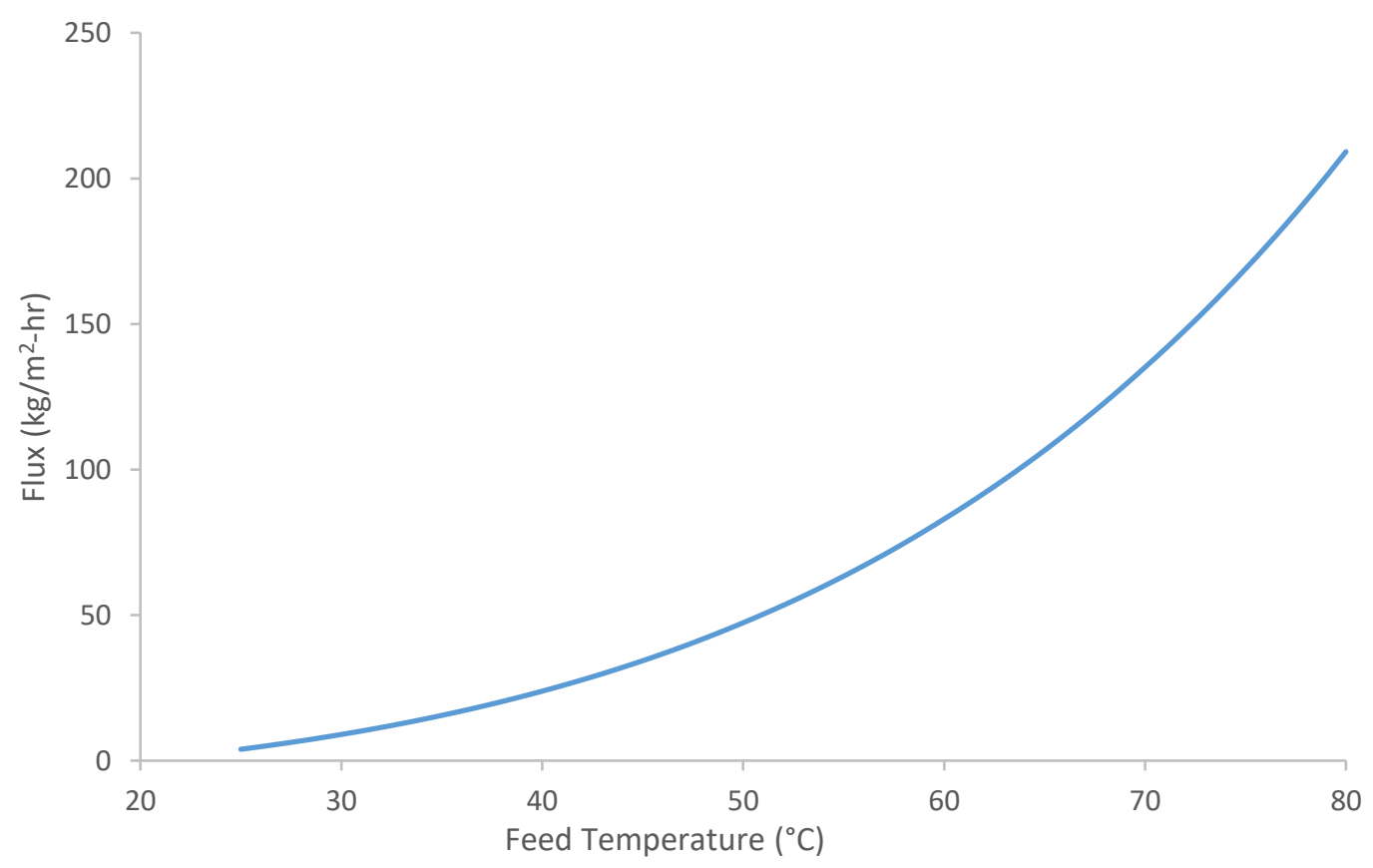

Figure 15: Mass flux vs. bulk feed temperature. Permeate temperature is $20^{\circ} \mathrm{C}$. All other parameters are from the Cath et al 2003 study (see Section 3.5). 


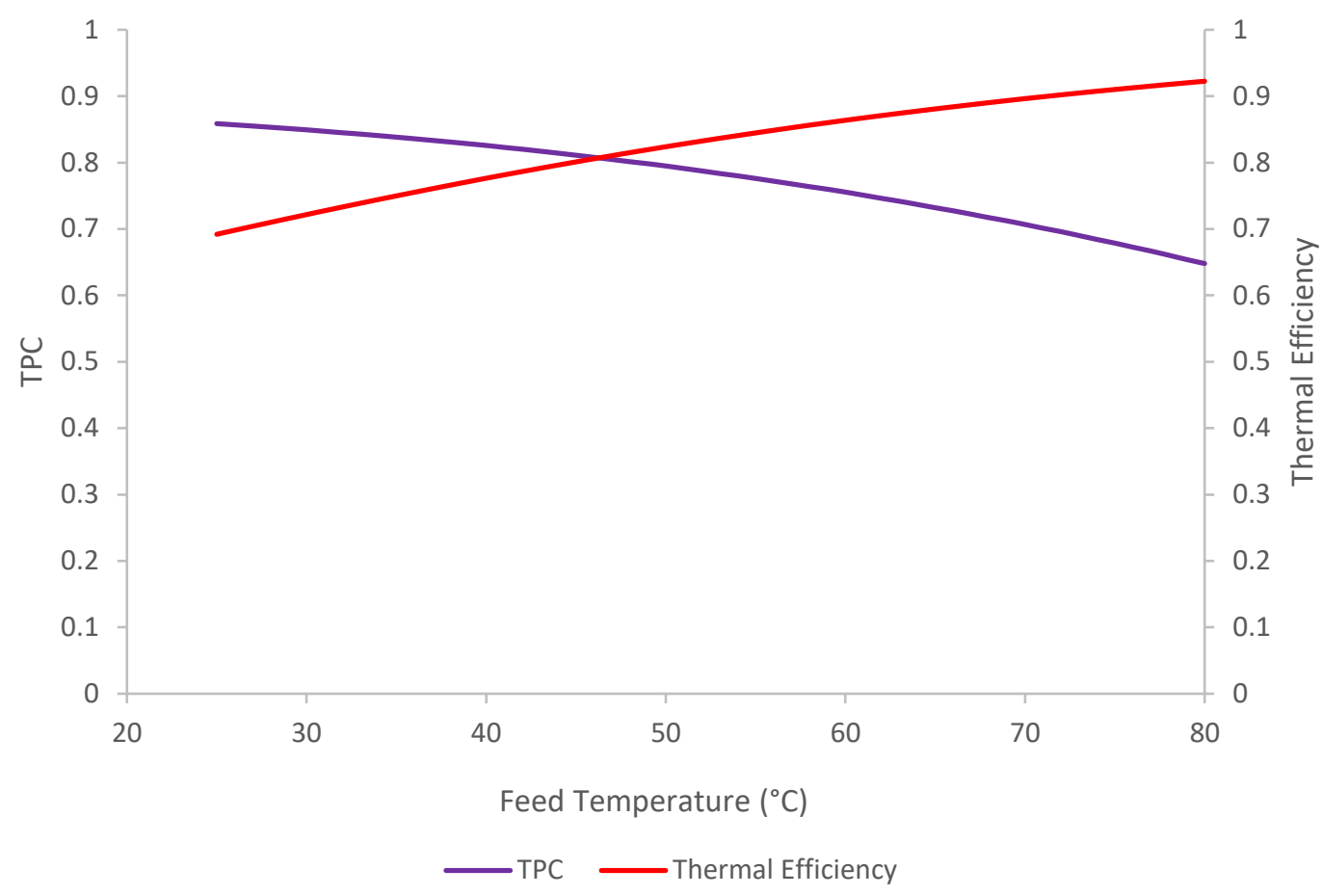

Figure 16: TPC and thermal efficiency vs. bulk feed temperature. Permeate temperature is $20^{\circ} \mathrm{C}$. All other parameters are from the Cath et al 2003 study (see Section 3.5).

When selecting input parameters, temperature has one of the greatest impacts on flux and process thermal efficiency, so bulk feed temperature should be maximized wherever possible. However, as discussed in Section 2.1.8.1, temperatures above $85^{\circ} \mathrm{C}$ have been seen to increase membrane wetting, reducing overall separation effectiveness (Tun et al, 2005).

\subsubsection{Bulk Permeate Temperature}

Increasing permeate feed temperature decreases the flux as the vapor pressure difference decreases (Figure 17). Because the vapor pressure increases at an increasing rate, changes to permeate temperature result in the largest flux change at high 
temperatures and the lowest flux change at low temperatures. With increasing

permeate bulk temperature, there is an increase in thermal efficiency as the driving

force for conductive losses is reduced, and there is a slight decrease in TPC (Figure 18).

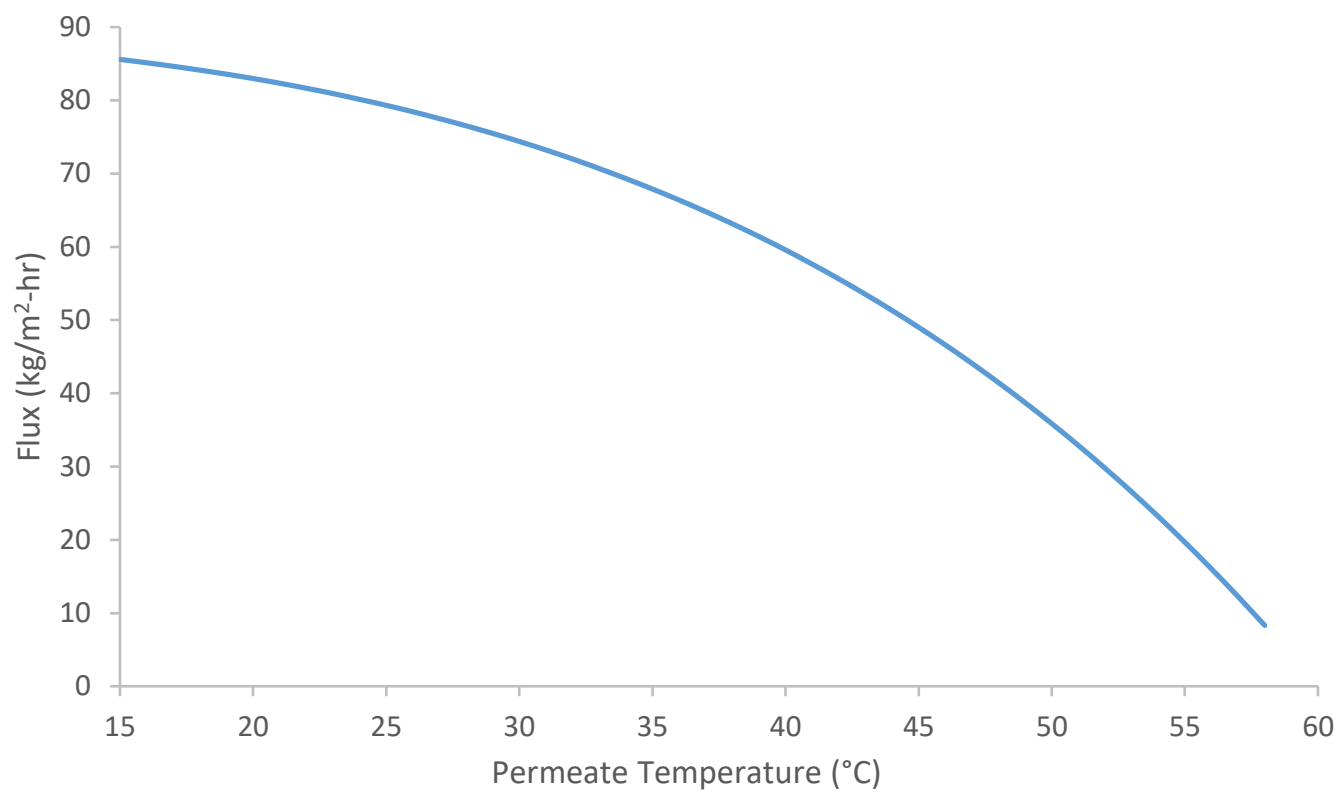

Figure 17: Mass flux vs. bulk permeate temperature. Feed temperature is $60^{\circ} \mathrm{C}$. All other parameters are from the Cath et al 2003 study (see Section 3.5). 


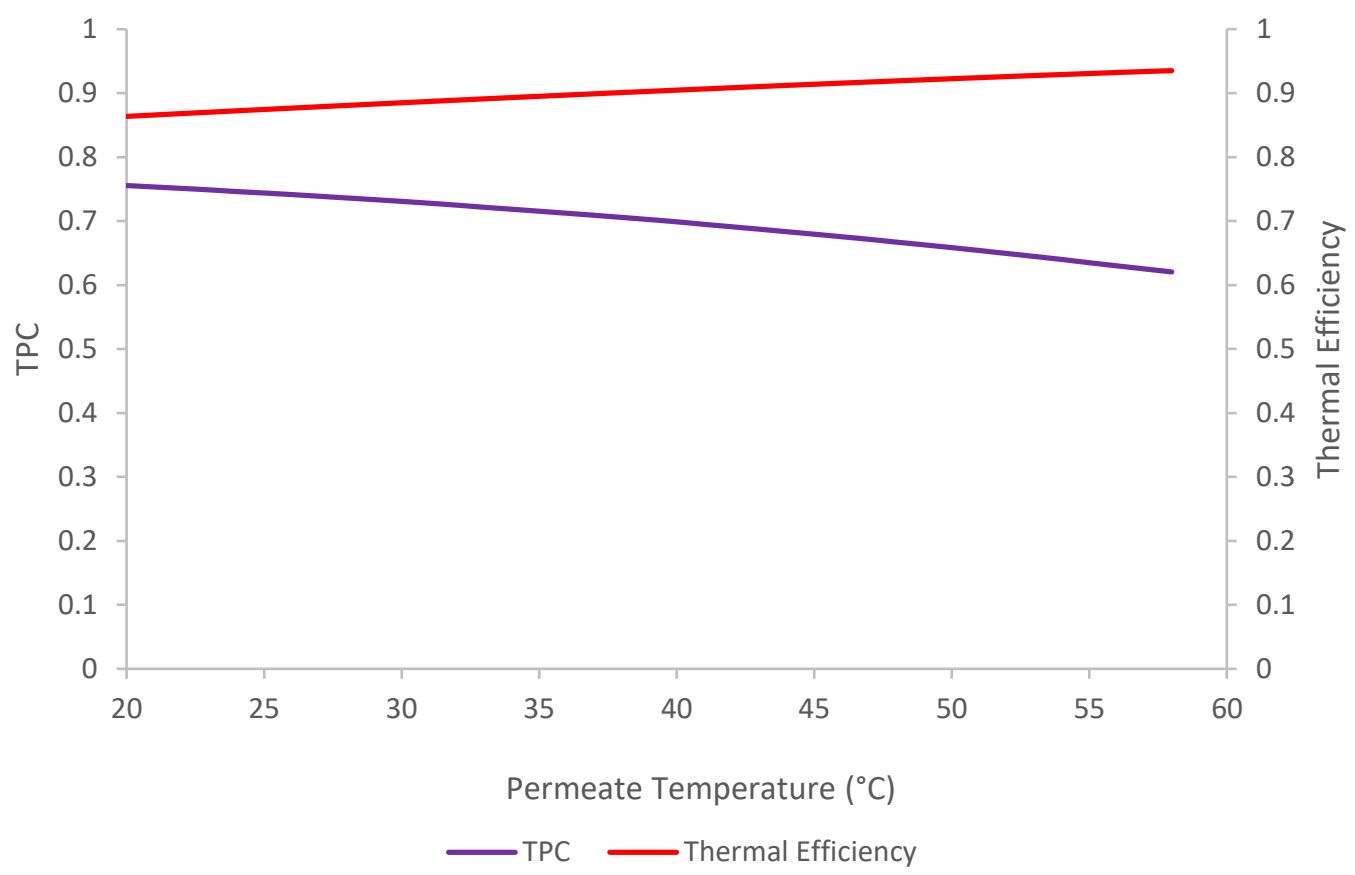

Figure 18: TPC and thermal efficiency vs. bulk permeate temperature. Feed temperature is $60^{\circ} \mathrm{C}$. All other parameters are from the Cath et al 2003 study (see Section 3.5).

Permeate temperature should be minimized when possible in DCMD to optimize performance. However, at low temperatures, the performance incentive of cooling the permeate stream decreases. If mechanical cooling of the permeate stream is considered to increase performance, the energy costs and the potential benefits should be assessed to determine whether cooling is beneficial to the operator's goals.

\subsubsection{Membrane Thickness}

Membrane thickness directly affects both the conductive heat losses and the overall mass transfer resistance. As membrane thickness decreases, the conductive heat transfer resistance decreases, and conductive heat transfer increases. Additionally, as membrane thickness decreases, mass transfer resistance decreases. However, 
increasing conductive heat transfer results in higher temperature polarization and lower transmembrane temperature differences. These lower transmembrane temperature differences can result in a reduction of flux for thin membranes despite low mass transfer resistances. Optimal membrane thicknesses have been reported to range from 10-700 $\mu \mathrm{m}$ based on membrane characteristics (Eykens et al, 2016). At membrane thickness below or above this optimal range, flux should decrease.

A limitation of the applied model algorithm is the inability to accurately predict the performance of low membrane thicknesses. With this limitation, small thicknesses that may reach the point where flux decreases are observed are not able to be evaluated. The trend of an optimal membrane thickness that maximizes flux can not be confirmed using the applied model algorithm. At the membrane thickness feasible for model application, flux decreases at a decreasing rate as membrane thickness increases (Figure 19). Within the range predicted, reducing the membrane thickness increases DCMD performance.

The increase of conductive heat losses as thickness decreases also results in higher temperature polarization and lower thermal efficiencies (Figure 20). Thicker membranes have less temperature polarization and a higher thermal efficiency, but they also have lower flux. 


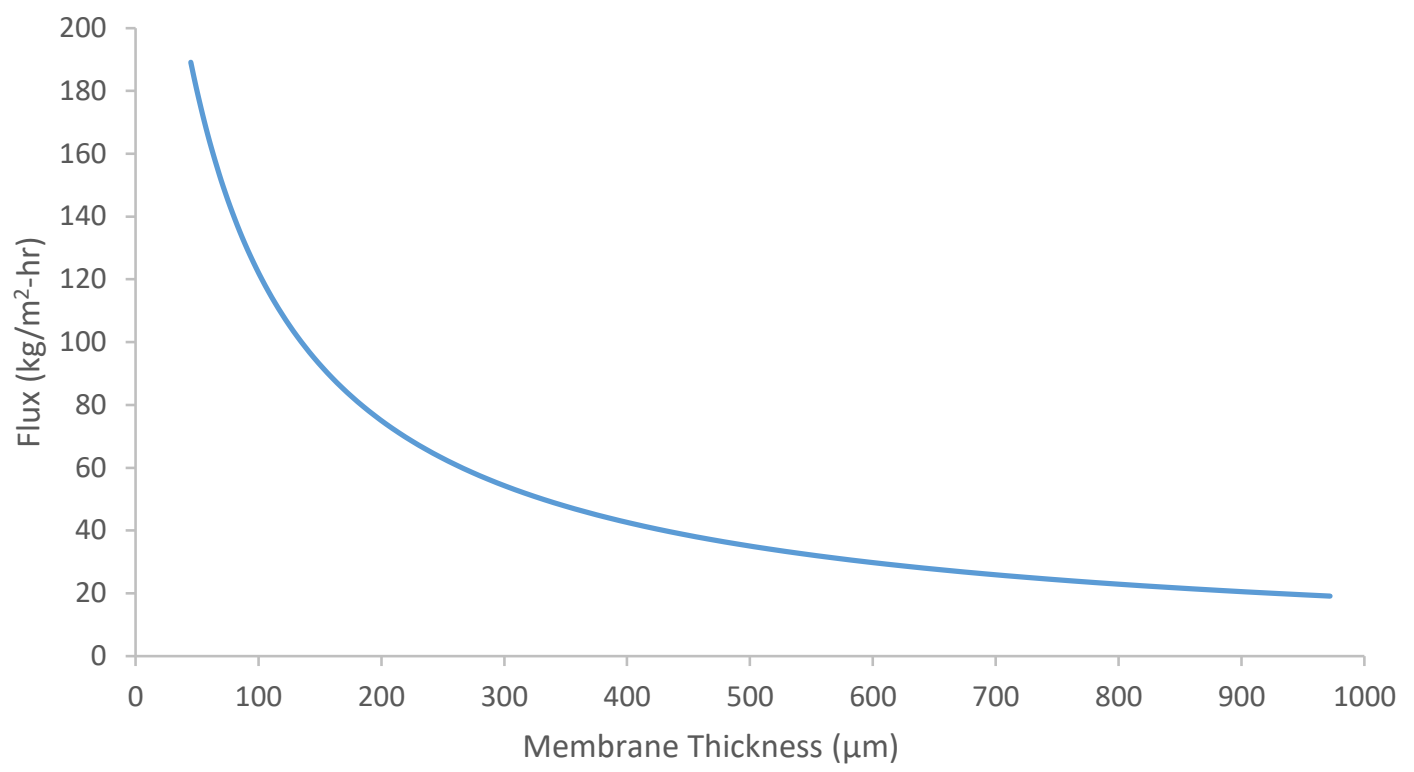

Figure 19: Mass flux vs. membrane thickness. Feed and permeate temperatures are $60^{\circ} \mathrm{C}$ and $20^{\circ} \mathrm{C}$, respectively. All other parameters are from the Cath et al 2003 study (see Section 3.5).

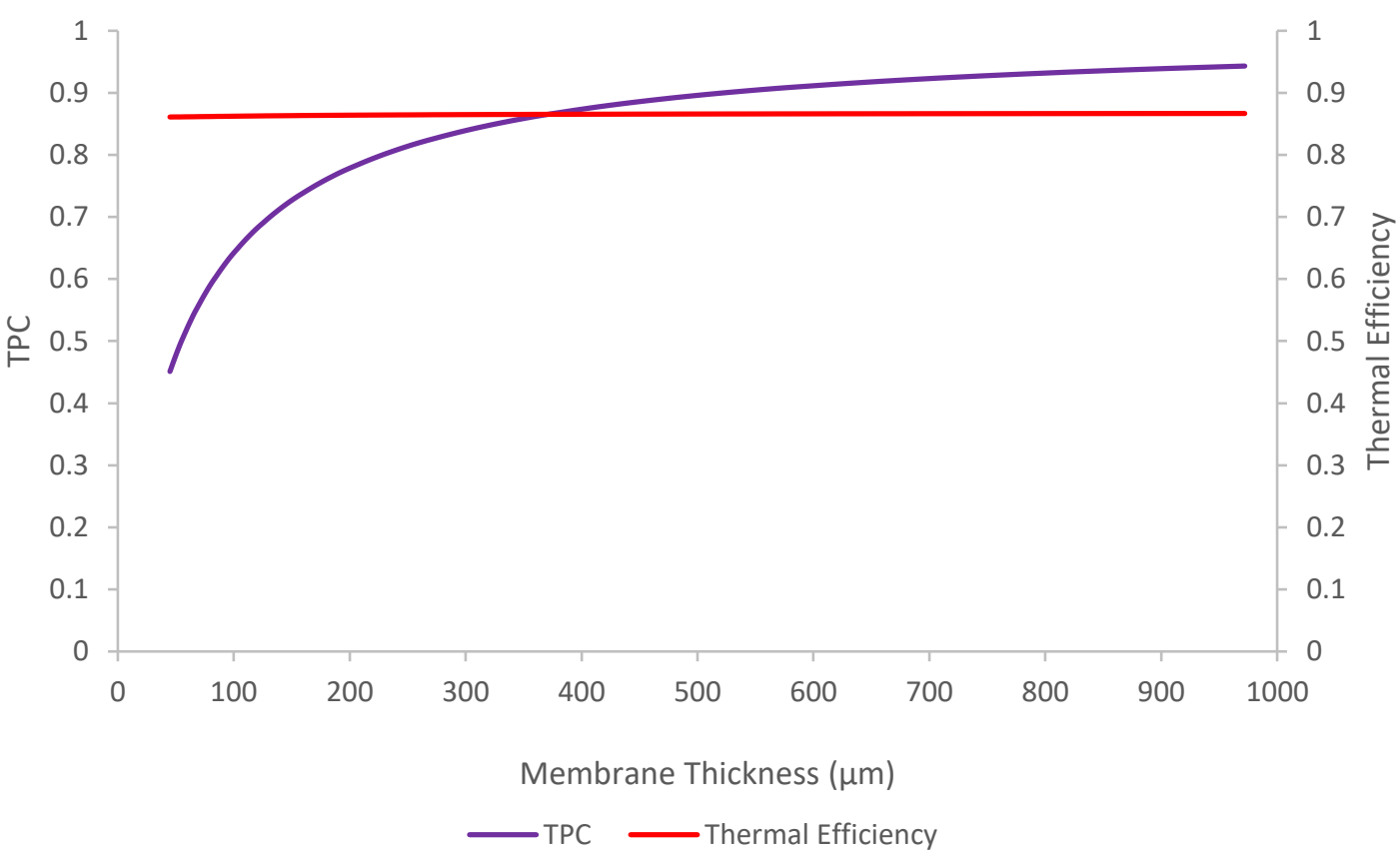

Figure 20: TPC and thermal efficiency vs. membrane thickness. Feed and permeate temperatures are $60^{\circ} \mathrm{C}$ and $20^{\circ} \mathrm{C}$, respectively. All other parameters are from the Cath et al 2003 study (see Section 3.5). 
Note that there may be an optimal range for a set of fluid and membrane parameters that optimizes performance that can not be predicted by this model. Another consideration with membrane thickness is the structural stability of the membrane. Depending on the module conditions and flow conditions, a thin membrane may not be feasible for DCMD. The thickness needed for a structurally stable membrane should be evaluated before selecting a membrane thickness.

\subsubsection{Membrane Porosity}

Membrane porosity affects heat losses due to conduction and mass transfer resistance. In the applied model, only the heat transfer component of porosity variation is reflected in performance prediction. In reality, the porosity of a DCMD membrane has a strong effect on mass transfer, and a flux is expected to approach zero as porosity approaches zero as the pore space available for diffusion is reduced. The model prediction of flux does not show this expected change in flux (Figure 21). Therefore, the trends shown are not accurate for varied membrane porosity. The trends only consider the heat transfer effects of varied porosity. Therefore, this model can not accurately predict performance with varied porosity. For the purpose of this study, a porosity of 0.7 was used because that is the porosity of the experimental data to which the mass transfer model was calibrated. Note that the porosity is independent of the pore size as discussed in Section 3.5. 


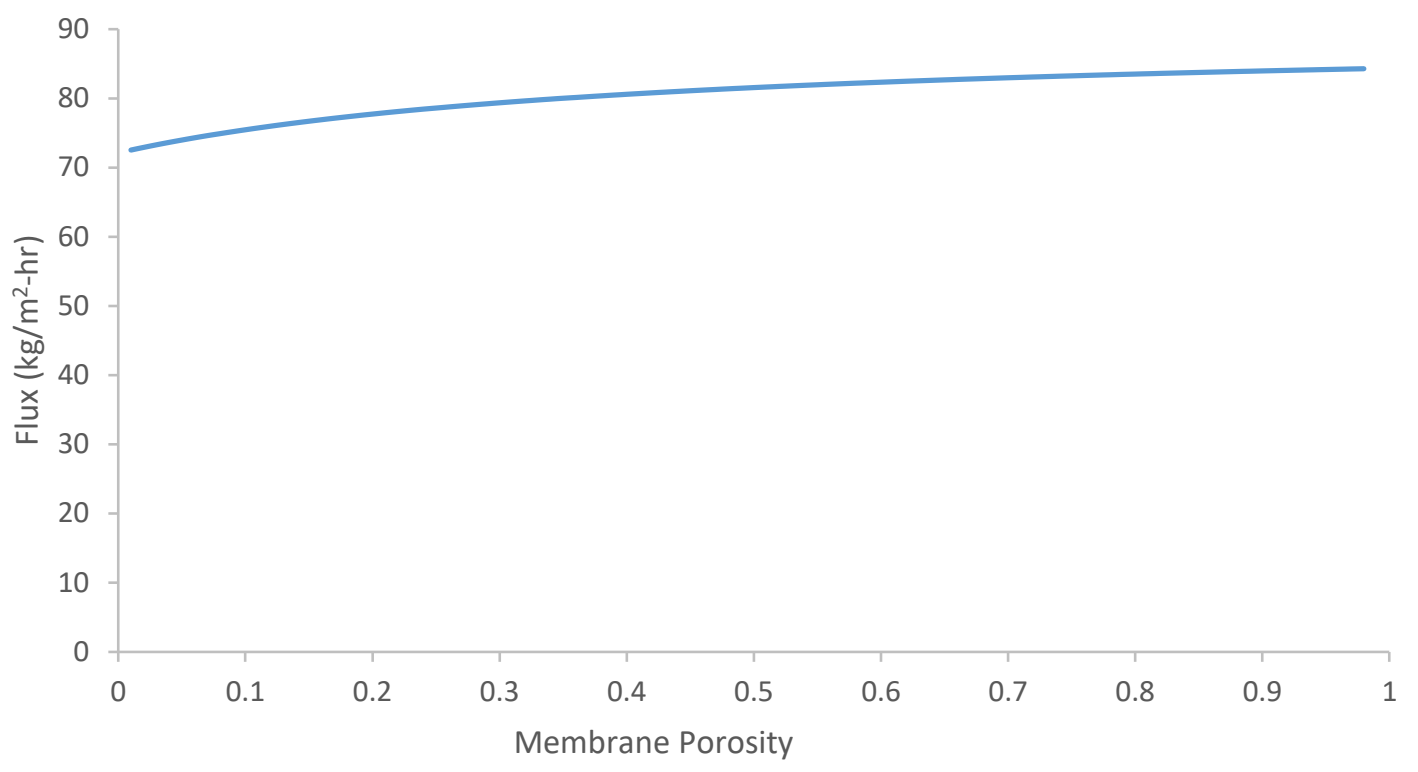

Figure 21: Mass flux vs. membrane porosity. Feed and permeate temperatures are $60^{\circ} \mathrm{C}$ and $20^{\circ} \mathrm{C}$. All other parameters are from the Cath et al 2003 study (see Section 3.5).

The heat losses due to conduction depend on the thermal conductivity of the membrane solid and the air in the membrane pores. The typical thermal conductivity for common membrane materials ranges from 0.11 to $0.27 \mathrm{~W} / \mathrm{m}-\mathrm{K}$, while the thermal conductivity of air in the pores is approximately $0.03 \mathrm{~W} / \mathrm{m}-\mathrm{K}$ (Zhang et al, 2015) (Hitsov et al, 2015). Conductive heat losses can be lowered by lowering the proportion of the higher conductivity membrane material. Increasing porosity decreases the overall thermal conductivity of the membrane and lowers heat losses. This decrease in heat losses results in an increase in predicted thermal efficiency (Figure 22). 


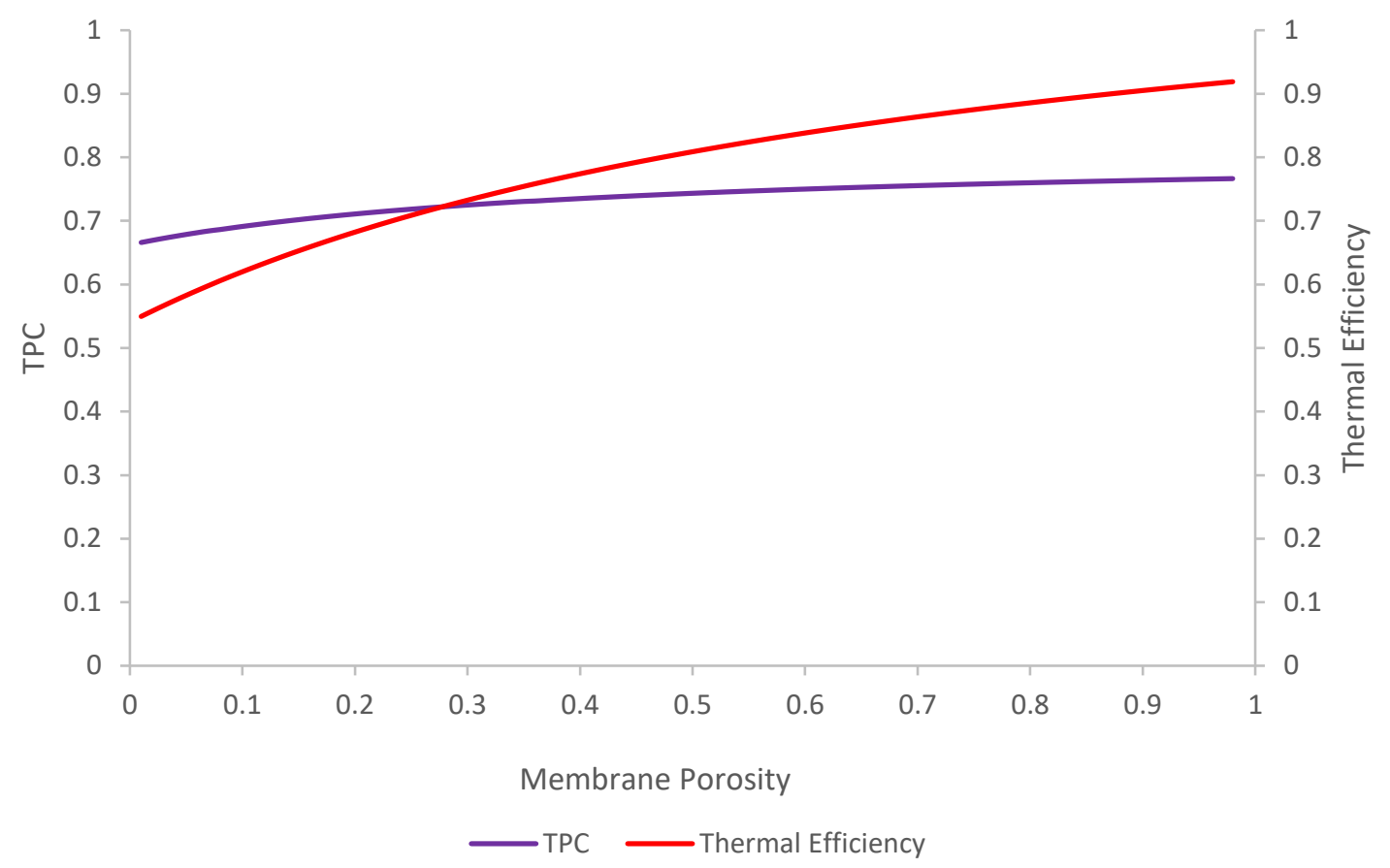

Figure 22: TPC and thermal efficiency vs. membrane porosity. Feed and permeate temperatures are $60^{\circ} \mathrm{C}$ and $20^{\circ} \mathrm{C}$. All other parameters are from the Cath et al 2003 study (see Section 3.5).

Porosity should be maximized when possible when selecting membranes for DCMD systems to increase flux and thermal efficiency. Eykens et al recommended a membrane porosity greater than 0.75 to maximize flux (2016). However, high membrane porosity can lead to increased membrane wetting that lowers permeate quality (Zhang et al, 2015a). A porosity that maintains the LEP of the membrane above operating conditions should be selected. In addition, the porosity of the membrane can affect the structural stability of the membrane. Very high porosity membranes could reduce the ability of the membrane to withstand DCMD operation. 


\subsubsection{Feed Velocity}

The feed stream velocity directly affects the temperature polarization and concentration polarization, which in turn affect the thermal efficiency and flux. Increasing feed velocity in the laminar regime increases the flux at a high rate, while increasing feed velocity in the turbulent flow regime increases the flux at a lower rate (Figure 23). Low feed velocities in the laminar flow regime correspond with a larger thermal boundary layer at the membrane surface. This increased boundary layer thickness leads to a larger temperature difference between the bulk fluid and the fluid at the membrane surface. This increased temperature difference is reflected in the increase in predicted temperature polarization (Decrease in TPC) (Figure 24). As flow rate increases in the laminar regime, the temperature polarization decreases (Increase in TPC) (Figure 24). Increases in velocity in the turbulent flow regime decrease predicted temperature polarization at a lower rate (Figure 24). Predicted thermal efficiency increases at a low rate with increased flow velocity in both flow regimes (Figure 24). 


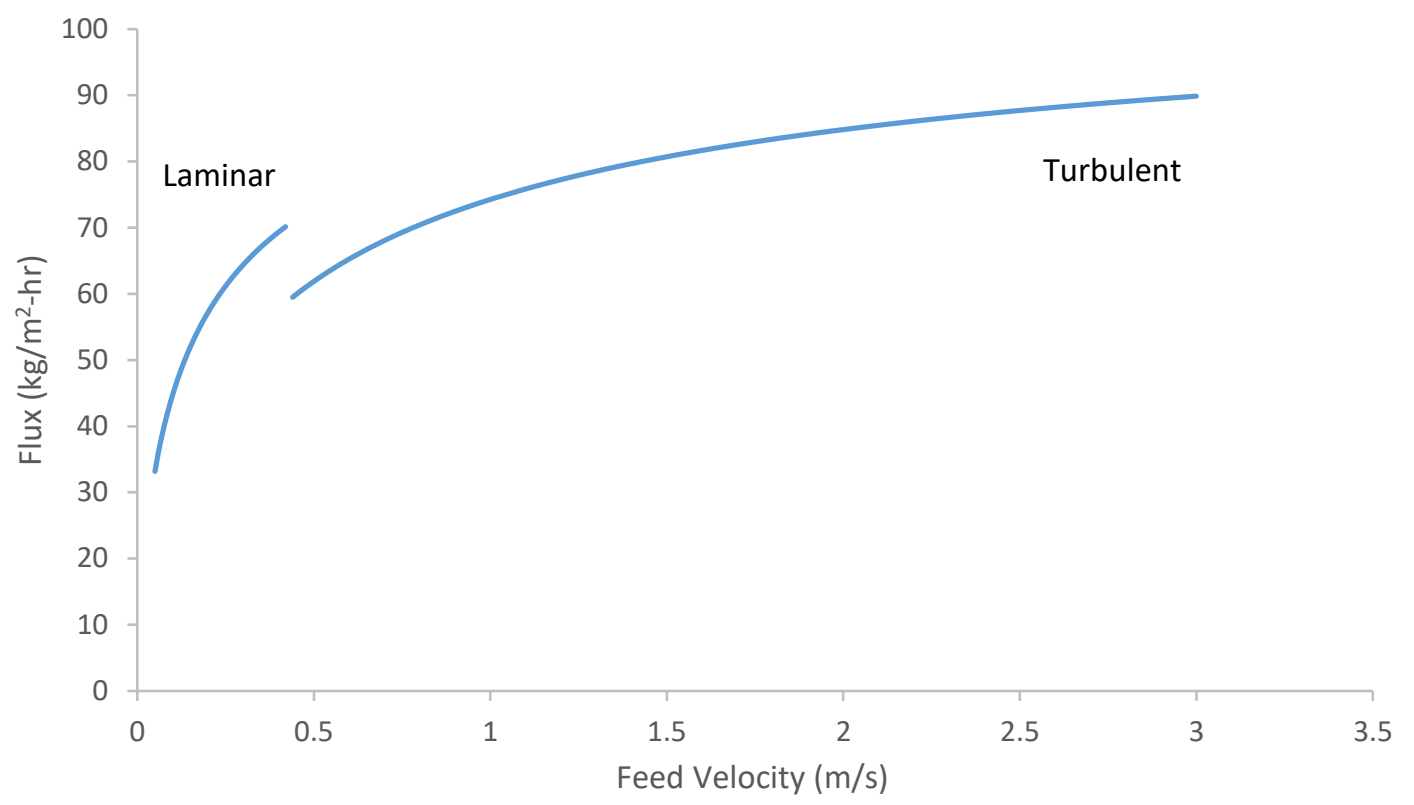

Figure 23: Mass flux vs. feed velocity. Feed and permeate temperatures are $60^{\circ} \mathrm{C}$ and $20^{\circ} \mathrm{C}$, respectively. All other parameters are from the Cath et al 2003 study (see Section 3.5). The point of discontinuity is the transition of laminar to turbulent flow.

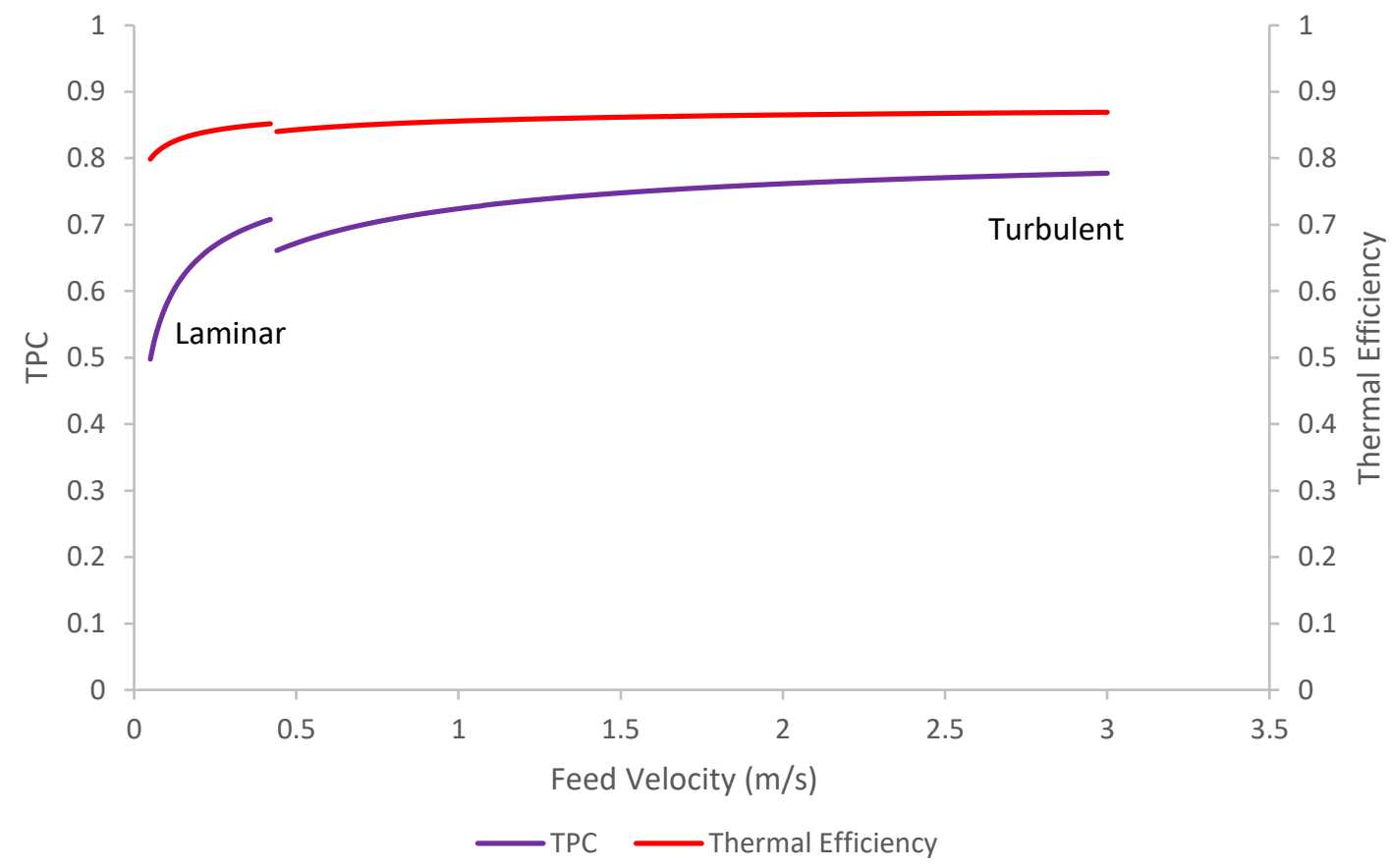

Figure 24: TPC and thermal efficiency vs. feed velocity. Feed and permeate temperatures are $60^{\circ} \mathrm{C}$ and $20^{\circ} \mathrm{C}$, respectively. All other parameters are from the Cath et al 2003 study (see Section 3.5). The point of discontinuity is the transition of laminar to turbulent flow. 
The two convective heat transfer correlations for laminar and turbulent flow account for the discontinuity in the model predictions as feed velocity is increased. This discontinuity is present with the two models because in reality, the transition region between laminar and turbulent flow has thermal and hydraulic characteristics that cannot be accurately predicted by the laminar or turbulent Nusselt correlations.

As feed velocity increases, a decrease in CPC is expected as there is more mixing in the feed stream. With more mixing, the concentration at the membrane surface should be closer to the bulk concentration. The predicted concentration polarization decreases as velocity increases in the laminar regime and concentration polarization decreases in the turbulent regime as velocity increases (Figure 25). The large discontinuity in the predicted concentration polarization is due to the change in the Sherwood correlation from laminar to turbulent. The discontinuity and related increase in CPC at the beginning of the turbulent regime does not reflect a trend that is supported by the theory. The Sherwood correlations that were used to approximate CPC produce this effect, so to improve the CPC prediction, the Sherwood correlations should be re-evaluated. 


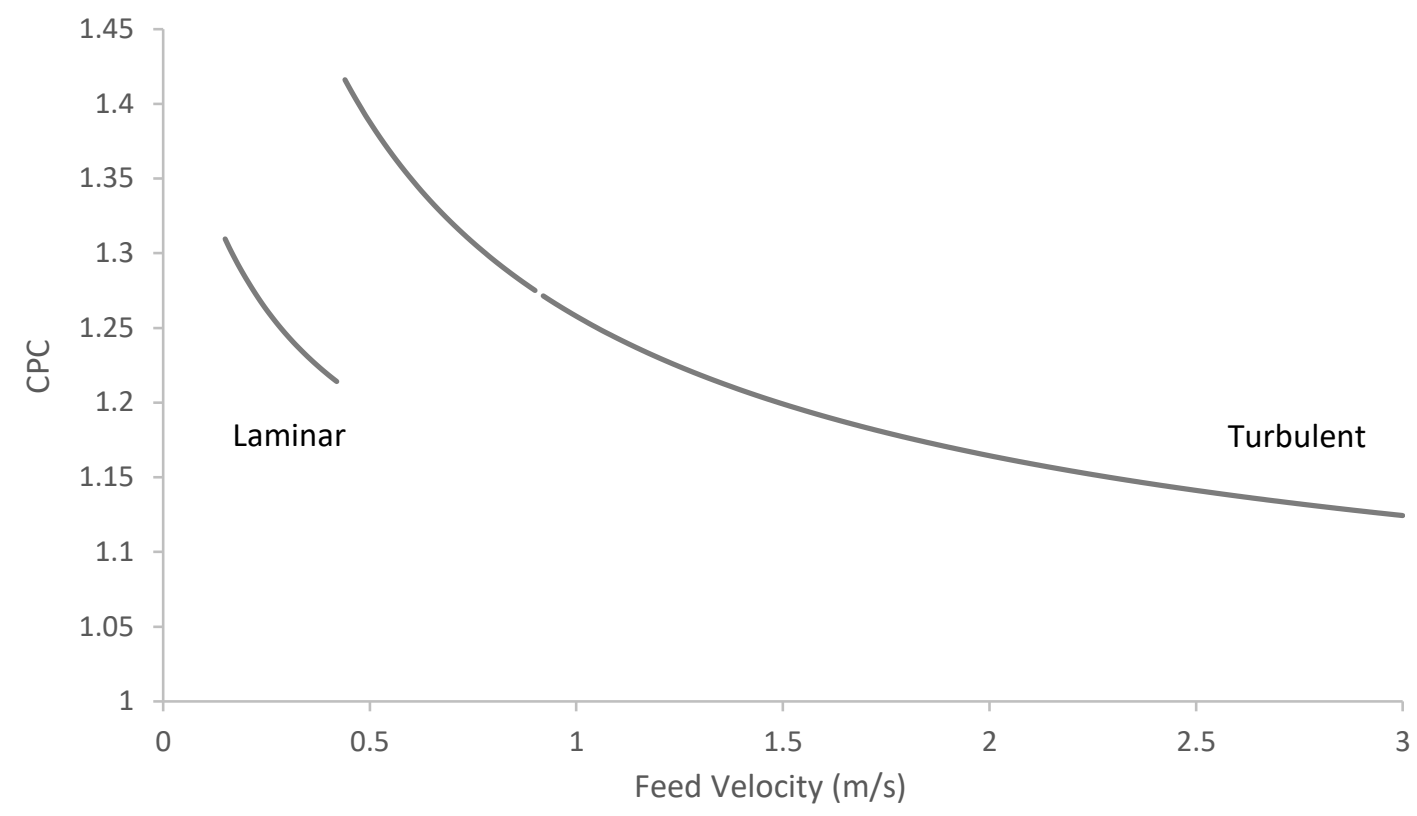

Figure 25: Concentration polarization vs feed velocity. Feed and permeate temperatures are $60^{\circ} \mathrm{C}$ and $20^{\circ} \mathrm{C}$, respectively. All other parameters are from the Cath et al 2003 study (see Section 3.5). The point of discontinuity is the transition of laminar to turbulent flow.

The predicted hydraulic energy consumption decreases as the feed velocity increases (Figure 26). There is a large decrease in hydraulic energy consumption as velocity increases in the laminar regime. As the flow rate increases in the laminar regime, the hydraulic energy consumption decreases at a decreasing rate. This trend is continued in the turbulent regime where increasing velocity gradually decreases hydraulic energy consumption. While friction losses increase with increased velocity, the increase in flux from increased feed velocity reduces the membrane length needed to treat the feed solution. In the laminar and low turbulent regimes, the effect of flux increase is stronger than the effect of increased friction losses. As the rate of flux 
increase decreases, the effect of increased friction losses begins to dominate and gradually increases the hydraulic energy consumption at high velocities.

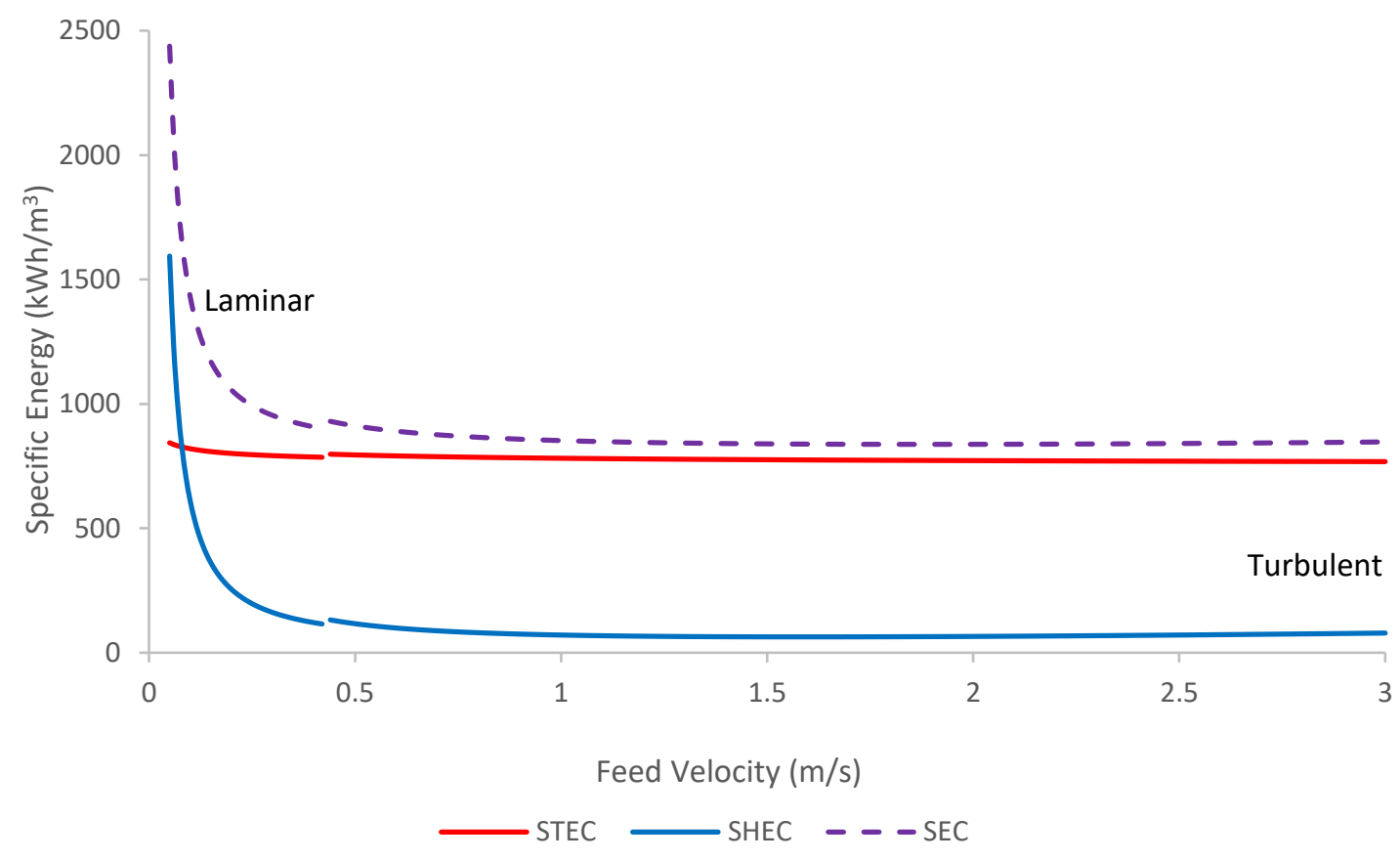

Figure 26: Specific energy vs feed velocity. Feed and permeate temperatures are $60^{\circ} \mathrm{C}$ and $20^{\circ} \mathrm{C}$, respectively. Length is $20 \mathrm{~m}$. All other parameters are from the Cath et al 2003 study (see Section 3.5). The point of discontinuity is the transition of laminar to turbulent flow.

When possible, the feed velocity should be maximized to increase the flux and thermal efficiency while decreasing the temperature polarization. However, the effect of the increase in these performance parameters diminishes at high velocities. The point of optimal hydraulic energy consumption is in the turbulent flow regime, and the corresponding feed velocity can be applied to minimize the energy consumption of the DCMD system. 


\subsubsection{Permeate Velocity}

The permeate velocity, like the feed velocity, directly affects the temperature polarization and concentration polarization, which in turn affect the thermal efficiency and flux. In the laminar flow regime, the predicted flux increases at a decreasing rate (Figure 27). Near the end of the laminar regime, the increase in flux with increased permeate flow is reduced. In the turbulent flow regime, there is a small increase in flux as velocity is increased (Figure 27). Similar to flux in the laminar regime, increased permeate velocity decreases the temperature polarization (Increases TPC) at a decreasing rate (Figure 28). In the turbulent flow regime, the temperature coefficient continues to increase at a decreasing rate.

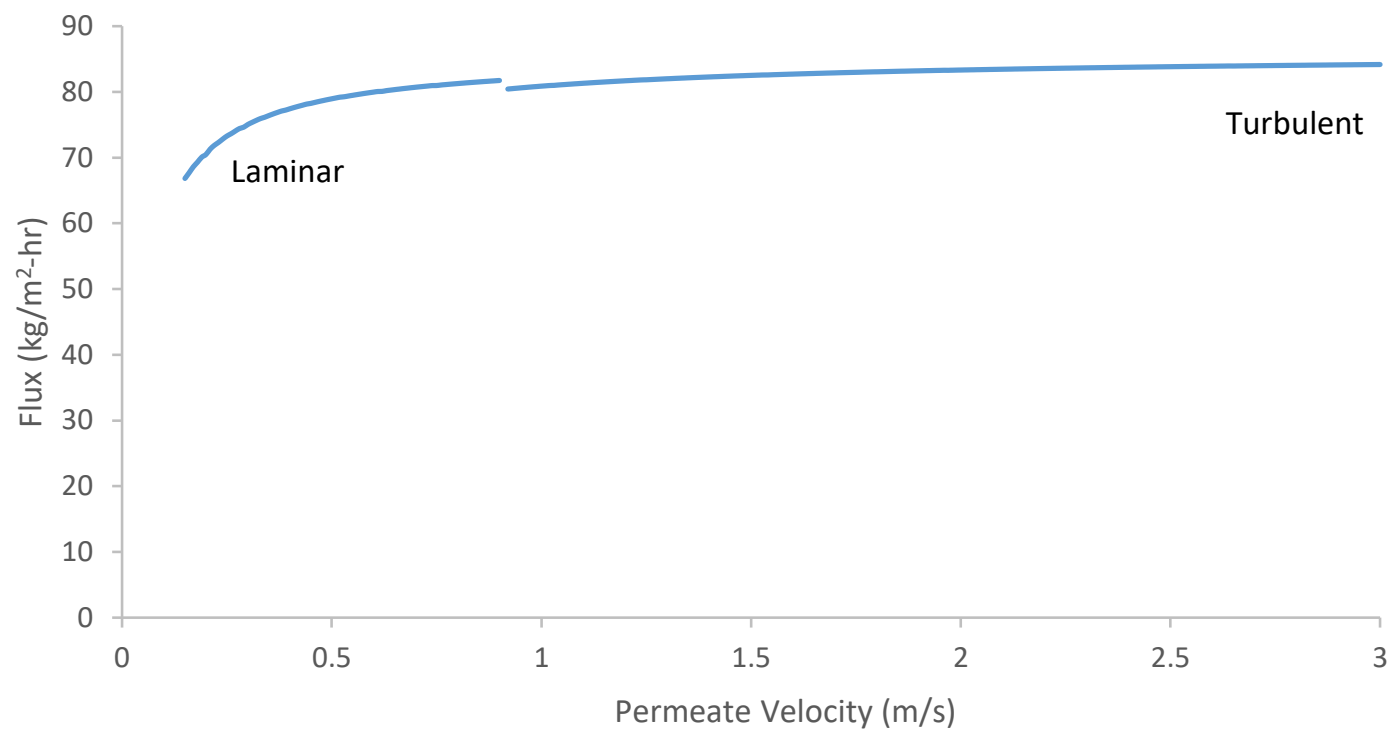

Figure 27: Mass flux vs. permeate velocity. Feed and permeate temperatures are $60^{\circ} \mathrm{C}$ and $20^{\circ} \mathrm{C}$, respectively. All other parameters are from the Cath et al 2003 study (see Section 3.5). The point of discontinuity is the transition of laminar to turbulent flow. 


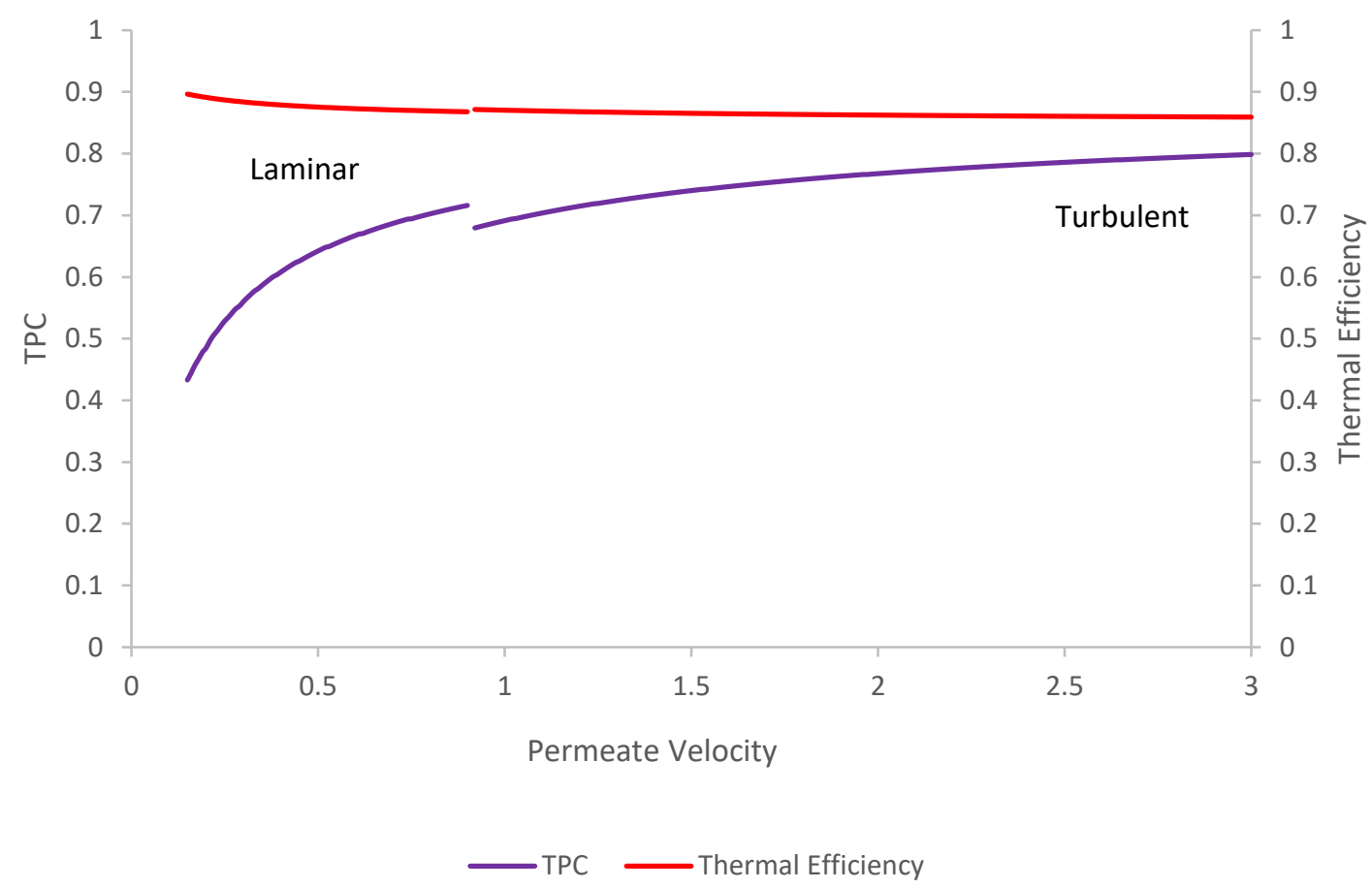

Figure 28: TPC and thermal efficiency vs. permeate velocity. Feed and permeate temperatures are $60^{\circ} \mathrm{C}$ and $20^{\circ} \mathrm{C}$, respectively. All other parameters are from the Cath et al 2003 study (see Section 3.5). The point of discontinuity is the transition of laminar to turbulent flow.

This reduction of TPC and increase in flux is associated with a reduction in the thermal boundary layer creating a larger trans-membrane temperature difference. A larger trans-membrane temperature difference results in larger driving forces for both mass transfer and conductive heat transfer. For the permeate flow, increased velocity increases the conductive heat transfer at a slightly faster rate than the mass transfer heat proportion. This results in a slight decrease in thermal efficiency as permeate velocity increases (Figure 28). In the low ranges of the laminar flow regime, where TPC is low, this decrease of thermal efficiency is slightly greater. 
As permeate velocity increases, the hydraulic energy consumption increases at an increasing rate (Figure 29). In the laminar regime, the increase in hydraulic energy consumption is low as the increase in flux from increased velocity decreases the hydraulic energy consumption. In the turbulent regime, the increase in flux decreases, so the increase in friction losses dominates, and the hydraulic energy consumption increases. As the permeate velocity increases, the gradual decrease in thermal efficiency leads to a gradual increase in STEC.

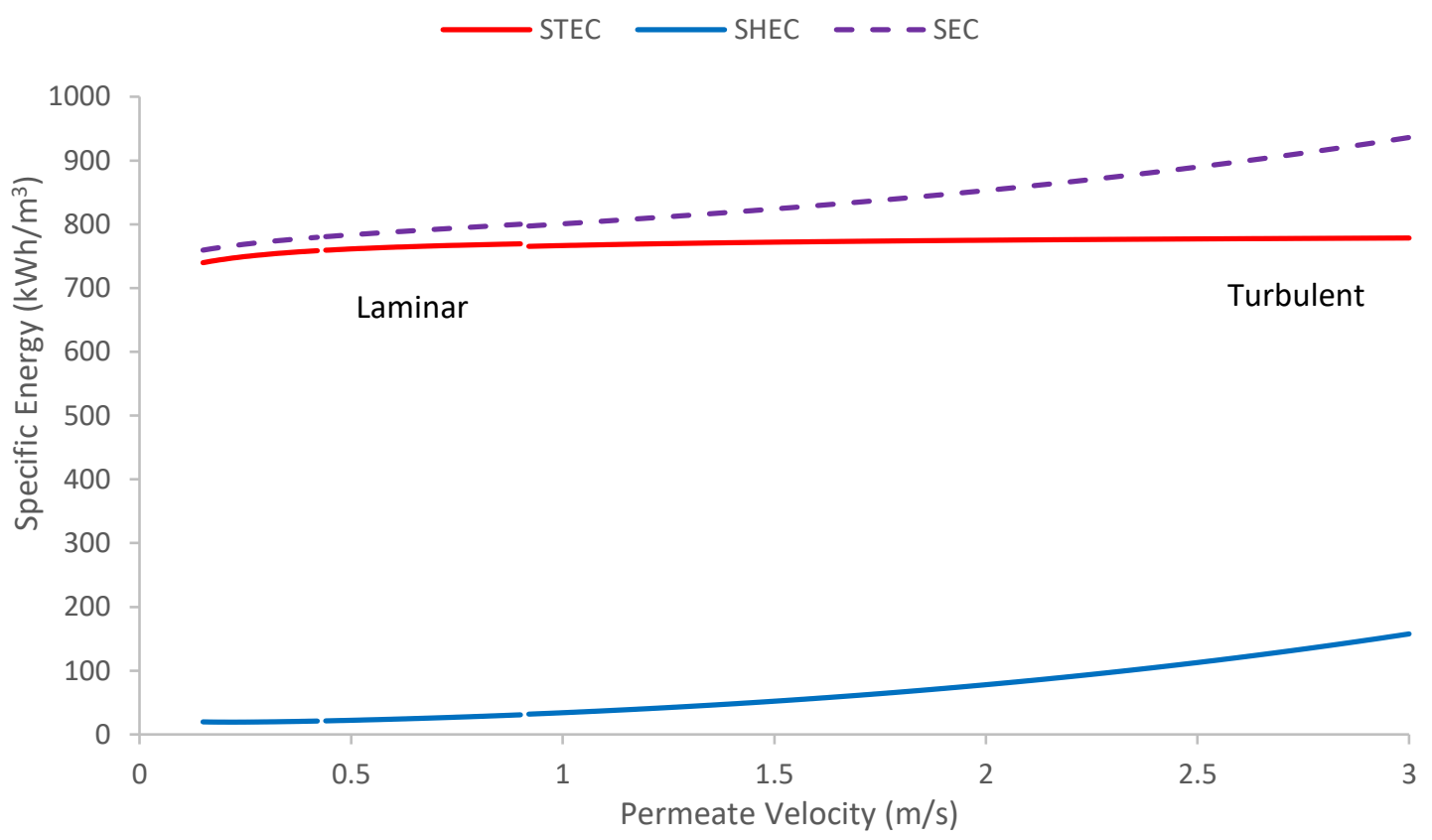

Figure 29: Specific energy vs permeate velocity. Length is $20 \mathrm{~m}$. Feed and permeate temperatures are $60^{\circ} \mathrm{C}$ and $20^{\circ} \mathrm{C}$, respectively. All other parameters are from the Cath et al 2003 study (see Section 3.5). The point of discontinuity is the transition of laminar to turbulent flow.

In general, increases in performance are observed with increased permeate velocity, but the benefits of increased permeate velocity diminish at high velocities. 
Velocities in the upper end of the laminar regime or in the turbulent regime should be used to maximize DCMD performance. Increased permeate velocity increases the hydraulic energy consumption and SEC of DCMD. The benefits of increased permeate velocity decrease at lower velocities than the corresponding feed velocity decreased benefits, so permeate velocity can be lower than feed velocity without significant reduction in performance. Operating the permeate stream at a lower velocity than the feed stream can reduce the hydraulic energy demand of the system without significantly reducing performance.

\subsubsection{Bulk NaCl Concentration}

The concentration of $\mathrm{NaCl}$ in the feed solution affects the feed viscosity and the vapor pressure of water on the feed side. As $\mathrm{NaCl}$ concentration increases, the activity of the water vapor decreases due to increased viscosity. This lower activity coefficient leads to a lower effective water vapor pressure at the feed side of the membrane, and a lower overall driving force for mass transfer. Therefore, as $\mathrm{NaCl}$ concentration increases, flux decreases (Figure 30). This decrease in flux is relatively small, as water at levels nearing seawater (3.5\%) experience a flux reduction of $2 \%$ when compared to pure water. Feed water that is nearing saturation at the membrane surface with $22 \%$ bulk $\mathrm{NaCl}$ experienced a flux reduction of $21 \%$ compared to pure water. This relatively low variation in flux shows the capability of DCMD to treat brine solutions with similar performance to lower salinity feed streams at least up to $22 \% \mathrm{NaCl}$. For the predicted bulk $\mathrm{NaCl}$ concentrations, the variation was from zero to $25 \%$, but concentrations above $22 \%$ resulted in membrane $\mathrm{NaCl}$ concentrations greater than $25 \%$. The model can only 
predict performance for concentrations up to $25 \%$. As bulk $\mathrm{NaCl}$ concentration increases, the predicted concentration polarization decreases (Figure 30).

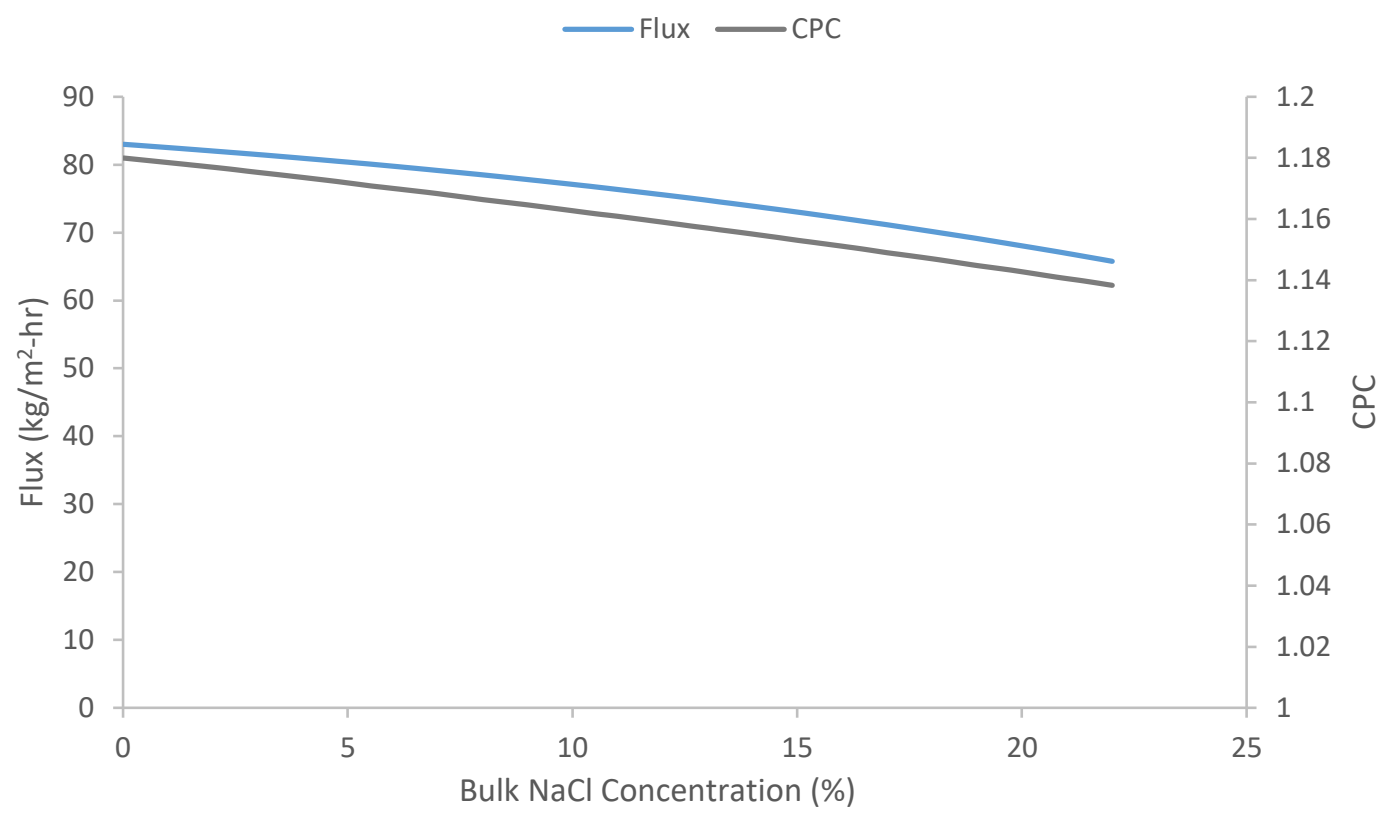

Figure 30: Flux vs bulk $\mathrm{NaCl}$ concentration. Feed and permeate temperatures are $60^{\circ} \mathrm{C}$ and $20^{\circ} \mathrm{C}$, respectively. All other parameters are from the Cath et al 2003 study (see Section 3.5).

The temperature polarization decreases slightly as (increase in TPC) as $\mathrm{NaCl}$ concentration increases (Figure 31). This is due to the reduction of flux reducing the overall heat transferred to the permeate side. Reducing heat transferred to the permeate side lowers the permeate membrane surface temperature. On the feed side, a higher viscosity leads to a larger thermal boundary layer and a larger difference between the bulk and membrane feed temperatures. This feed side increase in 
polarization is slightly outweighed by the decrease in permeate polarization, leading to the gradual decline in temperature polarization.

The predicted thermal efficiency slightly decreases with increased $\mathrm{NaCl}$ concentration (Figure 31). This slight decrease is attributed to a decrease in heat transfer related to vaporization relative to a slightly increasing conductive heat transfer. The low variation in thermal efficiency demonstrates that DCMD can operate at $\mathrm{NaCl}$ concentrations approaching saturation with low variation in thermal energy demand.

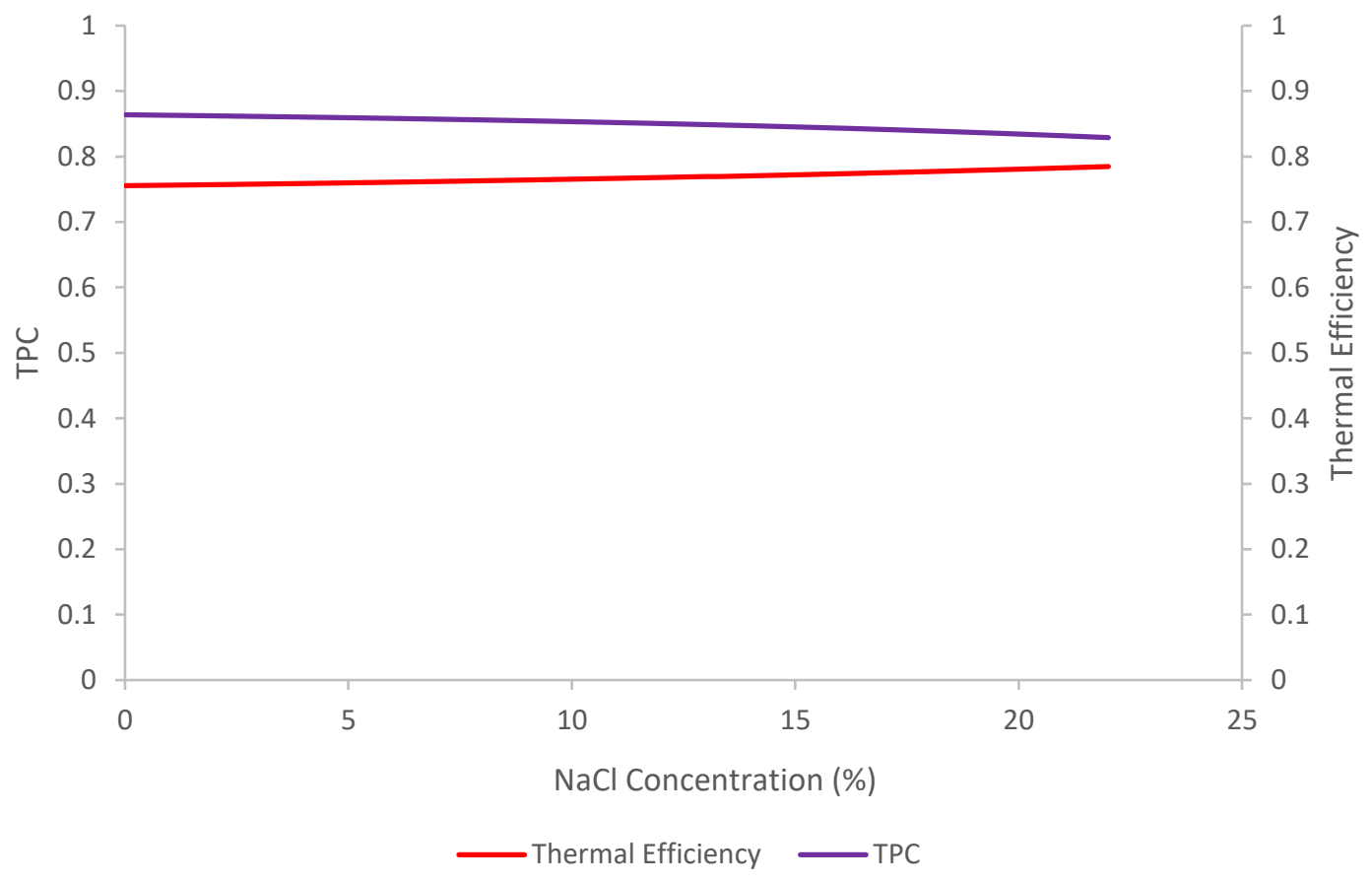

Figure 31: Temperature polarization and thermal efficiency vs $\mathrm{NaCl}$ concentration. Feed and permeate temperatures are $60^{\circ} \mathrm{C}$ and $20^{\circ} \mathrm{C}$, respectively. All other parameters are from the Cath et al 2003 study (see Section 3.5).

These performance criteria demonstrate the potential effectiveness of DCMD to treat even brine solutions with only slightly reduced performance as for lower 
concentration solutions. This consistency in performance can be used to achieve higher recovery than other desalination technologies, such as RO at high salinity or for high salinity feed. The limitation on high $\mathrm{NaCl}$ concentration $\mathrm{DCMD}$ treatment is precipitation of $\mathrm{NaCl}$ on the membrane surface at concentrations that approach the saturation point (see Section 2.1). Since the concentration of $\mathrm{NaCl}$ is greater at the membrane surface due to concentration polarization, precipitation may occur at the membrane when bulk concentrations are below the saturation point. Precipitation of $\mathrm{NaCl}$ on the membrane surface can block pores and reduce membrane hydrophobicity, leading to flux decline and membrane wetting. In an experiment conducted by Yun et al (2006), at concentrations nearing $25 \%$ by weight, precipitation on the membrane greatly reduced flux and decreased permeate quality.

\subsubsection{Pressure}

Within the applied model, the absolute pressure of the DCMD module directly relates to the predicted mass transfer rate. The diffusion coefficient decreases with increased pressure (Bergman et al, 2011), so flux decreases (Figure 32). Since flux decreases, but conductive heat transfer is unaffected, the thermal efficiency decreases as pressure increases (Figure 33). Similarly, with a decrease in flux there is an overall decrease in heat transfer, leading to lower temperature polarization (Higher TPC) (Figure 33). 


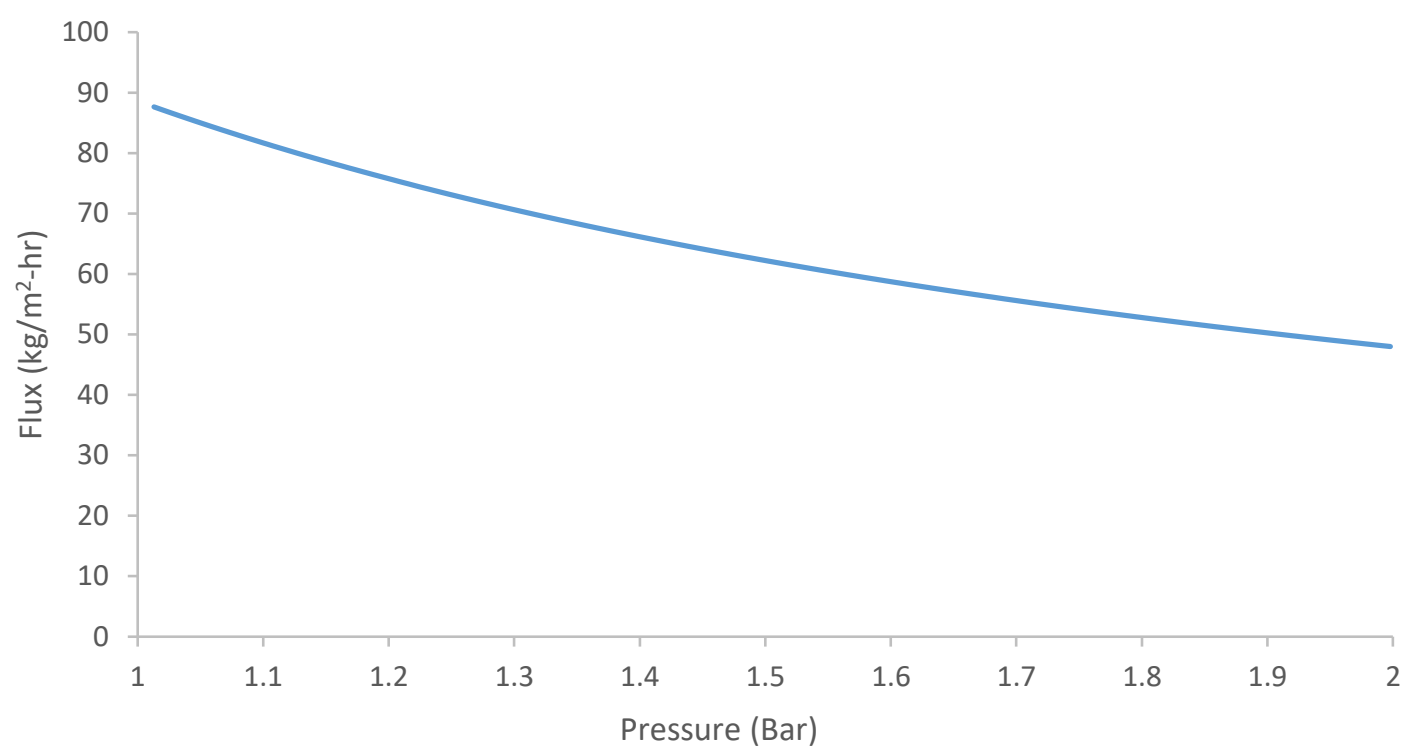

Figure 32: Flux vs pressure. Feed and permeate temperatures are $60^{\circ} \mathrm{C}$ and $20^{\circ} \mathrm{C}$, respectively. All other parameters are from the Cath et al 2003 study (see Section 3.5).

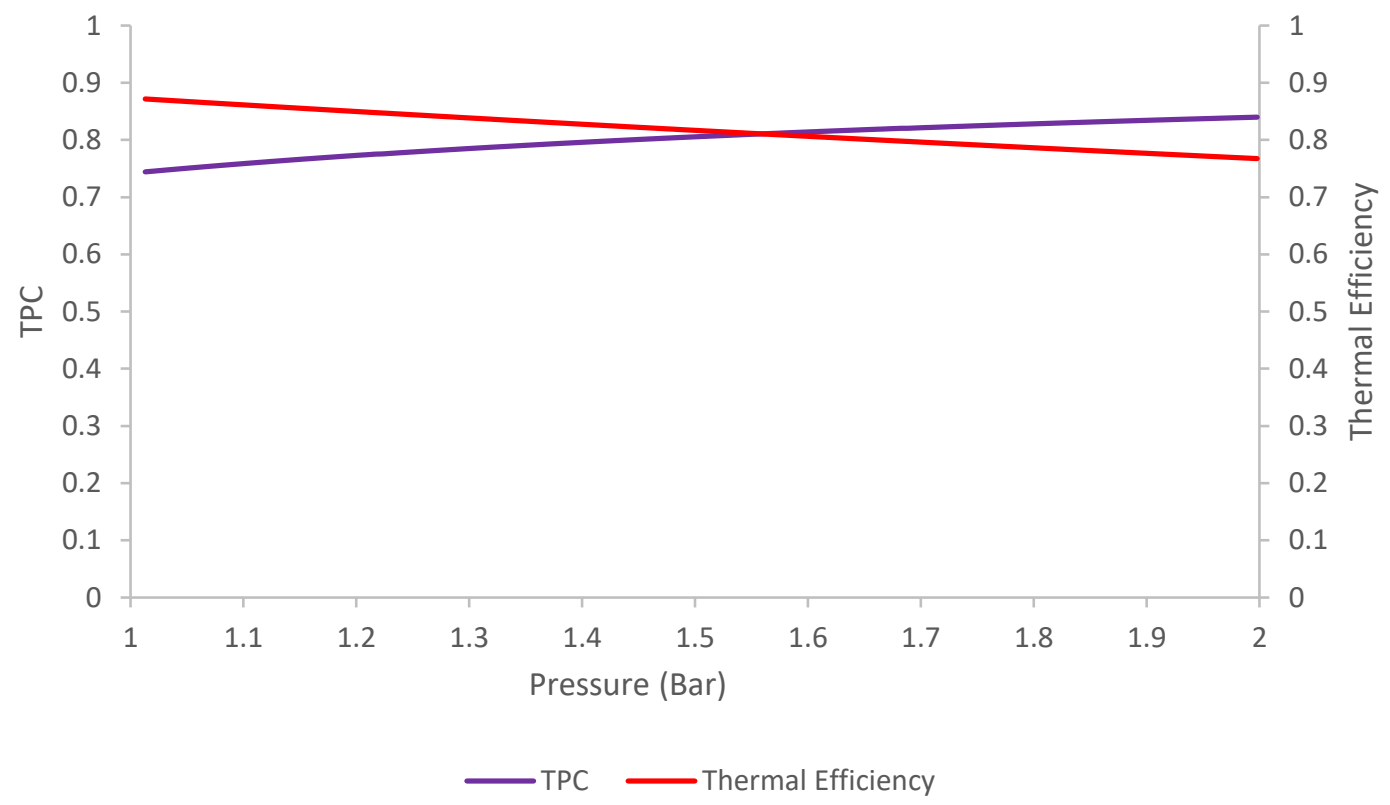

Figure 33: TPC and thermal efficiency vs pressure. Feed and permeate temperatures are $60^{\circ} \mathrm{C}$ and $20^{\circ} \mathrm{C}$, respectively. All other parameters are from the Cath et al 2003 study (see Section 3.5). 
This model does not account for the changes to fluid parameters that may be seen at variable pressures. This model also assumes a constant pressure in the DCMD module, so changes in pressure due to friction losses are not represented. The model also may not accurately represent pressures lower than atmospheric pressure.

In general, reducing the pressure increases the flux and thermal efficiency of a DCMD system. For optimal performance, the pressure of the module should be as low as operationally possible. Practically, the upper limit of module pressure is the liquid entry pressure (LEP). At the LEP, membrane wetting can occur as the hydrophobicity of the membrane is overcome and water can enter the membrane pores. The LEP is related to membrane composition and should be considered when selecting a membrane.

\subsubsection{Hydraulic Diameter}

The hydraulic diameter of the membrane channel directly effects the hydraulic energy consumption and the mixing of the fluid streams. As hydraulic diameter is decreased, the hydraulic energy consumption increases (Figure 34). Decreasing the hydraulic diameter below $1 \mathrm{~mm}$ increases the hydraulic energy consumption but does not result in significant increases to performance (Figure 34). For this reason, the performance criteria of hydraulic diameters less than $1 \mathrm{~mm}$ were not evaluated as the hydraulic energy required is prohibitively high. 


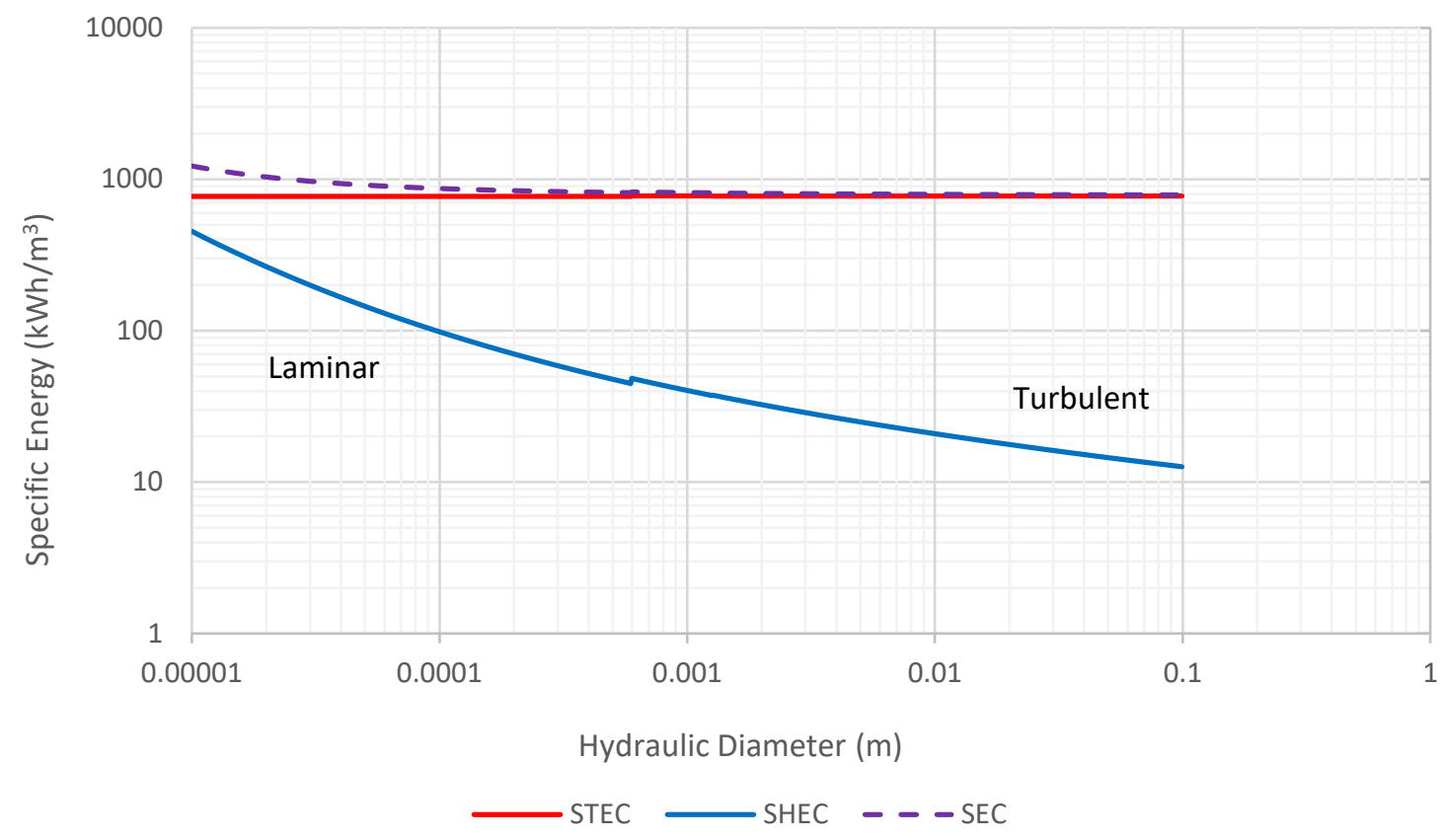

Figure 34: Specific energy vs hydraulic diameter. Feed and permeate temperatures are $60^{\circ} \mathrm{C}$ and $20^{\circ} \mathrm{C}$, respectively. Channel width is maintained at five times the channel height. Length is $20 \mathrm{~m}$. All other parameters are from the Cath et al 2003 study (see Section 3.5). The point of discontinuity is the transition of laminar to turbulent flow.

When utilizing waste heat to drive DCMD, the hydraulic energy demand reflects the largest cost requirement, so it should be minimized. From $1 \mathrm{~mm}$ to $10 \mathrm{~cm}$, the hydraulic energy consumption decreases at a decreasing rate (Figures 35 and 36). Increasing the hydraulic diameter while the velocity of the fluid streams is held constant results in larger thermal and hydraulic boundary layers. The increase in thermal boundary layer thickness increases the temperature polarization and results is a gradual decrease in flux as hydraulic diameter is increased (Figures 35 and 36). For the conditions presented, there is no significant change $(<0.05 \%)$ in the predicted thermal efficiency as hydraulic diameter is increased. With no change in thermal efficiency, there is no change to STEC. 


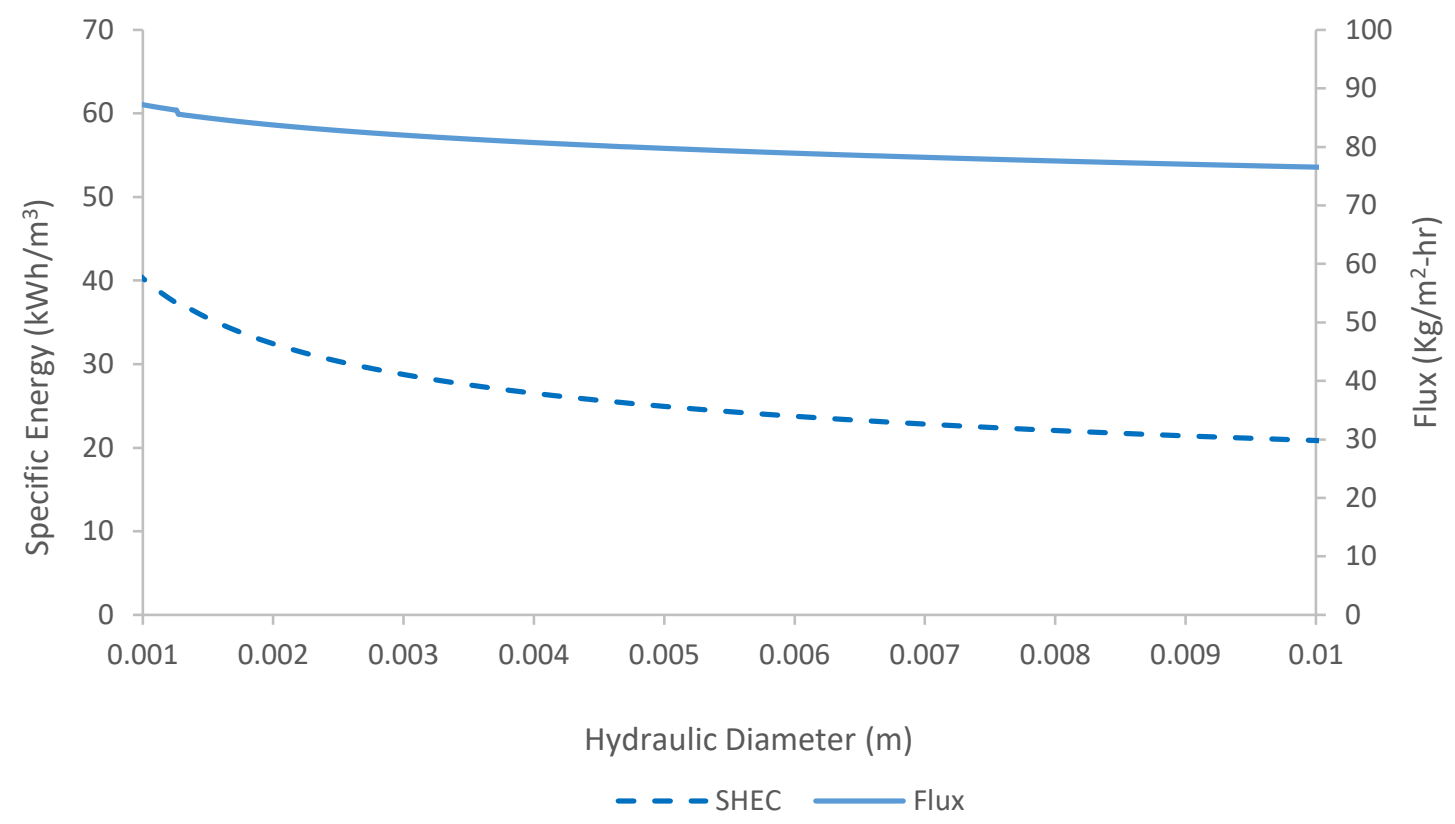

Figure 35: Hydraulic energy consumption and flux vs hydraulic diameter from $1 \mathrm{~mm}$ to $1 \mathrm{~cm}$. Feed and permeate temperatures are $60^{\circ} \mathrm{C}$ and $20^{\circ} \mathrm{C}$, respectively. Length is $20 \mathrm{~m}$. Channel width is maintained at five times the channel height. All other parameters are from the Cath et al 2003 study (see Section 3.5). The point of discontinuity is the transition of laminar to turbulent flow. 


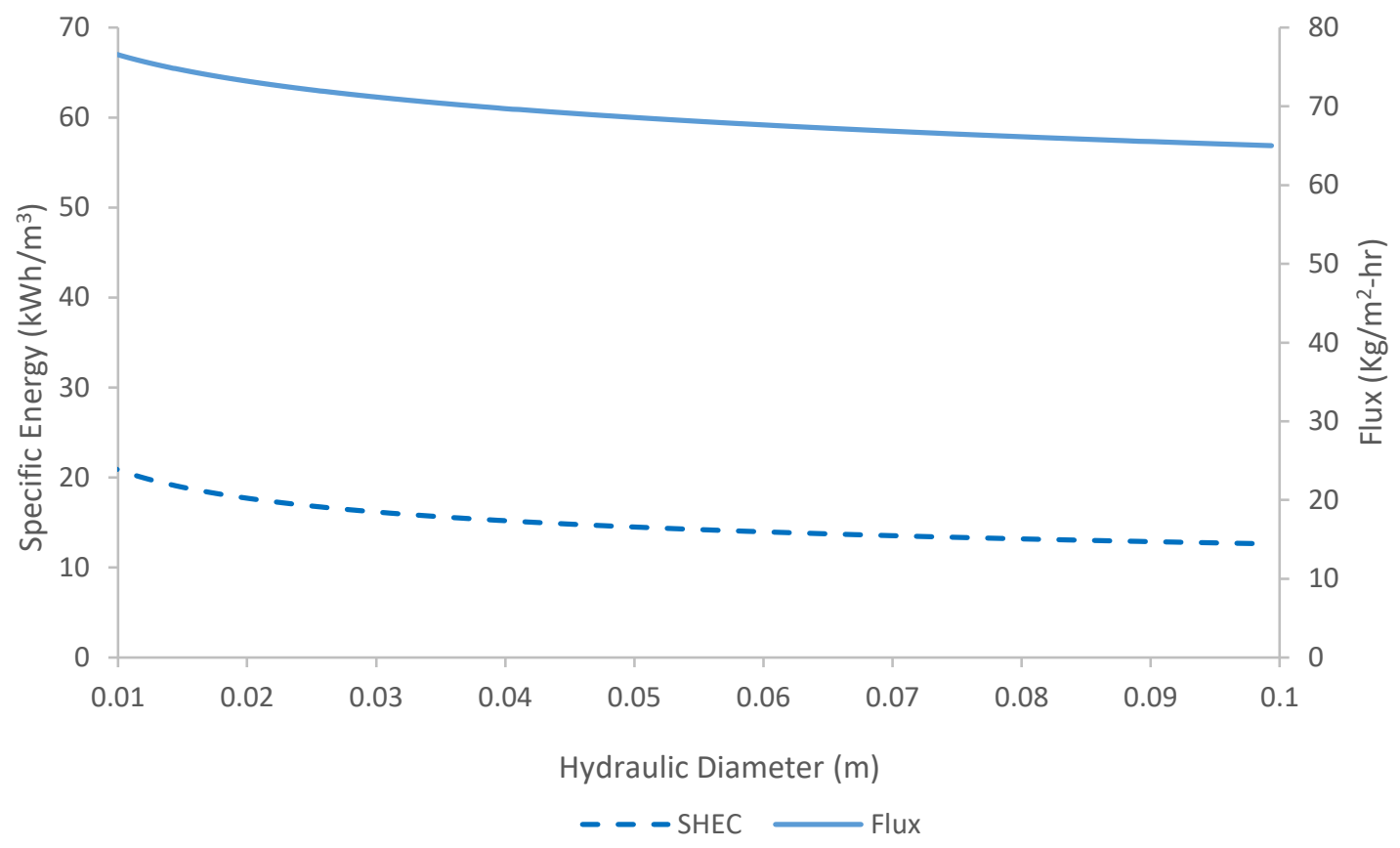

Figure 36: Hydraulic energy consumption and flux vs hydraulic diameter from $1 \mathrm{~cm}$ to $10 \mathrm{~cm}$. Feed and permeate temperatures are $60^{\circ} \mathrm{C}$ and $20^{\circ} \mathrm{C}$, respectively. Length is 20 $\mathrm{m}$. Channel width is maintained at five times the channel height. All other parameters are from the Cath et al 2003 study (see Section 3.5). The point of discontinuity is the transition of laminar to turbulent flow.

As the hydraulic diameter is increased, the convective mass transfer coefficient decreases. This leads to an increased CPC as hydraulic diameter is increased (Figure 37). At high bulk $\mathrm{NaCl}$ concentrations, this increase in CPC may limit the extent of concentration that may be treated. If brine concentrations are being treated, the hydraulic diameter may need to be reduced to expand the treatment potential of the system. 


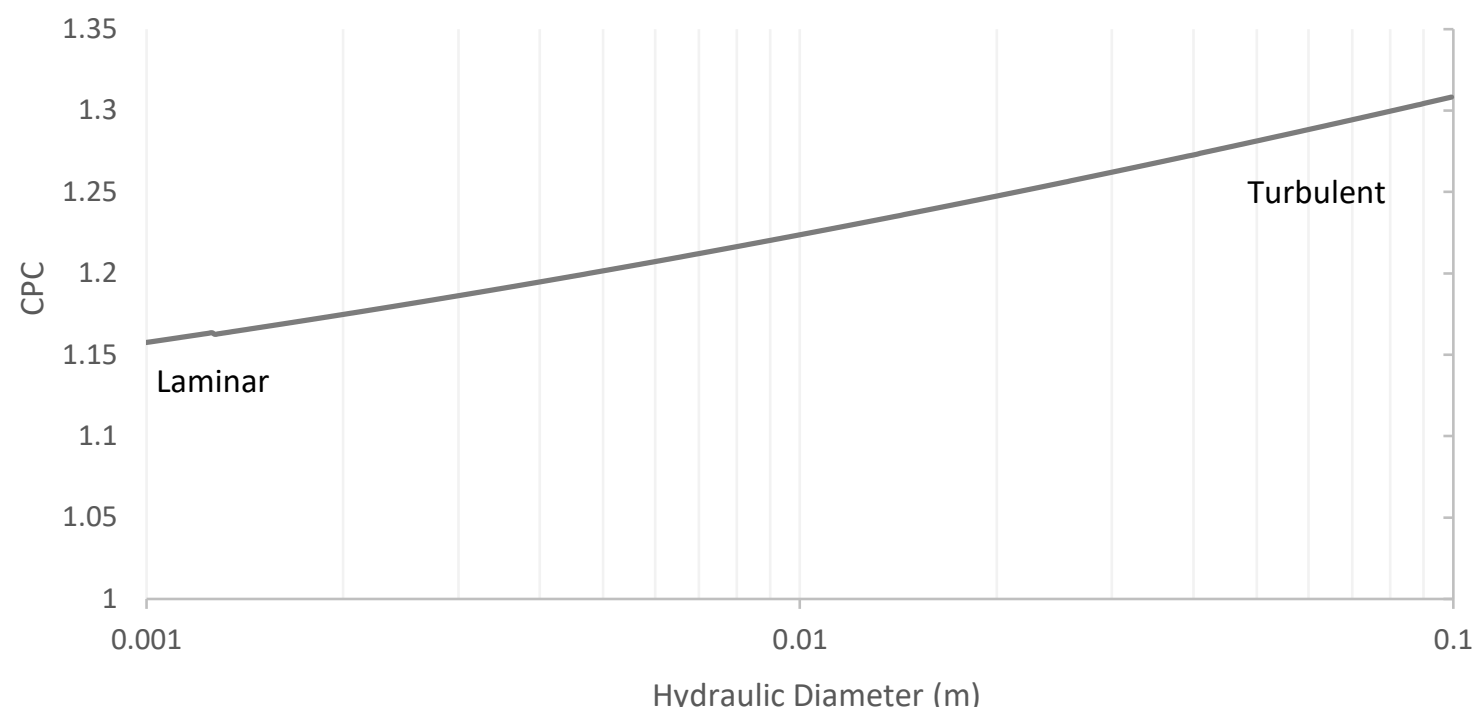

Figure 37: Concentration polarization vs hydraulic diameter from $1 \mathrm{~mm}$ to $10 \mathrm{~cm}$. Feed and permeate temperatures are $60^{\circ} \mathrm{C}$ and $20^{\circ} \mathrm{C}$, respectively. Length is $20 \mathrm{~m}$. Channel width is maintained at five times the channel height. All other parameters are from the Cath et al 2003 study (see Section 3.5). The point of discontinuity is the transition of laminar to turbulent flow.

To minimize of energy consumption, the hydraulic diameter should be increased to lower the electrical energy demands. At high hydraulic diameters, the benefit of increasing the hydraulic diameter is reduced. In reality, the dimensions of the flow channels may affect the membrane area and cost of a DCMD module. Large flow channels may increase the overall size requirement of a DCMD treatment system or limit the packing density of membrane area in DCMD modules.

\subsection{DCMD Desalination Potential Using Sensible Heat}

High temperature produced waters may provide an opportunity for high quality water extraction using waste heat and fluid streams. This potential recovery of sensible heat driven DCMD is thermodynamically limited to recoveries under $10 \%$ in most cases. This is due to the heat of vaporization of water being significantly larger than the 
specific heat available for driving vaporization. For utilization of sensible heat driven DCMD to be favorable for produced water treatment, the total energetic demand must be lower than other alternatives. Reducing STEC is important to reducing energy demand, but as thermal energy is the waste heat that is supplied without charge in sensible heat driven treatment, reducing the SHEC is the most important factor in selecting feasible operational parameters. Reducing energy consumption increases the range of recoveries that this application of the present waste heat may be feasible. The ranges of recovery that were energetically favorable or competitive with treatment alternatives were evaluated for both DCMD alone and for RO-DCMD hybrid systems.

\subsubsection{Selection of Operational Parameters for DCMD Produced Water}

\section{Treatment}

The fluid and membrane parameters for DCMD systems have a strong effect on the operating performance, so selecting operating parameters that optimize performance is necessary for effective utilization of MD. In addition to a wide variety in produced water conditions (see section 2.2), there is a large variation in membrane and operating parameters of DCMD systems. For the purpose of demonstrating the potential of DCMD produced water treatment, a set of parameters were selected with the goal of determining the potential recovery while minimizing energy consumption (Table 2). The selected parameters reflect a reasonable DCMD system for an oilfield treatment site.

However, limitations to the model prevented the selection of some optimal conditions identified from the sensitivity analysis (see Sections 4.1.1-4.1.9). For membrane thickness, the lowest energy consumption parameters could not be selected 
as the model could not converge at the optimal cases. For feed and permeate velocity, the selected parameter was greater than the optimal value to increase the range at which the model could predict performance.

\section{Table 2: Parameters for Produced Water Recovery Analysis}

\begin{tabular}{|c|c|}
\hline Porosity & 0.7 \\
\hline Hydraulic Diameter $(\mathrm{m})$ & 0.03 \\
\hline Pressure (Bar) & 1.2 \\
\hline Feed Velocity $(\mathrm{m} / \mathrm{s})$ & 2.5 \\
\hline Permeate Velocity $(\mathrm{m} / \mathrm{s})$ & 1.5 \\
\hline Membrane Thickness $(\mu \mathrm{m})$ & 400 \\
\hline Permeate Temperature $\left({ }^{\circ} \mathrm{C}\right)$ & 25 \\
\hline NaCl Weight Fraction $(\%)$ & $1,3.5$ \\
\hline
\end{tabular}

As stated in Section 4.1.3, as membrane thickness increases, the flux decreases due to the limitations of the model, the optimal thicknesses can not be evaluated. In addition, low membrane thickness can limit the extent to which the counter-current flow model can be applied. At low membrane thicknesses that result in very large flux predictions from the mass transfer model, the temperatures at which a converging prediction of performance can be predicted are limited. At high temperatures and low membrane thicknesses, the model may not be able to produce a prediction of performance. A larger thickness than optimal was used for the evaluation of typical DCMD parameters. A larger thickness allows the model to demonstrate a wide range of temperatures and counter-current model lengths.

Low pressure is optimal for DCMD systems to maximize the mass transfer (see Section 4.1.8). Increased pressure results in decreased thermal efficiency that lowers 
the ability of a DCMD system to utilize waste heat for treatment. For this reason, a relatively low absolute pressure of 1.2 bar was applied to reflect an operating pressure that could be applied for a DCMD system to maintain high performance.

A hydraulic diameter of $0.03 \mathrm{~m}$ was selected to decrease the hydraulic energy consumption (see Section 4.1.9), while minimizing the reduction of flux due to lower convective heat transfer. Low hydraulic diameters lead to high electrical energy consumption. Increasing hydraulic diameter gradually lowers flux. With the goal of minimizing thermal and electrical energy consumption, the reduction in hydraulic energy consumption at high hydraulic diameters is likely more significant than the reduction in flux. When designing for minimal energy consumption, hydraulic diameters greater than $0.01 \mathrm{~m}$ may provide more optimal conditions than smaller hydraulic diameters.

Increased feed velocity increases the flux and convective heat transfer (see Section 4.1.5). There is an optimal point of feed velocity where hydraulic energy consumption is minimized (see Section 4.1.5). The operational range of the model is improved with increased feed velocity, so the velocity of $2.5 \mathrm{~m} / \mathrm{s}$ was selected to maintain a relatively low hydraulic energy consumption while improving the range of countercurrent temperatures and lengths that can display a converging performance prediction. The selected velocity is larger than the optimal feed velocity that minimizes hydraulic energy consumption, so the hydraulic energy consumption is $31 \%$ greater than at the optimal feed velocity (When $T_{f}=60^{\circ} \mathrm{C}$ and $T_{p}=20^{\circ} \mathrm{C}$ ). This higher hydraulic energy 
consumption is not ideal when minimizing energy consumption, but is selected to show a larger range of temperatures and lengths for the counter-current flow model.

Increased permeate velocity increases flux and hydraulic energy consumption (see Section 4.1.6). In the turbulent regime, the increase in flux with increasing velocity slows and levels off at high permeate velocity. Permeate flow velocity should be minimized when possible, but low velocities can increase temperature polarization and lower the flux. The selected permeate velocity has a hydraulic energy consumption that is $82 \%$ larger than the optimal value for hydraulic energy consumption (When $T_{f}=60^{\circ} \mathrm{C}$ and $T_{p}=20^{\circ} \mathrm{C}$. This higher permeate velocity is not optimal, but increased permeate velocity increases the range of temperatures and lengths that can be used in the counter-current model. Due to the limitation of the model, a greater-than-optimal permeate velocity was selected to reduce energy consumption.

Increased permeate temperature decreases the flux and the hydraulic energy consumption, so the permeate temperature should be minimized when possible (see Section 4.1.2). When minimizing energy consumption, there should be consideration about the method of permeate cooling. When selecting a permeate temperature that is lower than the ambient temperature, mechanical cooling of the permeate stream is needed, which imparts an additional energy demand. A permeate temperature of $25^{\circ} \mathrm{C}$ was selected to maintain high performance while operating at a temperature that would be similar to average ambient temperatures at oilfield sites.

Two salinities were tested: a salinity of $1 \% \mathrm{NaCl}$ and a salinity similar to seawater (3.5\%) were selected for analysis because those values are within the range of highest 
TDS probability for conventional oil and gas produced water (see Section 4.1.7). These salinities can also be compared against the specific energy consumption of RO treatment as an alternative. Saline RO and Seawater RO SEC can be used to evaluate the feasibility of utilizing DCMD treatment driven by produced water sensible heat.

While this set of membrane parameters is useful for demonstrating a possible DCMD produced water system's performance, this scenario may not be best suited for all treatment applications. Limitations to the model resulted in a set of parameters that does not fully optimize energy consumption. For different applications, there may be

different parameters that best suit the needs of the treatment process. Also, optimizing energy consumption may not be the goal for all DCMD system designs. Module costs, fluid composition and thermal conditions, hydraulic energy demands, recovery goals, and heat sources should all be evaluated when selecting the most practical DCMD parameters for a given application. With produced water treatment using sensible heat, the most applicable DCMD parameters changes based on the temperature of the produced water, the recovery goals, and the extent to which DCMD is cost competitive.

\subsubsection{Evaluation of Sensible Heat Driven DCMD Produced Water Treatment}

The ability of DCMD to treat feed solutions at temperatures below the solution's boiling point presents an opportunity to partially treat high temperature produced water using the sensible heat present in that water. Water treated using the sensible heat present in produced water would be treated with no additional thermal input, significantly lowering the overall energy demand of DCMD. 
The selected operational parameters discussed in Section 4.2.1 were used in the counter-current model algorithm (see Section 3.1) at various feed temperatures and membrane lengths. As stated in Section 4.1.1, increasing the feed temperature increases the overall performance of a DCMD system. Increasing the length of a DCMD module increases the temperature difference between the feed inlet and feed outlet. This temperature difference reflects an increase in the sensible heat that is used for treatment. With increased module length, there is also a decrease in the average bulk temperature difference. This lower average bulk temperature difference results in a lower average flux. However, the longer length of the module results in a larger mass of treated water. Increasing the membrane length increases mass of treated water, but peak and average flux decreases. In addition, flux decreases along the length of the membrane as bulk temperatures change (Figure 38). Along the membrane length, as the flux decreases, the rate of mass transfer decreases. 


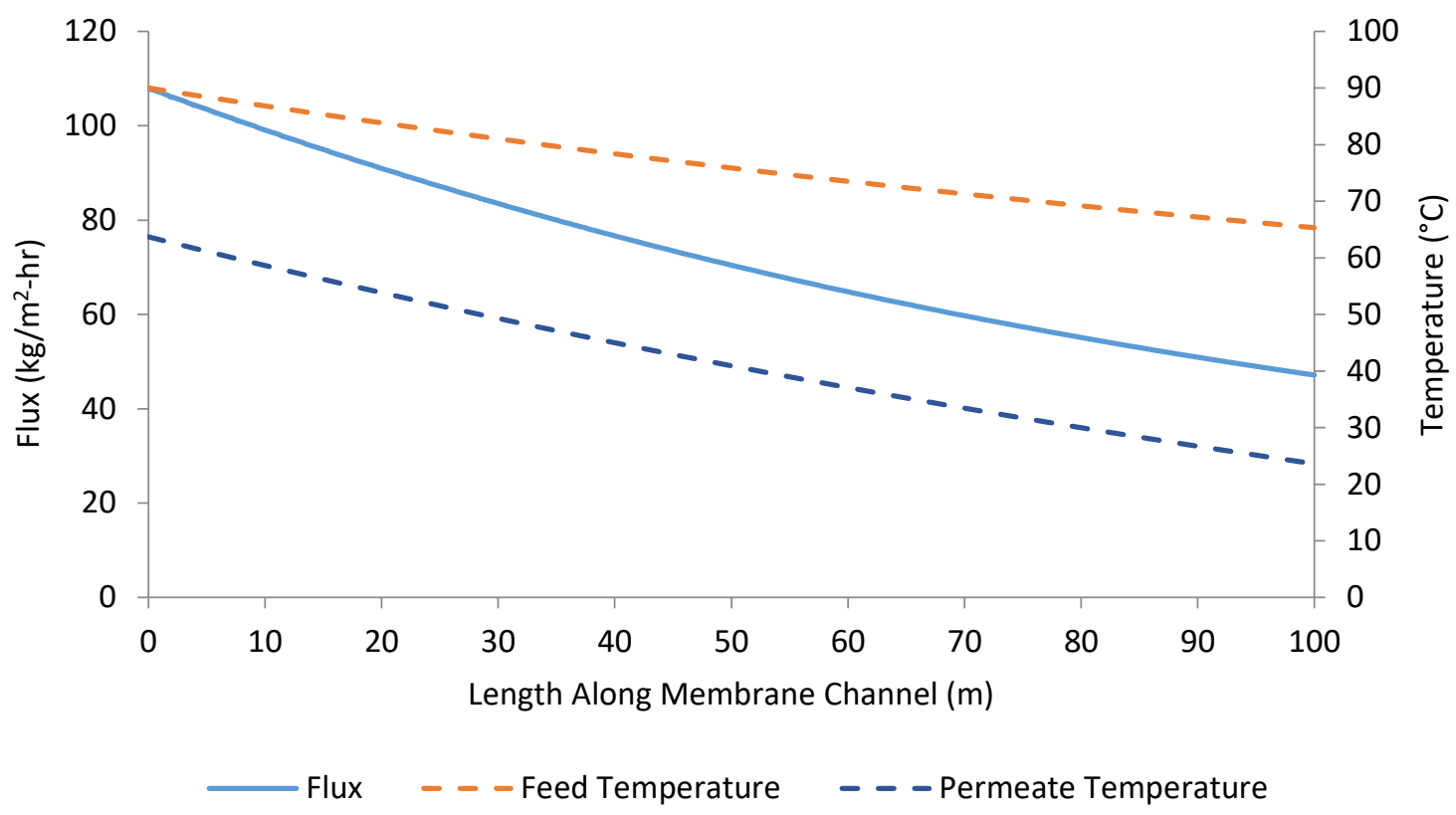

Figure 38: Results of counter-current DCMD algorithm showing bulk temperatures and flux vs the length along the membrane channel. Total module length is $100 \mathrm{~m}$. Feed inlet temperature is $90^{\circ} \mathrm{C}$. Permeate inlet temperature is $25^{\circ} \mathrm{C}$. Bulk Feed salinity is $1 \%$. see section 4.2.1 for other operational parameters.

The range of temperatures evaluated for DCMD sensible heat desalination was the range of produced water temperatures given by Ray \& Engelhardt of $50-94^{\circ} \mathrm{C}(1992)$. The countercurrent model was applied over various module lengths. The extent to which the module length of each temperature series was evaluated depended on the ability of the model to produce a converging prediction of results. At $90^{\circ} \mathrm{C}$ and $94^{\circ} \mathrm{C}$, the lengths that allowed a converging prediction were lower than for other temperatures.

For each application of the counter-current model with a specified feed inlet temperature and length, the model was used to find a recovery percentage of the feed stream. The percent recovery of the counter-current system in this work is derived from 
the temperature difference between the feed outlet and feed inlet and the average STEC of the module (Equation 41).

$$
\text { Recovery }=\frac{\Delta T_{b f} C p_{f, a v e}}{3600 \cdot S T E C_{\text {ave }}} \times 100 \%
$$

where: Recovery $=$ Percent of feed stream treated in DCMD module (\%)

$\Delta T_{b f}=$ Bulk temperature difference of feed inlet and feed outlet (K)

$C p_{f, a v e}=$ Average specific heat of the bulk feed solution $(\mathrm{J} / \mathrm{kg} . \mathrm{K})$

$S T E C_{\text {ave }}=$ Module average specific thermal energy consumption $\left(\mathrm{KWh} / \mathrm{m}^{3}\right)$

Conversion factor $=3600 \mathrm{~J} / \mathrm{kg}$ per $\mathrm{kWh} / \mathrm{m}^{3}$

As membrane length increases, recovery increases, initially at a high rate (Figure 39). As membrane length continues to increase, the additional recovery per additional unit of module length begins to slow down. At higher temperatures, the recovery is larger and the rate of increase with length is larger. The given predictions for high temperatures suggest that they would follow the same pattern and eventually level out at a large membrane length as shown in the lower temperatures as predicted by theory. 


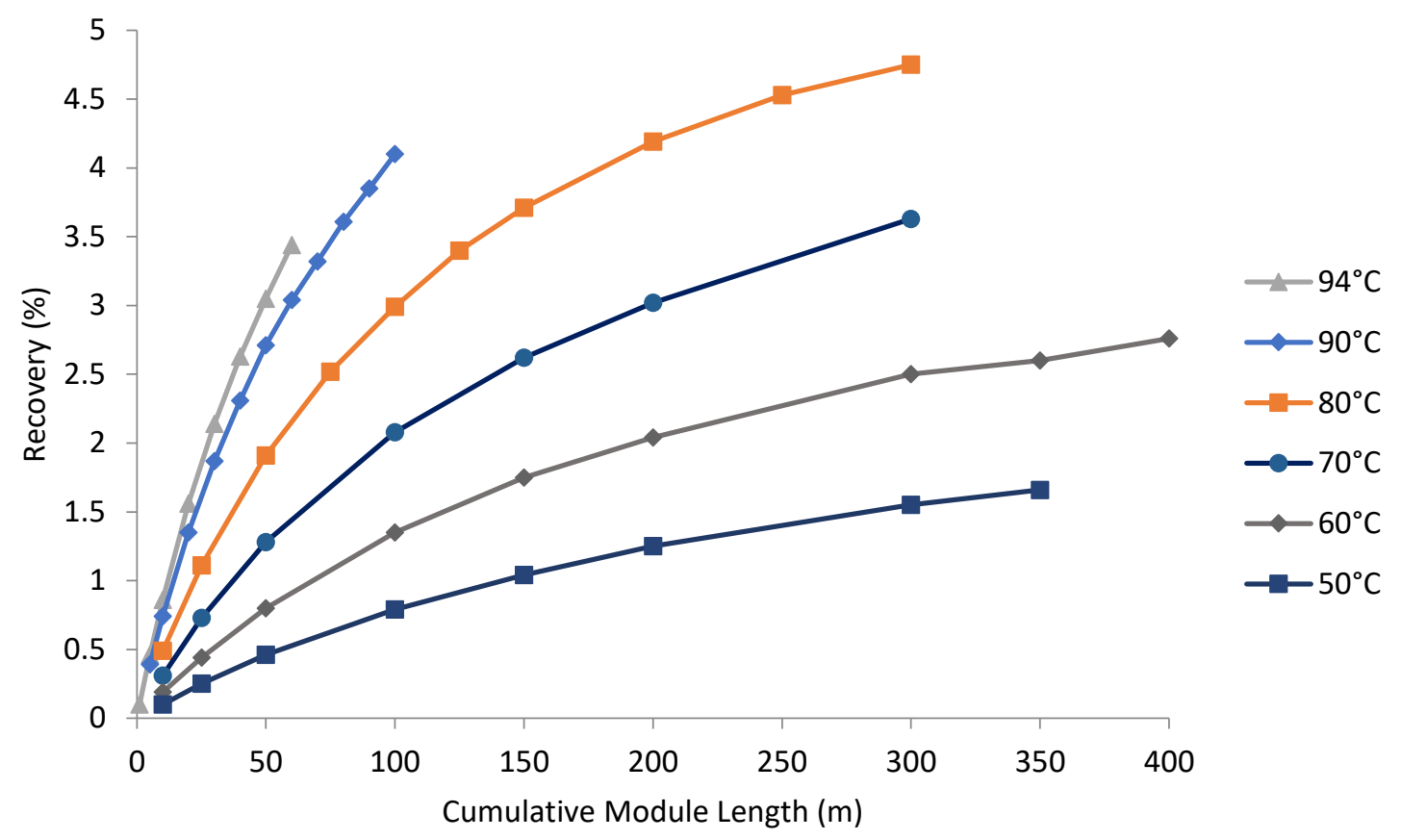

Figure 39: Percent recovery from sensible heat vs counter-current DCMD module length for feed inlet temperatures ranging from $50^{\circ} \mathrm{C}$ to $94^{\circ} \mathrm{C}$. Permeate inlet temperature is $25^{\circ} \mathrm{C}$. Bulk Feed salinity is $1 \%$. see Section 4.2 .1 for other operational parameters used.

As module length increases, the hydraulic energy consumption increases (Figure 40). The rate of increase of hydraulic energy consumption increases as length increases. In the context of waste heat driven DCMD, this means that the amount of high cost energy (for pumping) needed for treatment increases significantly as length increases. As temperature decreases, the hydraulic energy required increases. At high temperatures such as $94^{\circ} \mathrm{C}$ and $90^{\circ} \mathrm{C}$, the hydraulic energy consumption is lower and the rate of hydraulic energy consumption increase is lower (Figure 40). The trend in these predications suggests that if membrane length was increased, the rate of increase would be greater at high lengths similar to the other temperature series. 


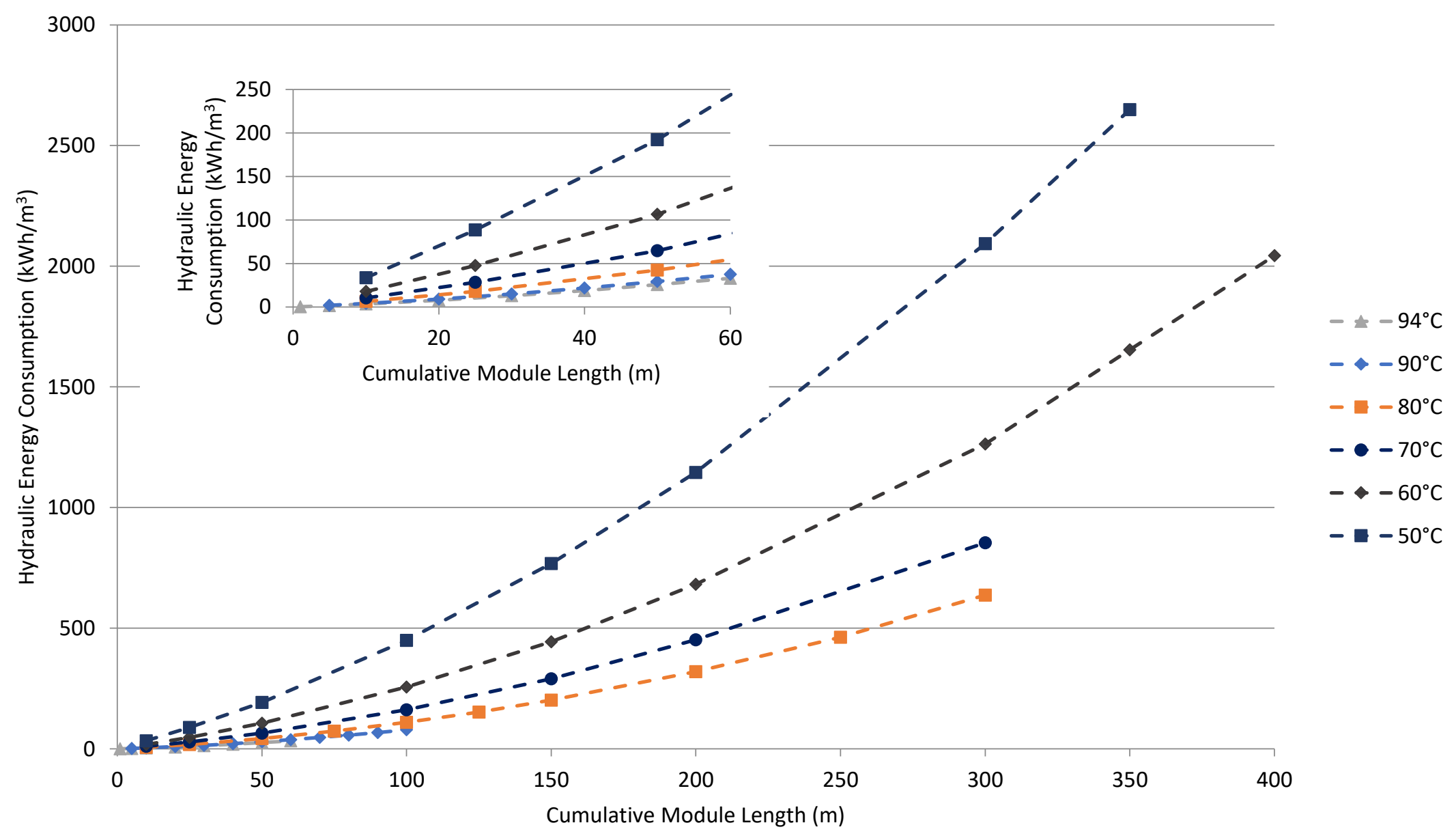

Figure 40: Hydraulic energy consumption vs counter-current DCMD module length for feed inlet temperatures ranging from $50^{\circ} \mathrm{C}$ to $94^{\circ} \mathrm{C}$. Inset chart shows results for lengths from 0-60 m. Permeate inlet temperature is $25^{\circ} \mathrm{C}$. Bulk Feed salinity is $1 \%$. see Section 4.2.1 for other operational parameters used. 
High temperature produced waters provide the greatest potential for DCMD treatment using sensible heat. High temperatures provide the highest recoveries and lowest hydraulic energy consumption (Figure 41). At low module lengths, recovery increases at a high rate and hydraulic energy consumption increases at a low rate.

Because of this, low module lengths are energetically optimal, but have low recovery. As the module length is increased, the incremental energy cost of increasing recovery rises. At very large membrane lengths there is a large increase in energy consumption compared to a low increase in recovery. Depending on the recovery goals, produced water temperature, and cost of energy, the membrane length that is best suited may vary. At long membrane lengths, the hydraulic energy consumption becomes limiting as the energy cost for treating water becomes infeasible.

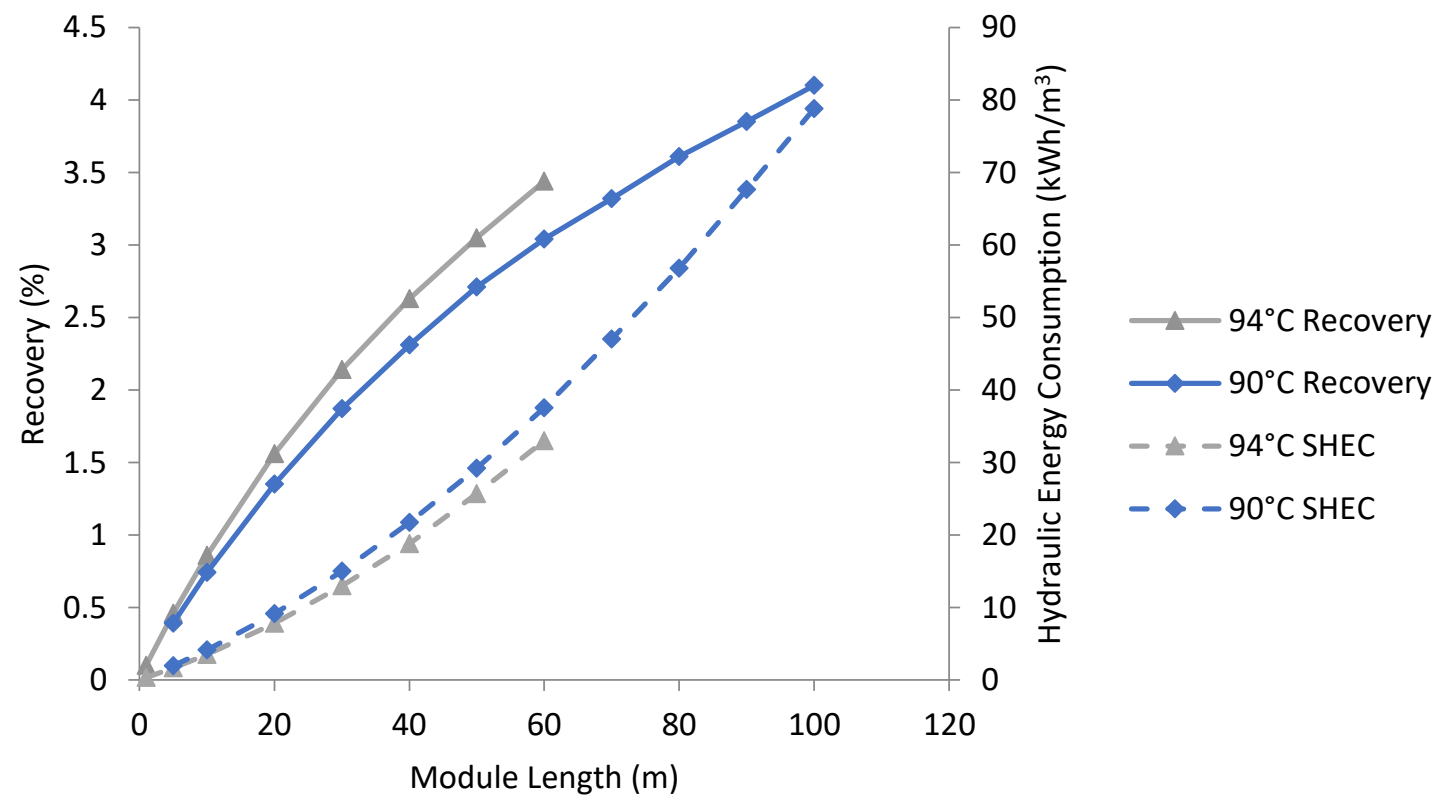

Figure 41: Percent recovery from sensible heat and hydraulic energy consumption vs counter-current DCMD module length for feed inlet temperatures of $90^{\circ} \mathrm{C}$ and $94^{\circ} \mathrm{C}$. Bulk Feed salinity is $1 \%$. Permeate inlet temperature is $25^{\circ} \mathrm{C}$. see Section 4.2 .1 for other operational parameters used. 
The model was applied again at a bulk feed salinity of 3.5\% for a temperature of $94^{\circ} \mathrm{C}$ to demonstrate optimal conditions at a salinity similar to seawater. The recovery was just slightly higher and energy consumption was just slightly lower for the $1 \% \mathrm{NaCl}$ feed than the $3.5 \%$ feed (Figure 42 ).

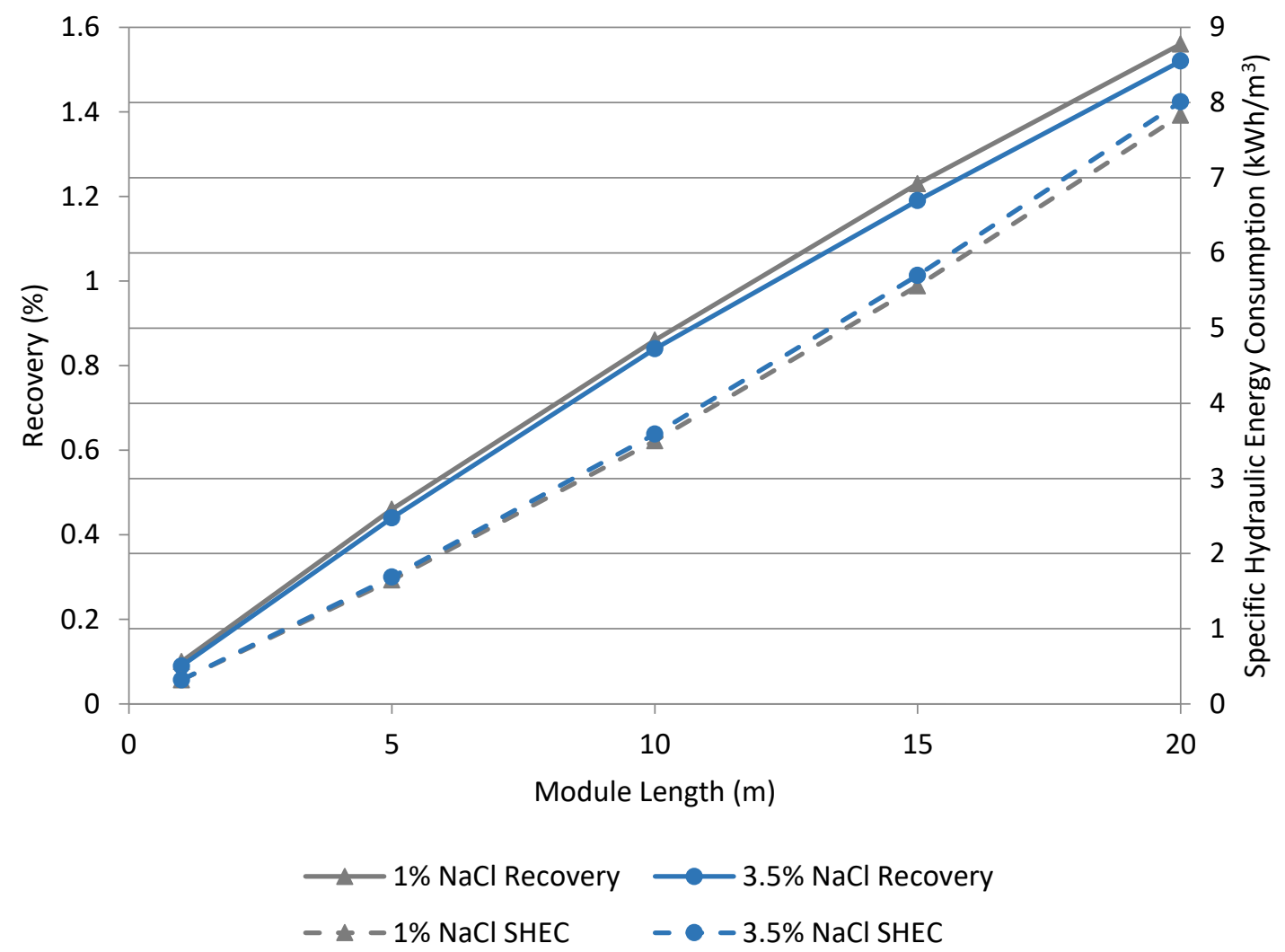

Figure 42: Counter-current simulation of recovery and specific hydraulic energy consumption vs module length for $1 \%$ and $3.5 \%$ by weight $\mathrm{NaCl}$ feeds. Bulk feed inlet temperature is $94^{\circ} \mathrm{C}$. Permeate inlet temperature is $25^{\circ} \mathrm{C}$. see Section 4.2 .1 for other operational parameters used.

To compare the energy requirement of sensible heat driven DCMD that of RO, the hydraulic energy consumption was compared with a range electrical energy consumption requirements for $\mathrm{RO}$ at similar dissolved solids concentrations. For the $1 \%$ and $3.5 \%$ solutions, the electrical energy consumption of RO is $2-3 \mathrm{kWh} / \mathrm{m}^{3}$ and $3-4$ 
$\mathrm{kWh} / \mathrm{m}^{3}$ (IAEA, 2013). These values are based on RO simulation results for TDS of 10,000 $\mathrm{mg} / \mathrm{L}$ and 35,000 mg/L, respectively (IAEA, 2013). The conditions for which the countercurrent model simulation predicted lower energy consumption compared to RO result in very low predicted recovery (Figure 42). The highest recoveries corresponding to energy consumption less than these ranges for $\mathrm{RO}$ are $0.5 \%$ for $1 \% \mathrm{NaCl}$ and $0.75 \%$ for $3.5 \%$ $\mathrm{NaCl}$. When hydraulic energy consumption is greater than comparable RO energy consumption, DCMD treatment is not a competitive treatment method.

For these operational parameters, sensible heat driven DCMD treatment of produced water has a limited range of feasibility. This limited feasibility demonstrates that in most cases, utilizing this waste heat source to drive DCMD treatment is not energetically advantageous when compared with treatment using other desalination technologies. Under the conditions considered, there is little to no feasibility for energetically favorable sensible heat utilization for DCMD. Under these operational conditions, the highest recovery that is energetically favorable are $0.5 \%$ and $0.75 \%$ for $1 \% \mathrm{NaCl}$ and $3.5 \% \mathrm{NaCl}$, respectively.

The larger energetically favorable recovery at $3.5 \% \mathrm{NaCl}$ suggests that the increase in RO energy demand is greater than the increase in DCMD hydraulic energy demand as $\mathrm{NaCl}$ concentration increases. As salinity increases, the percentage of recovery that is favorable increases. This has a limit though; bulk $\mathrm{NaCl}$ concentrations that experience precipitation at the membrane surface would limit the maximum salinity (maximum bulk salinity varies with CPC). With increased salinity and a fixed module temperature and length, the recovery slightly decreases (Figure 43). With 
increased salinity, the hydraulic energy consumption slightly decreases. This demonstrates that even at high salinities, the effectiveness of DCMD to treat produced water using sensible heat does not significantly diminish. At $15 \% \mathrm{NaCl}$, where the concentration at the membrane approaches saturation for these parameters, the percent recovery was decreased by $23 \%$ and the SHEC was increased by $19 \%$ compared to a $1 \% \mathrm{NaCl}$ bulk concentration.

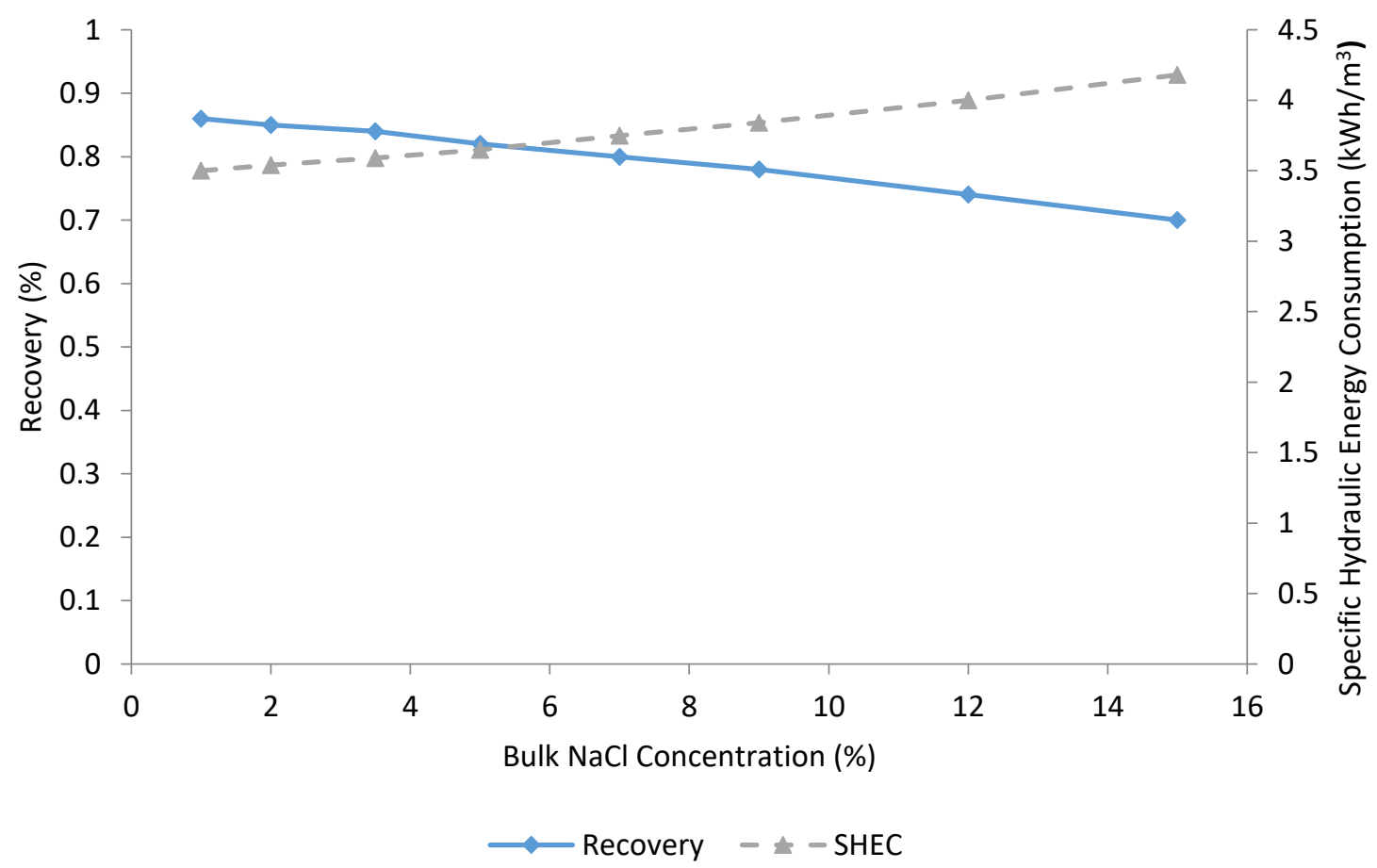

Figure 43: Counter-current simulation of recovery and specific hydraulic energy consumption vs bulk $\mathrm{NaCl}$ concentration. Bulk feed inlet temperature is $94^{\circ} \mathrm{C}$. Module length is $10 \mathrm{~m}$. Permeate inlet temperature is $25^{\circ} \mathrm{C}$. see Section 4.2.1 for other operational parameters used. 
As bulk $\mathrm{NaCl}$ concentration increases, the feasibility of using sensible heat to drive DCMD treatment is expected to increase, and the maximum feasible recovery is expected to increase.

The overall feasibility of sensible heat driven DCMD treatment is limited to very low percent recoveries. However, the model applied for performance simulation can not predict optimal conditions for SHEC minimization. Both the selected feed and permeate velocities selected result in higher SHEC than the optimal conditions. A membrane thickness was selected that results in lower flux and higher STEC than the optimal thickness. These parameters were selected as their performance could be predicted at a wide range, while the extent of the model to predict the optimal conditions was limited.

At the optimal conditions that could not be predicted by the model, the favorable recovery is expected to be larger due to reduced SHEC. The recovery possible by sensible heat is low at optimal conditions due to the large amount of heat necessary to vaporize water compared to the relatively small amount of heat available with sensible heat. For example, a counter-current application with a fed inlet temperature of $94^{\circ} \mathrm{C}$ and a feed temperature difference of $35^{\circ} \mathrm{C}$ has a thermodynamic limit of approximately $6 \%$ recovery. If high recoveries are required, sensible heat driven DCMD treatment alone is not sufficient. Due to the model limitations, a definitive conclusion on the full extent of the feasibility of sensible heat driven DCMD to treat produced water can not be made in this work. However, the premise of sensible heat driven DCMD produced water treatment is that two waste streams (produced water and the heat therein) are utilized to produce a high quality treated water. Any recovery that can 
be achieved from the process is a benefit if it is energetically advantageous to other treatment technologies.

\subsubsection{Hybrid RO-DCMD Produced Water Treatment Using Sensible Heat}

Hybrid treatment systems that include RO treatment followed by DCMD

treatment of the RO retentate can provide advantages if high overall recovery and low brine waste volumes are desired. At high salinities, the ability of RO to desalinate diminishes. Recovery of produced water in excess of RO recovery can be achieved by further treating the rejected permeate stream with DCMD (see Section 2.1.9). In the context of produced water sensible heat driven DCMD in a hybrid system, the produced water stream needs to be cooled for pretreatment and RO desalination. The heat can be exchanged back to the feed solution for DCMD treatment. Similar, but slightly decreased overall recovery is expected for RO retentate as it is at a much higher salinity than the brackish water evaluated in Section 4.2.2. Additional recovery beyond the typical operating range of RO using $\mathrm{RO}$ is energetically intensive. The relatively low change in DCMD energy consumption with salinity makes its application most feasible for treating high salinity solutions.

For an evaluation of produced water sensible heat treatment, the same selected operational parameters (see Section 4.2.1) were applied. The only difference in the application of the counter-current DCMD algorithm was the selected bulk feed $\mathrm{NaCl}$ concentration. A bulk NaCl concentration of $6 \%$ was selected as this represents a reasonable limit of RO desalination preceding DCMD treatment. In a 2013 simulation of the sensitivity of two RO membranes with max pressures of 69 bar and 85 bar, sharp 
increases in electrical energy required were seen at 55,000 mg/L and 65,000 mg/L, respectively (IAEA, 2013). For this reason, a bulk feed $\mathrm{NaCl}$ concentration was selected to reflect the range at which energy consumption of RO significantly increases. This increase in energy consumption limits the pressure at which an RO unit can operate. In this range of $\mathrm{NaCl}$ concentration, it is difficult to quantify the range of energy consumption for reverse osmosis.

At these high concentrations, multi-stage flash distillation (MSF) and multiple effect distillation (MED) would be the most common energetically competitive treatment technologies. The ranges of electrical equivalent energy consumption are 21$59 \mathrm{kWh} / \mathrm{m}^{3}$ for MSF and 15-57 kWh/m $\mathrm{m}^{3}$ for MED (Stillwell and Webber, 2016). For DCMD operation at $6 \% \mathrm{NaCl}$, the lengths that have a SHEC below $15 \mathrm{kWh} / \mathrm{m}^{3}$ can be considered favorable for DCMD treatment, and SHEC between $15 \mathrm{kWh} / \mathrm{m}^{3}$ and $59 \mathrm{kWh} / \mathrm{m}^{3}$ can be considered competitive for DCMD treatment. The largest recovery that can be considered energetically favorable (SHEC $<15 \mathrm{kWh} / \mathrm{m}^{3}$ ) was $2.2 \%$, corresponding to a module length of approximately $25 \mathrm{~m}$. The largest value for which a prediction could be made was for a module length of $85 \mathrm{~m}$, which had a SHEC of $57 \mathrm{kWh} / \mathrm{m}^{3}$. The corresponding recovery for this point is $4.0 \%$, which can be considered the approximate upper limit of DCMD competitiveness for these conditions. 


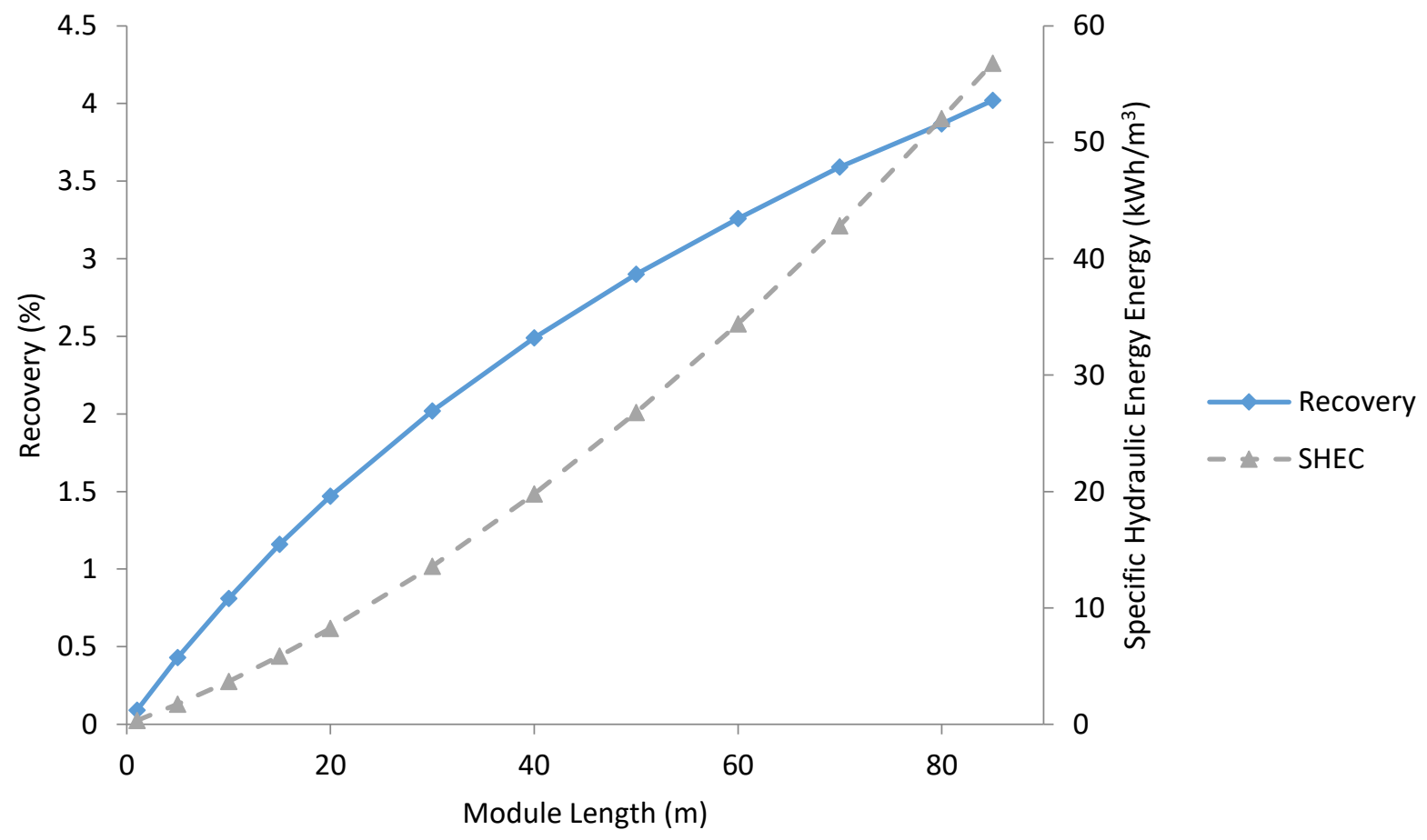

Figure 44: Counter-current simulation of recovery and specific hydraulic energy consumption vs module length for $6 \%$ by weight $\mathrm{NaCl}$ feed. Bulk feed inlet temperature is $94^{\circ} \mathrm{C}$. Permeate inlet temperature is $25^{\circ} \mathrm{C}$. see Section 4.2 .1 for other operational parameters used.

These simulation results suggest that there is an increased range of recovery in which sensible heat driven DCMD treatment of produced water is favorable or competitive at bulk $\mathrm{NaCl}$ concentrations that exceed the typical operational range of $\mathrm{RO}$ desalination. If recovery in excess of RO capabilities is desired for high temperature produced water streams, DCMD may be favorable for some additional recovery. However, the recovery extent of DCMD using sensible heat is limited to low percentages. Utilization of the sensible heat is more feasible in a hybrid RO-DCMD system, but the overall extent to which it is practical to apply sensible heat driven DCMD is still limited. 
As with the simulation results in Section 4.1.2, these simulated recoveries and their applicability to real-world scenarios are limited by the ability of the model to predict performance for ideal operational parameters. Feed velocity and permeate velocities that increase the energy consumption past the optimal conditions for minimizing SHEC were applied, so the SHEC for optimal conditions would be expected to be lower. With a lower SHEC, the membrane length and corresponding recovery that is favorable or competitive would be higher. Due to model limitations, the membrane thickness was larger than the optimal value, resulting in lower flux and lower SHEC. With a more optimal membrane thickness, lower SHEC and a higher rate of increase in recovery is expected. At the optimal conditions, the recovery extent and overall feasibility of hybrid RO-DCMD treatment using sensible heat to drive DCMD is expected to increase, but limitations in the model are unable to provide a prediction of these optimal conditions. Due to these limitations in the applied model, a definitive conclusion can not be made on the extent of hybrid RO-DCMD feasibility using sensible heat. However, any range of recoveries where sensible heat driven DCMD is favorable for desalination represents lower cost treatment of a waste stream of produced water that is driven using another waste stream. Utilizing these waste streams can provide some energetically favorable treatment of saline produced water to high quality permeate that may be beneficial to certain applications. 


\section{Chapter 5}

\section{SUMMARY AND CONCLUSIONS}

A model for predicting DCMD performance was created using algorithms for instantaneous performance prediction and counter-current DCMD module performance prediction. Equations for heat transfer, mass transfer, concentration polarization, and counter-current flow were applied in the model. The mass transfer model was calibrated against the results of an experimental data set. The calibration and validation demonstrated reasonable performance predictions and highlighted some limitations to the current model.

The model was applied to conduct a sensitivity analysis of DCMD parameters on performance and to evaluate the feasibility of sensible heat driven DCMD produced water treatment. The instantaneous algorithm was applied to conduct a sensitivity analysis of nine DCMD operational parameters (see Section 5.2). The counter-current algorithm was applied to evaluate sensible heat driven produced water treatment using DCMD alone and using an RO-DCMD hybrid system (see Section 5.3). For both evaluations, the extent of performance prediction was not complete due to limitations in the model. Limitations to the extent of model predictions and the ability of the model to accurately reflect DCMD performance should be considered when evaluating the results from this work.

All performance predictions in this work were created using the calibrated algorithms and were iteratively convergent. All values reported had fluxes, feed membrane temperatures, and permeate membrane temperatures that converged to 
values with less than a $0.1 \%$ variation between iterations. The predictions made represent converging results of the algorithm that demonstrate trends that are reasonable when compared to the theory of DCMD operation, but the predictions may not fully represent all aspects that affect DCMD performance. The conclusions made represent the current extent to which the model can predict DCMD performance.

\subsection{Limitations of Applied Model and Assumptions}

Assumptions in both the equation-based models and the algorithms limit the extent to which the performance predictions made are applicable (see Chapter 3 for model assumptions). Not implementing a convective heat transfer correlation and Sherwood correlation for the transition flow region resulted in a discontinuity of performance parameters at the transition point from laminar to turbulent. The prediction for mass transfer was based on molecular diffusion through a stagnant film. This simplified approximation of mass transfer does not reflect the role that membrane porosity, pore size, and tortuosity have in affecting mass transfer. Because these factors are not accurately portrayed, the diffusion was calibrated against experimental data. This calibration resulted in strong correlations between the experimental data and the prediction for flux vs bulk feed temperature. The predicted flux with varying feed velocity showed a trend that had some similarity to the experimental data. The discrepancies in the trends of the predicted and experimental flux suggest that variations in performance caused by pore size may not be fully accounted for in this model. This demonstrates that the extent of this calibration is limited, and some factors are not accounted for. 
Multiple factors lead to model instability at some conditions that predicted high mass transfer and low convective heat transfer. Both the equation-based models and the algorithm for instantaneous performance prediction contribute to this instability. In these cases of instability, large mass transfer predictions resulted in the heat transfer model predicting membrane temperatures where the permeate membrane temperature was greater than the feed membrane temperature for the following iteration. This un-realistic switching of the temperature gradient resulted in feedback loop where permeate membrane temperature was reduced to lower values on subsequent iterations until a negative temperature value was predicted. Once a negative temperature value is present, there are not corresponding fluid properties to reference, and the algorithm crashes. At low feed or permeate velocities, low membrane thicknesses, high bulk feed temperatures, low bulk temperature differences, or a combination of those parameters, the model may not be able to predict performance.

\subsection{DCMD Operational Parameter Sensitivity}

Increases to bulk feed temperature significantly increases predicted flux. Bulk feed temperature also increases thermal efficiency, but high temperatures result in increased temperature polarization. Bulk feed temperature is a parameter that has one of the largest overall impacts on DCMD performance, so in general, a high bulk feed temperature is suggested for DCMD operation (see Section 4.1.1).

Increases to bulk permeate temperature result in a decreased predicted flux, slight increases of thermal efficiency, and slight increases of temperature polarization. 
Bulk permeate temperature should be minimized when possible. However, variation in bulk permeate temperature has a lower overall effect on performance than bulk feed temperature (see Section 4.1.2).

Decreased membrane thickness increases predicted flux, increases temperature polarization, and does not significantly change thermal efficiency. There is expected to be an optimal value of membrane thickness that optimizes flux, but this work was unable to predict such an optimal value due to model limitations. Generally, reducing the membrane thickness increases DCMD performance, but the structural stability of the membrane should also be considered (see Section 4.1.3).

The mass transfer model applied does not include consideration of membrane porosity. In reality, porosity would be expected to have a significant effect on performance, so the model predictions can not be considered reflective of reality at membrane porosities other than the porosity of 0.7 associated with the calibration data. The membrane porosity only accounts for the effect of porosity on heat transfer, where increased porosity slightly increases flux, increases thermal efficiency, and decreases temperature polarization (see Section 4.1.4). These performance trends are based only on the effect that porosity has on heat transfer across the membrane.

Increasing feed velocity in the laminar flow regime increases flux and thermal efficiency while decreasing hydraulic energy consumption, concentration polarization, and temperature polarization. In the turbulent regime, increasing feed velocity only slightly increases flux and thermal efficiency while decreasing concentration polarization and slightly decreasing temperature polarization. The hydraulic energy consumption 
slightly decreases with increased feed velocity until an optimal point. After the optimal point, increasing feed velocity increases the hydraulic energy consumption (see Section 4.1.5).

Increasing permeate velocity in the laminar regime increases flux and slightly increases hydraulic energy consumption while decreasing temperature polarization and slightly decreasing thermal efficiency. In the high end of the laminar regime the increase in flux begins to level off and returns begin to diminish. This trend continues into the turbulent regime as flux increases slightly as velocity increases. In the turbulent regime the rate of increase in hydraulic energy consumption increases with increased velocity. For some DCMD conditions, an optimal permeate velocity for hydraulic energy consumption was observed in both the laminar and turbulent regimes. The permeate velocity that produces an optimal hydraulic energy consumption was generally lower than the optimal velocity for the feed solution (see Section 4.1.6).

Increasing bulk $\mathrm{NaCl}$ concentration decreases the flux and concentration polarization and slightly decreases temperature polarization while slightly increasing thermal efficiency. A small flux decrease (2\%) was predicted between treatment of pure water and $3.5 \% \mathrm{NaCl}$. A decrease in flux of $21 \%$ was predicted between pure water and $22 \% \mathrm{NaCl}$. The ability to treat high $\mathrm{NaCl}$ concentrations without large reductions in performance is a strength of the DCMD process (see Section 4.1.7). Increasing operating pressure decreases flux, thermal efficiency, and temperature polarization. To maximize performance, the operating pressure should be minimized when practical (see Section 4.1.8). 
Increasing the hydraulic diameter greatly decreases the hydraulic energy consumption. At hydraulic diameters less than $1 \mathrm{~mm}$, the hydraulic energy consumption is prohibitively large, so a hydraulic diameter between $1 \mathrm{~mm}$ and $10 \mathrm{~cm}$ is recommended. As hydraulic diameter increases in this range, hydraulic energy consumption and flux decrease while concentration polarization increases. The increase in concentration polarization at large hydraulic diameters limits the concentration of $\mathrm{NaCl}$ that can be treated (see Section 4.1.9).

\subsection{Feasibility of DCMD Produced Water Treatment Using Sensible Heat}

The feasibility of utilizing the waste heat present in high temperature produced water to treat produced water was evaluated for DCMD treatment alone and for RODCMD hybrid systems. Sensible heat driven produced water treatment using DCMD has a thermodynamically limited recovery. The largest recoveries associated with the selected operational conditions that was energetically favorable over treatment alternatives for $1 \%$ and $3.5 \%$ bulk $\mathrm{NaCl}$ feeds were $0.5 \%$ and $0.75 \%$, respectively. However, any recovery that is achieved represents the use of waste streams to produced high quality treated water without additional energy input. For the performance simulation, the counter-current DCMD algorithm was applied using operational parameters that reflected realistic conditions while minimizing hydraulic energy consumption. Non-optimal conditions for membrane thickness, feed velocity, and permeate velocity were selected due to the limitations in the model (see Section 4.2.1). These selected parameters resulted in lower than optimal flux and larger than optimal SHEC. 
As the module length of a counter-current DCMD module increases, the average bulk temperature difference decreases, reducing average flux along the membrane length. However, as the module length increases, the total amount of mass transferred increases leading to larger recoveries. Increased module length also results in increased SHEC. The SHEC of counter-current DCMD operation was compared to ranges of RO energy consumption for $1 \%$ and $3.5 \%$ bulk $\mathrm{NaCl}$ solutions. These very low recoveries demonstrate that at bulk $\mathrm{NaCl}$ concentrations where $\mathrm{RO}$ is an alternative for treatment, there is a small range where sensible heat driven DCMD is less energy intensive.

As bulk $\mathrm{NaCl}$ concentration increases for a given module length, the recovery for DCMD slightly decreases and the hydraulic energy consumption slightly increases. For the conditions that were tested (see Table 2 ), recovery decreased by $23 \%$ and SHEC was increased by $19 \%$ when bulk $\mathrm{NaCl}$ concentration was increased from $1 \%$ to $15 \%$. The relatively low decrease in performance demonstrates that the energetic competitiveness of waste heat driven DCMD generally increases as the $\mathrm{NaCl}$ concentration of the feed solution increases. This increase in competitiveness would be associated with increased recoveries that are favorable or competitive energetically with alternatives.

For the hybrid RO-DCMD system, reverse osmosis is used to treat produced water until the $\mathrm{NaCl}$ concentration approaches its operational limit (approximately 6\% $\mathrm{NaCl}$. The RO retentate is then treated with DCMD using the sensible heat initially present in the produced water (obtained via heat exchange). For this analysis, the treatment of a $6 \%$ bulk $\mathrm{NaCl}$ concentration feed solution by DCMD was compared 
energetically against MSF and MED. The largest recovery that was energetically favorable over alternative treatment technologies for these conditions was $2.8 \%$, and the largest recovery that was competitive with the alternative treatment technologies was $4.0 \%$ (see Section 4.2.3). This range of favorable or competitive recovery rates is much larger than the favorable recovery rates at lower bulk $\mathrm{NaCl}$ concentrations. Hybrid RO-DCMD treatment or treatment of produced water feeds in excess of $6 \% \mathrm{NaCl}$ provides a much more energetically feasible treatment opportunity than sensible heat driven $\mathrm{DCMD}$ alone.

The most feasible conditions for application of sensible heat driven produced water treatment are in hybrid systems or high $\mathrm{NaCl}$ feeds. Produced water feeds with low $\mathrm{NaCl}$ concentrations have a very limited range of feasibility for sensible heat driven DCMD treatment. Even with high $\mathrm{NaCl}$ concentrations and optimal conditions, the recovery range is very limited. As the optimal conditions could not be fully explored due to model limitations, the full extent of favorability and associated recovery can not be determined, but at optimal conditions the recovery is expected to increase.

\subsection{Future Work}

The main limitation of the evaluation of the feasibility of DCMD produced water treatment using sensible heat was the inability of the model and algorithm to apply the optimal operating conditions. Without predictions of the optimal conditions, the extent to which the feasibility of produced water DCMD treatment using sensible heat can be assessed is limited. To further evaluate the feasibility, the model should be expanded to allow for converging predictions of performance for optimal conditions. In addition, 
expanding the model to allow converging predictions for a DCMD module at high temperatures and module lengths would serve to better evaluate the feasibility.

In addition to expanding the extent to which performance predictions can be made, adjustments to the model can be made to more accurately represent the factors involved in DCMD operation. The mass transfer model could be improved by incorporating consideration of pore diameter, porosity, and membrane tortuosity. Currently, the mass transfer model predictions are based on diffusion through a thin film, which neglects the effects that these parameters have on mass transfer resistance. This modification would allow improved understanding of the effect of pore diameter and porosity on DCMD performance, and better reflect actual membrane operation.

The results of the model calibration showed a discrepancy between the predicted and experimental values for flux as feed velocity was varied. This difference in trends presents a limitation in the model's ability to predict performance results as feed velocity changes. This discrepancy could be caused by the convective heat transfer correlations. The convective heat transfer correlations may not be representative of the actual effect that feed velocity has on performance. Further work could be done to evaluate if applying alternate convective heat transfer correlations would result in predictions that more closely fit the experimental data. As concentration increases, the most energetically competitive desalination technologies changes, so a more in-depth analysis of favorability at various concentrations is needed.

The correlations applied in the concentration polarization model for Sherwood number showed an unrealistic discontinuity at the laminar and turbulent transition 
region. This discrepancy likely lowered the accuracy of the model to predict concentration polarization in the transition region between laminar and turbulent flow. Further exploration into Sherwood correlations that produce more reasonable predictions is needed to improve the accuracy of concentration polarization predictions.

The predictions in this work do not consider many of the constituents of produced water that could affect DCMD performance. Constituents of produced water that may have an impact on DCMD performance include oil and grease, alkalinity, hardness, surfactants, volatile organic compounds, silica, iron oxide, and microbes. These common produced water constituents were not considered when modeling DCMD performance in this study. Expanding the model to consider these parameters would improve the ability of the model to predict performance for produced water treatment. These constituents have varying effects on performance, so further consideration into the pretreatment of produced water DCMD treatment is needed.

Sensible heat is not the only waste heat source that could be applied to drive DCMD treatment of produced water. Other sources of waste heat available at oilfield sites may be available for limited utilization. Further evaluation of waste heat sources that could be applied to drive DCMD could provide a more complete evaluation of the feasibility of DCMD to treat produced water. Recovery of the heat of vaporization of the permeate was not considered in this work. If heat is recovered, the STEC can be greatly reduced. This would pose a lower thermal energy demand for DCMD, but may also necessitate greater membrane area requirements and greater hydraulic energy consumption. Further investigation into heat recovery DCMD systems should be 
conducted to further evaluate the feasibility of DCMD produced water treatment. The DCMD model and this study do not estimate the energetic impact of permeate cooling, but further work should consider this as a factor when selecting operating parameters. 


\section{REFERENCES}

Abdullah, A., Lindsay, K. and AbdelGawad, A. (2015). Parsimonious constitutive expressions with good accuracy and suitable for modelling the properties of aqueous sodium chloride in solar ponds. Solar Energy, 122, pp.617-629.

Alkhudhiri, A., Darwish, N., \& Hilal, N. (2012). Membrane distillation: A comprehensive review. Desalination, 287, 2-18. doi: 10.1016/j.desal.2011.08.027

Alkhudhiri, A., Darwish, N., \& Hilal, N. (2013). Produced water treatment: Application of Air Gap Membrane Distillation. Desalination, 309, 46-51. doi:

10.1016/j.desal.2012.09.017

Alklaibi, A., \& Lior, N. (2005). Membrane-distillation desalination: Status and potential. Desalination, 171(2), 111-131. doi: 10.1016/j.desal.2004.03.024

Ali, A., Tufa, R., Macedonio, F., Curcio, E., \& Drioli, E. (2018). Membrane technology in renewable-energy-driven desalination. Renewable And Sustainable Energy Reviews, 81, 1-21. doi: 10.1016/j.rser.2017.07.047

Alsaadi, A., Francis, L., Maab, H., Amy, G., \& Ghaffour, N. (2015). Evaluation of air gap membrane distillation process running under sub-atmospheric conditions: Experimental and simulation studies. Journal Of Membrane Science, 489, 73-80. doi: 10.1016/j.memsci.2015.04.008

Arthur, J., Langhus, B., \& Patel, C. (2005). Technical Summary of Oil \& Gas Produced Water Treatment Technologies. Tulsa, OK: ALL Consulting. 
Bahmanyar, A., Asghari, M., \& Khoobi, N. (2012). Numerical simulation and theoretical study on simultaneously effects of operating parameters in direct contact membrane distillation. Chemical Engineering and Processing: Process Intensification, 61, 42-50. doi: 10.1016/j.cep.2012.06.012

Bergman, T., Lavine, A., Incropera, F. and Dewitt, D. (2011). Fundamentals of heat and mass transfer. 7th ed. Hoboken: J. Wiley \& Sons.

Bird, R., Stewart, W., \& Lightfoot, E. (2007). Transport Phenomena (2nd ed.). New York: Wiley.

British Columbia Ministry of Natural Gas Development (BCMNGD). Conventional versus Unconventional Oil and Gas.

Buck, A. (1981). New Equations for Computing Vapor Pressure and Enhancement Factor. Journal Of Applied Meteorology, 20(12), 1527-1532. doi: 10.1175/15200450(1981)020<1527:nefcvp>2.0.co;2

Bush, J., Vanneste, J., \& Cath, T. (2016). Membrane distillation for concentration of hypersaline brines from the Great Salt Lake: Effects of scaling and fouling on performance, efficiency, and salt rejection. Separation And Purification Technology, 170, 78-91. doi: 10.1016/j.seppur.2016.06.028

Camacho, L., Dumée, L., Zhang, J., Li, J., Duke, M., Gomez, J. and Gray, S. (2013). Advances in Membrane Distillation for Water Desalination and Purification Applications. Water, 5(1), pp.94-196. 
Cath, T., Adams, V., \& Childress, A. (2003). Experimental study of desalination using direct contact membrane distillation: a new approach to flux enhancement. Journal Of Membrane Science, 228(1), 5-16. doi: 10.1016/j.memsci.2003.09.006

Chew, N., Zhao, S., Loh, C., Permogorov, N., \& Wang, R. (2017). Surfactant effects on water recovery from produced water via direct-contact membrane distillation. Journal Of Membrane Science, 528, 126-134. doi: 10.1016/j.memsci.2017.01.024

Chittick, E., \& Srebotnjak, T. (2017). An analysis of chemicals and other constituents found in produced water from hydraulically fractured wells in California and the challenges for wastewater management. Journal Of Environmental Management, 204, 502-509. doi: 10.1016/j.jenvman.2017.09.002

Cho, D., Song, H., Yoon, K., Kim, S., Han, J., \& Cho, J. (2016). Treatment of Simulated Coalbed Methane Produced Water Using Direct Contact Mem brane Distillation. Water, 8(5), 194. doi: 10.3390/w8050194

Colorado School of Mines. (2009). TECHNICAL ASSESSMENT OF PRODUCED WATER TREATMENT TECHNOLOGIES (pp. 39-41).

Drioli, E., Ali, A., \& Macedonio, F. (2015). Membrane distillation: Recent developments and perspectives. Desalination, 356, 56-84. doi: 10.1016/j.desal.2014.10.028 
(A) Duong, H., Chivas, A., Nelemans, B., Duke, M., Gray, S., Cath, T., \& Nghiem, L. (2015).

Treatment of RO brine from CSG produced water by spiral-wound air gap membrane distillation - A pilot study. Desalination, 366, 121-129. doi: 10.1016/j.desal.2014.10.026

(B) Duong, H., Gray, S., Duke, M., Cath, T., \& Nghiem, L. (2015). Scaling control during membrane distillation of coal seam gas reverse osmosis brine. Journal Of Membrane Science, 493, 673-682. doi: 10.1016/j.memsci.2015.07.038

(C) Duong, H., Cooper, P., Nelemans, B., Cath, T., \& Nghiem, L. (2015). Optimising thermal efficiency of direct contact membrane distillation by brine recycling for small-scale seawater desalination. Desalination, 374, 1-9. doi: 10.1016/j.desal.2015.07.009

Duong, H., Duke, M., Gray, S., Cooper, P., \& Nghiem, L. (2016). Membrane scaling and prevention techniques during seawater desalination by air gap membrane distillation. Desalination, 397, 92-100. doi: 10.1016/j.desal.2016.06.025

Duong, H., Xia, L., Ma, Z., Cooper, P., Ela, W., \& Nghiem, L. (2017). Assessing the performance of solar thermal driven membrane distillation for seawater desalination by computer simulation. Journal of Membrane Science, 542, 133 142. doi: 10.1016/j.memsci.2017.08.007 
El-Bourawi, M., Ding, Z., Ma, R., \& Khayet, M. (2006). A framework for better understanding membrane distillation separation process. Journal Of Membrane Science, 285(1-2), 4-29. doi: 10.1016/j.memsci.2006.08.002

Ellsworth, W. (2013). Injection-Induced Earthquakes. Science, 341(6142), 12259421225942. doi: $10.1126 /$ science. 1225942

Eykens, L., De Sitter, K., Dotremont, C., Pinoy, L., \& Van der Bruggen, B. (2016). How To Optimize the Membrane Properties for Membrane Distillation: A Review. Industrial \& Engineering Chemistry Research, 55(35), 9333-9343. doi: 10.1021/acs.iecr.6b02226

Gilron, J., Ladizansky, Y., \& Korin, E. (2013). Silica Fouling in Direct Contact Membrane Distillation. Industrial \& Engineering Chemistry Research, 52(31), 10521-10529. doi: $10.1021 /$ ie400265b

Gordon, D. (2012). Understanding Unconventional Oil. Carnegie Endowment.

Gregory, K., Vidic, R., \& Dzombak, D. (2011). Water Management Challenges Associated with the Production of Shale Gas by Hydraulic Fracturing. Elements, 7(3), 181186. doi: 10.2113/gselements.7.3.181

Gryta, M. (2008). Alkaline scaling in the membrane distillation process. Desalination, 228(1-3), 128-134. doi: 10.1016/j.desal.2007.10.004 
Gryta, M. (2009). Calcium sulphate scaling in membrane distillation process. Chemical Papers, 63(2). doi: 10.2478/s11696-008-0095-y

Guillen-Burrieza, E., Ruiz-Aguirre, A., Zaragoza, G., \& Arafat, H. (2014). Membrane fouling and cleaning in long term plant-scale membrane distillation operations. Journal Of Membrane Science, 468, 360-372. doi: 10.1016/j.memsci.2014.05.064

Ground Water Protection Council (GWPC). (2015). U.S. Produced Water Volumes and Management Practices in 2012.

Han, L., Tan, Y., Netke, T., Fane, A., \& Chew, J. (2017). Understanding oily wastewater treatment via membrane distillation. Journal Of Membrane Science, 539, 284294. doi: 10.1016/j.memsci.2017.06.012

He, F., Sirkar, K., \& Gilron, J. (2009). Effects of antiscalants to mitigate membrane scaling by direct contact membrane distillation. Journal Of Membrane Science, 345(1-2), 53-58. doi: 10.1016/j.memsci.2009.08.021

Hitsov, I., Maere, T., De Sitter, K., Dotremont, C., \& Nopens, I. (2015). Modelling approaches in membrane distillation: A critical review. Separation And Purification Technology, 142, 48-64. doi: 10.1016/j.seppur.2014.12.026

International Atomic Energy Agency (IAEA). (2013). DEEP 5 User Manual.

Karakulski, K., \& Gryta, M. (2005). Water demineralisation by NF/MD integrated processes. Desalination, 177(1-3), 109-119. doi: 10.1016/j.desal.2004.11.018 
Kayvani Fard, A., Manawi, Y., Rhadfi, T., Mahmoud, K., Khraisheh, M. and Benyahia, F. (2015). Synoptic analysis of direct contact membrane distillation performance in Qatar: A case study. Desalination, 360, pp.97-107.

Kesieme, U., Milne, N., Aral, H., Cheng, C., \& Duke, M. (2013). Economic analysis of desalination technologies in the context of carbon pricing, and opportunities for membrane distillation. Desalination, 323, 66-74. doi:

10.1016/j.desal.2013.03.033

Kim, J., Kwon, H., Lee, S., Lee, S., \& Hong, S. (2017). Membrane distillation (MD) integrated with crystallization (MDC) for shale gas produced water (SGPW) treatment. Desalination, 403, 172-178. doi: 10.1016/j.desal.2016.07.045

Kim, J., Kim, J., \& Hong, S. (2018). Recovery of water and minerals from shale gas produced water by membrane distillation crystallization. Water Research, 129, 447-459. doi: 10.1016/j.watres.2017.11.017

Koo, T., Lee, Y., \& Sheikholeslami, R. (2001). Silica fouling and cleaning of reverse osmosis membranes. Desalination, 139(1-3), 43-56. doi: 10.1016/s00119164(01)00293-4/

Kucera, J. (2014). Desalination: Water from Water. Wiley.

Lawson, K., \& Lloyd, D. (1997). Membrane distillation. Journal Of Membrane Science, 124(1), 1-25. doi: 10.1016/s0376-7388(96)00236-0 
Lokare, O., Tavakkoli, S., Wadekar, S., Khanna, V., \& Vidic, R. (2017). Fouling in direct contact membrane distillation of produced water from unconventional gas extraction. Journal Of Membrane Science, 524, 493-501. doi:

10.1016/j.memsci.2016.11.072

Martínez, L. (2004). Comparison of membrane distillation performance using different feeds. Desalination, 168, 359-365. doi: 10.1016/j.desal.2004.07.022

Mishra, D. (2018). The Cost of Desalination. Retrieved from https://www.advisian.com/en-us/global-perspectives/the-cost-of-desalination

Patil, D. and Shirsat, S. (2015). Membrane Distillation Review and Flux prediction in Direct Contact Membrane Distillation Process. International Research Journal of Engineering and Technology, 04(07).

Peng, Y., Ge, J., Li, Z., \& Wang, S. (2015). Effects of anti-scaling and cleaning chemicals on membrane scale in direct contact membrane distillation process for RO brine concentrate. Separation And Purification Technology, 154, 22-26. doi: 10.1016/j.seppur.2015.09.007

Prince, J., Rana, D., Matsuura, T., Ayyanar, N., Shanmugasundaram, T., \& Singh, G. (2014). Nanofiber based triple layer hydro-philic/-phobic membrane - a solution for pore wetting in membrane distillation. Scientific Reports, 4(1). doi: $10.1038 /$ srep06949 
Ray, J., \& Engelhardt, F. (1992). Produced Water: Technological/Environmental Issues and Solutions. New York u.a.: Plenum Press.

Sagle, A., \& Freeman, B. (2004). Fundamentals of Membranes for Water Treatment.

Sanmartino, J., Khayet, M., García-Payo, M., El-Bakouri, H., \& Riaza, A. (2017). Treatment of reverse osmosis brine by direct contact membrane distillation: Chemical pretreatment approach. Desalination, 420, 79-90. doi:

10.1016/j.desal.2017.06.030

Sheikholeslami, R., Al-Mutaz, I., Tan, S., \& Tan, S. (2002). Some aspects of silica polymerization and fouling and its pretreatment by sodium aluminate, lime and soda ash. Desalination, 150(1), 85-92. doi: 10.1016/s0011-9164(02)00932-3

Society of Petroleum Engineers (SPE). (2005). Glossary of Terms Used in Petroleum Reserves/Resources Definitions.

Society of Petroleum Engineers (SPE). (2012). Hydraulic Fracturing 101: What Every Representative, Environmentalist, Regulator, Reporter, Investor, University Researcher, Neighbor and Engineer Should Know About Estimating Frac Risk and Improving Frac Performance in Unconventional Gas and Oil Wells. The Woodlands, TX.

Srisurichan, S., Jiraratananon, R., \& Fane, A. (2006). Mass transfer mechanisms and transport resistances in direct contact membrane distillation process. Journal of Membrane Science, 277(1-2), 186-194. doi: 10.1016/j.memsci.2005.10.028 
Stillwell, A., \& Webber, M. (2016). Predicting the Specific Energy Consumption of Reverse Osmosis Desalination. Water, 8(12), 601. doi: 10.3390/w8120601

Tan, Z. (2014). Air pollution and greenhouse gases (p. 38). Springer Verlag, Singapore.

Tun, C., Fane, A., Matheickal, J., \& Sheikholeslami, R. (2005). Membrane distillation crystallization of concentrated salts - flux and crystal formation. Journal of Membrane Science, 257(1-2), 144-155. doi: 10.1016/j.memsci.2004.09.051

Warsinger, D., Swaminathan, J., Guillen-Burrieza, E., Arafat, H., \& Lienhard V, J. (2015). Scaling and fouling in membrane distillation for desalination applications: A review. Desalination, 356, 294-313. doi: 10.1016/j.desal.2014.06.031

United States Bureau of Reclamation (USBR). (2011). Oil and Gas Produced Water Management and Beneficial Use in the Western United States. Denver, CO: U.S. Department of the Interior.

United States Bureau of Reclamation (2014). Produced Water Treatment Primer: Case Studies of Treatment Applications. Science and Technology Program Research Report.

United States Bureau of Reclamation (USBR). (2016). Summary of Current Research on Produced Water Treatment. Denver, CO.

United States Geological Survey (USGS). (2000). Coal-Bed Methane: Potential and Concerns. 
Yun, Y., Ma, R., Zhang, W., Fane, A., \& Li, J. (2006). Direct contact membrane distillation mechanism for high concentration $\mathrm{NaCl}$ solutions. Desalination, 188(1-3), 251262. doi: 10.1016/j.desal.2005.04.123

Zhang, Y., Peng, Y., Ji, S., Li, Z., \& Chen, P. (2015a). Review of thermal efficiency and heat recycling in membrane distillation processes. Desalination, 367, 223-239. doi: 10.1016/j.desal.2015.04.013

Zhang, P., Knötig, P., Gray, S., \& Duke, M. (2015b). Scale reduction and cleaning techniques during direct contact membrane distillation of seawater reverse osmosis brine. Desalination, 374, 20-30. doi: 10.1016/j.desal.2015.07.005 


\section{APPENDICES}

\section{Appendix A: Supplemental Background Information}

\section{A1.0 MD Fouling}

Water type and fouling constituents have a large effect on scale formation and other fouling. Groundwater typically has the most variable constituents and is the most susceptible to fouling (Warsinger et al, 2015). Produced water shares many of the challenges of groundwater and faces additional challenges. When operating at high recovery rates, fouling is often the factor that most limits permeate flux and must be mitigated for high recovery applications (Kim, Kim \& Hong, 2018). Information on fouling from individual constituents of produced water can be found in section 3.2.

In MD operation, temperature has one of the largest effects on scaling. Depending on the solvent, solubility can either increase or decrease with increased temperature. $\mathrm{NaCl}$ solubility increases with temperature while alkaline salts, such as CaCO3, decrease in solubility. High temperatures inhibit microbial scaling, but it increases protein scaling within the feed solution that can be difficult to remove (Warsinger et al, 2015). While the flux and thermal efficiency are decreased greatly at lower temperatures, scaling is also decreased as common scale forming compounds have lowered solubility in high temperature solutions (Warsinger et al, 2015)(Duong et

al, 2015b)(Duong et al, 2016). Duong et al found that MD treatment coal seam gas (CSG) produced water brine was able to operate at high recovery (80\%) without scale formation at $35^{\circ} \mathrm{C}$ with a small dose of antiscalant. Higher temperatures were found to have considerable scaling at lower recoveries (Duong et al, 2015b). 


\section{A1.1 Fouling Mitigation and Cleaning}

Addressing the challenge of membrane scaling has been investigated using membrane cleaning, antiscalants, surface modifications, and filtration. Intermittent cleaning of membrane surfaces with $3 \%$ to as low as $0.5 \%$ by weight $\mathrm{HCl}$ was found to restore flux and remove scaling (Duong et al, 2015b)(Gryta, 2008). Additional solutions explored for removing scaling from membrane surfaces include tap water, vinegar, humic acid, $\mathrm{NaOH}$, sulfuric acid, MC3 metal cleaner and other acids have been shown to restore membrane flux to varying degrees (Duong et al, 2015b)(Duong et al, 2016)(Gryta, 2008)(Guillen-Burrieza et al, 2014)(Peng et al, 2015). While membrane cleaning using solutions such as $\mathrm{HCl}$ and $\mathrm{MC} 3$ restored flux closer to initial value even at high water recovery, some scale deposits were not removed and resulted in worsening flux degradation with successive cleanings (Duong et al, 2015b)(Duong et al, 2016). Peng et al found that slightly higher flux recoveries were observed when the cleaning solution was at a higher temperature (Peng et al, 2015).

Silicate scaling is not as readily removed with acid washing, and over time the buildup of silicate scaling may lead to lower flux recovery from cleaning (Duong et al, 2015b)(Duong et al, 2016). For MD brine concentration operating at high recovery, rinsing with brine feed and distillate can restore flux. Distillate has a higher potential for cleaning than feed brine, but represents a loss of product (Zhang et al, 2015b)(He, Sirkar, \& Gilron, 2009).

Preventative measures to reduce scaling using antiscalants can limit scale formation even at high recovery rates. Antiscalants typically contain polyphosphates, 
organophosphates, and polyelectrolytes (Zhang et al, 2015b). Duong et al found that small doses of antiscalant $(0.5 \mathrm{mg} / \mathrm{L})$ in seawater and $5 \mathrm{mg} / \mathrm{L}$ in CSG produced water brine limited scaling (Duong et al, 2015b)(Duong et al, 2016). Addition of acids alone into the feed stream may be effective in reducing scaling associated with high $\mathrm{pH}$, but they may increase the occurrence of non-alkaline scale such as CaSO4 (Karakulski \& Gryta, 2005). Typical antiscalants do not pose a significant risk of membrane wetting (Zhang et al, 2015b). He el al found antiscalants at concentrations as low as $0.6 \mathrm{mg} / \mathrm{L}$ to increase the induction time of calcite and gypsum.

Surface modification has been explored for MD and other membrane processes to reduce membrane scaling. Surface modification can be achieved by coating or grafting compounds onto the membrane surface. Hydrophilic, hydrophobic, and amphiphilic compounds have been used to reduce scaling (Shahkaramipour et al, 2017). Hydrophobic modification can prevent wetting by increasing contact angle and reducing pore size (Kucera, 2014). Hydrophobic coatings such as fluoropolymers have also been found to lower surface energy of membranes and make membrane cleaning more effective (Shahkaramipour et al, 2017). Hydrophilic modifications can protect pores from wetting and are often used to protect against oil and protein fouling (Shahkaramipour et al, 2017)(Kucera, 2014).

Introducing a filter prior to the membrane module can also reduce scale formation on the membrane (He et al, 2009)(Kesieme et al, 2013). Cartridge filters placed after the heat exchanger and before the module have been used to remove precipitates. This location in the system most susceptible due to being the highest 
temperature location, so filtration is most effective. He et al found that including a 0.45

$\mu \mathrm{m}$ filter increased recovery of seawater RO brine from $45 \%$ to $60 \%$ (He et al, 2009).

\section{A1.2 Produced Water Constituents and effect on MD}

Many common constituents of produced water can affect MD operation. Each constituent produces unique challenges to MD operation that may need to be addressed. Commonly, the limiting factors of high recovery MD systems are calcium carbonate (CaCO3), calcium sulfate ( $\mathrm{CaSO} 4)$, and $\mathrm{NaCl}$ scale formation. Additional constituents that can reduce MD effectiveness include Oil and Grease, VOCs, silica, and surfactants.

\section{A1.2.1 Oil and Grease}

Oil and grease $(O \& G)$ present in produced water imposes difficulties in treatment using membrane processes. The presence of $O \& G$ can lead to coating of the membrane pores causing membrane wetting (Kim et al, 2017). O\&G have not been seen to decrease membrane porosity and flux (Kim et al, 2017). However, O\&G can lead to wetting that reduces permeate water quality. If $O \& G$ decreases permeate quality beyond allowable limits, it should be removed prior to MD treatment. MD brine concentration is susceptible to heavy membrane wetting as high $O \& G$ concentrations drastically lower the liquid entry pressure (LEP) that is associated with membrane wetting (Kim et al, 2017). If the produced water brine to be concentrated is RO retentate, then $O \& G$ should be removed before RO treatment and should not affect MD brine concentration. 


\section{A1.2.2 Hardness and Alkalinity}

Calcium Carbonate ( $\mathrm{CaCO} 3)$ and calcium sulfate (CaSO4) are constituents of concern for brine concentration using MD as their low solubility may result in membrane deposits. CaCO3 scale is one of the most common and pervasive scaling types for MD systems (Warsinger et al, 2015). These crystalline deposits can contribute to increased wetting or decreased membrane porosity. When RO brines are concentrated using MD, chemical pretreatment to remove calcium hardness is usually conducted. Removal of calcium hardness reduces the crystal formation on MD membranes, increasing the effective water recovery (Sanmartino et al, 2017). CaCO3 scaling often results in membrane wetting that reduces permeate quality. $\mathrm{CaCO} 3$ precipitation can be prevented through application of a weak acid, such as humic acid, to lower solution $\mathrm{pH}$ (Warsinger et al, 2015).

Duong et al found that with a low calcium concentration and high bicarbonate (HCO3-) concentration, high temperatures increase the decomposition of bicarbonate into $\mathrm{CO} 2$ and may decrease membrane flux by competing with water vapor. HCO3- may have also contributed to permeate conductivity as large as $500 \mu \mathrm{S} / \mathrm{cm}$ (Duong et al, 2015a). Bicarbonate present in MD feed can significantly reduce process effectiveness through fouling and reduction of permeate quality even without the presence of scale forming calcium. The decomposition of $\mathrm{HCO} 3-$ to $\mathrm{CO} 2$ produces additional problems as gaseous $\mathrm{CO} 2$ leaving the solution increases the $\mathrm{pH}$ of the feed solution making it more susceptible to alkaline scaling (Warsinger et al, 2015). 
The concentration of HCO3- affects permeate flux over time when high temperatures, $\mathrm{Mg}$, and/or $\mathrm{Ca}$ are present. High $\mathrm{NaCl}$ concentrations may increase the solubility of $\mathrm{CaCO} 3$ and $\mathrm{MgCO} 3$ possibly leading to less scaling in more saline solutions for similar HCO3- concentrations (Cho et al, 2016). The most common form of $\mathrm{CaCO} 3$ scaling is aragonite, but other species that scale are calcite and vaterite. These species can be viewed and identified with the use of a scanning electron microscope (SEM). Higher feed flow lowers the prevalence of scale formation and result in crystals that are smaller and less compact (Gryta, 2008).

At higher feed solution $\mathrm{pH}$, high magnesium concentrations may lead to precipitation of magnesium hydroxide $(\mathrm{Mg}(\mathrm{OH}) 2) . \mathrm{Mg}(\mathrm{OH}) 2$ has an inverse solubility with temperature making the scaling more prevalent at the elevated temperatures of MD (Warsinger et al, 2015).

\section{A1.2.3 Biological}

Microbial growth and fouling in MD systems is lower than in other membrane processes such as MF, UF, and RO. Microbial activity is limited by the high temperatures and high salinity typically found in MD (Warsinger et al, 2015). As most biofilms formed from microbial growth are relatively porous, the main impact of biofilm production is membrane wetting. Additionally, biofilms create stagnant layers at the membrane and lower diffusion. Flux reduction caused by biofilms is due to increased CP and TP that lowers mass transfer and increases conductive heat loss. Biofilms are difficult to remove from MD membranes, so prevention of biofilm development may be needed to reduce 
biological fouling, but chlorination should be avoided as it may damage the membrane (Warsinger et al, 2015).

\section{A1.2.4 VOCs}

Some MD applications target VOC removal as their primary goal. In these cases, the transport of VOCs is maximized instead of water vapor. In SGMD and VMD applications, VOC transport is maximized for this separation. In AGMD and DCMD used for desalination, water vapor flux is maximized, but VOCs can still pass through the membrane and potentially lower the quality of the permeate.

Size has a large effect on the selectivity of MD for volatile organic compounds (VOCs). As MD is often used for VOC removal from a stream, the permeate can contain large VOC concentrations. Small VOCs can pass through the membrane with little selectivity, while larger VOCs have higher rejection rates. Lack of VOC rejection can result in lower quality permeate, pretreatment for VOCs is recommended when low VOC permeate is required (Kim et al, 2018)

\section{A1.2.5 Silica}

The presence of colloidal silica common in petroleum produced water may lead to persistent membrane scaling (Gilron, Ladizanski, \& Korin, 2013). Silica scaling can lower flux over time in MD systems and is resistant to typical acid cleaning cycles. Silica scaling typically results in slower flux degradation than alkaline scaling, but its effect builds over time and is difficult to remove (Warsinger et al, 2015)(Duong et al, 2015b)(Duong et al, 2016). Silicon compounds can enter into membrane pores and clog them unlike most other scale formations that form a layer covering the membrane. This, 
along with silicon compounds not being affected by acidic solutions due to the uncharged nature, results in more resilient scale formations (Karakulski \& Gryta, 2005) (Warsinger et al, 2015) (Koo, Lee, \& Sheikholeslami, 2001) (Gilron et al, 2013) (Sheikholeslami, Al-Mutaz, Tan, \& Tan, 2002).

Factors that exacerbate silica fouling on membranes include $\mathrm{pH}$, temperature, flow rate, and presence of other salts. Silica solubility increases with increasing temperature and with increasing pH (Koo et al, 2001) (Gilron et al, 2013) (Warsinger et al, 2015). However, the rate of silica polymerization on membrane surfaces seems to be increased with temperature, which indicates that lower temperatures may result in less scale formation (Sheikholeslami et al, 2002). Gilron et al found that lowering the brine recycle rate of MD feed decreased the time it took for silica fouling to occur (Gilron et al, 2013). Additionally reduced flow rate increases $C P$ and TP which increase membrane scaling. Increases in CP and TP cause increased silica fouling (Warsinger et al, 2015).

The presence of certain salts contributes to the polymerization of silica on the membrane surface with the ions of greatest impact being $\mathrm{Mg}$ and $\mathrm{Ca}$ that act as a catalyst for silica polymerization. When together in solution, the effect of $\mathrm{Mg}$ on silica precipitation is larger than the effect of Ca in RO membranes (Koo et al, 2001)(Sheikholeslami et al, 2002). Koo et al found that when $\mathrm{Cl}$ and $\mathrm{CO} 3$ concentrations were compared, $\mathrm{CO} 3$ concentration had a larger effect on polymerization. Increased concentration of these ions was found to increase silica fouling (Koo et al, 2001).

Cleaning targeting silica deposits on membranes has been attempted using various solutions including solvents such as distilled water, sodium carbonate, and 
commercial cleaners (MT3100 \& MT5010). None of these treatments were effectively able to restore membrane flux to initial levels (Koo et al, 2001)(Gilron et al, 2013).

Due to the nature of silica deposits on membrane surfaces, pretreatment is often more effective than membrane cleaning.

\section{A1.2.6 Surfactants}

Surfactants present in produced water MD feeds may lower the hydrophobicity of the membrane and lead to wetting. When interacting with oils, surfactants can prevent the adsorption of oils onto the membrane. This may prevent fouling and increase wetting (Chew et al, 2017)(Han et al, 2017).

Surfactant interaction with $\mathrm{NaCl}$ may produce additional fouling concerns. Han et al found that interaction between sodium dodecyl sulfate (SDS) and $\mathrm{NaCl}$ resulted in severe wetting and fouling of MD membranes. $\mathrm{NaCl}$ and SDS alone had stable flux when isolated, but produced high fouling when together in solution. Presence of SDS, oil, and $\mathrm{NaCl}$ in the feed solution produced the worst fouling. Interactions of $\mathrm{NaCl}$ and other surfactants should be further studied to determine if similar fouling exists. SDS present in produced water should be removed prior to MD treatment (Han et al, 2017).

\section{A1.2.7 Iron Oxide}

Typically, iron oxide scaling is not present in feed solutions, but can appear as rust forms on MD components. For instance, Lokare et al found that treatment of shale gas produced water with low iron concentrations at high TDS concentrations $(300,000$ $\mathrm{mg} / \mathrm{L}$ ) resulted in a $12 \mu \mathrm{m}$ thick layer of iron oxide scale on the DCMD membrane. This layer was found to be porous and had a negligible effect on permeate flux (Lokare et al, 
2013). Iron oxide scaling is porous and does not greatly lower flux, but it may cause damage to the membrane. Cleaning membranes with high strength acid may result in iron oxide formation, but low strength acid cleaning may not be a concern for iron oxide generation(Warsinger et al, 2015). To minimize iron oxide fouling in MD systems, high strength plastics should be used where practical (Warsinger et al, 2015).

\section{A1.2.8 Value of Near-ZLD Produced Water Treatment}

Many of the wells in the US are located in states such as CA, NM, TX, CO, and WY that experience high to extreme water stress (USBR, 2016). In some cases, the cost of water acquisition can be greater than the cost of treating produced water. Treated produced water can be a valuable source of water for various purposes to lower water scarcity.

Depending on water quality, there are various technologies available for treatment. Concentrated brine from produced water treatment remains a disposal issue that needs to be addressed (USBR, 2016). 


\section{Appendix B: Visual Basic Code}

Counter-current flow model:

Sub Countercurrent()

Dim i As Integer

Dim j As Integer

Dim k As Integer

Dim sht1 As Worksheet

Dim sht2 As Worksheet

Set sht1 = Worksheets("Main Calculations")

Set sht2 = Worksheets("Counter-Current Time Step")

tf0 $=$ sht2.Cells (4, 2).Value

$\mathrm{I}=$ sht1.Cells $(11,2)$.Value

$\mathrm{Tp0}=$ sht2.Cells $(5,2)$.Value

$\mathrm{tp}=$ sht2.Cells $(13,2)$.Value

tpi $=$ sht2.Cells $(13,2)$.Value

delX = sht2.Cells $(2,2)$.Value

vf0 $=$ sht2.Cells $(15,2)$.Value

$\mathrm{vp0}=$ sht2.Cells $(16,2) \cdot$ Value

$\mathrm{vp}=$ sht2.Cells $(10,2) \cdot$ Value

vp00 $=$ sht2.Cells $(10,2)$.Value

SO = sht2.Cells $(17,2)$.Value

$\mathrm{mp0}=$ sht2.Cells $(12,2)$.Value

$\mathrm{mp00}=$ sht2.Cells $(8,2)$.Value

$\mathrm{mp}=$ sht2.Cells $(12,2)$.Value

sht1.Cells $(18,2) \cdot$ Value $=v p 0$

sht1.Cells $(17,2) \cdot$ Value $=$ vf0

sht1.Cells $(4,2) \cdot$ Value $=$ SO

$k=0$

Do

If $k>1000$ Then Exit Do

sht1.Cells (2, 2).Value $=\mathrm{tf0}$

sht1.Cells $(3,2) \cdot$ Value $=$ tpi

sht1.Cells $(18,2) \cdot$ Value $=$ vp0

sht1.Cells $(17,2)$.Value $=$ vf0

sht1.Cells $(4,2) \cdot$ Value $=$ SO 


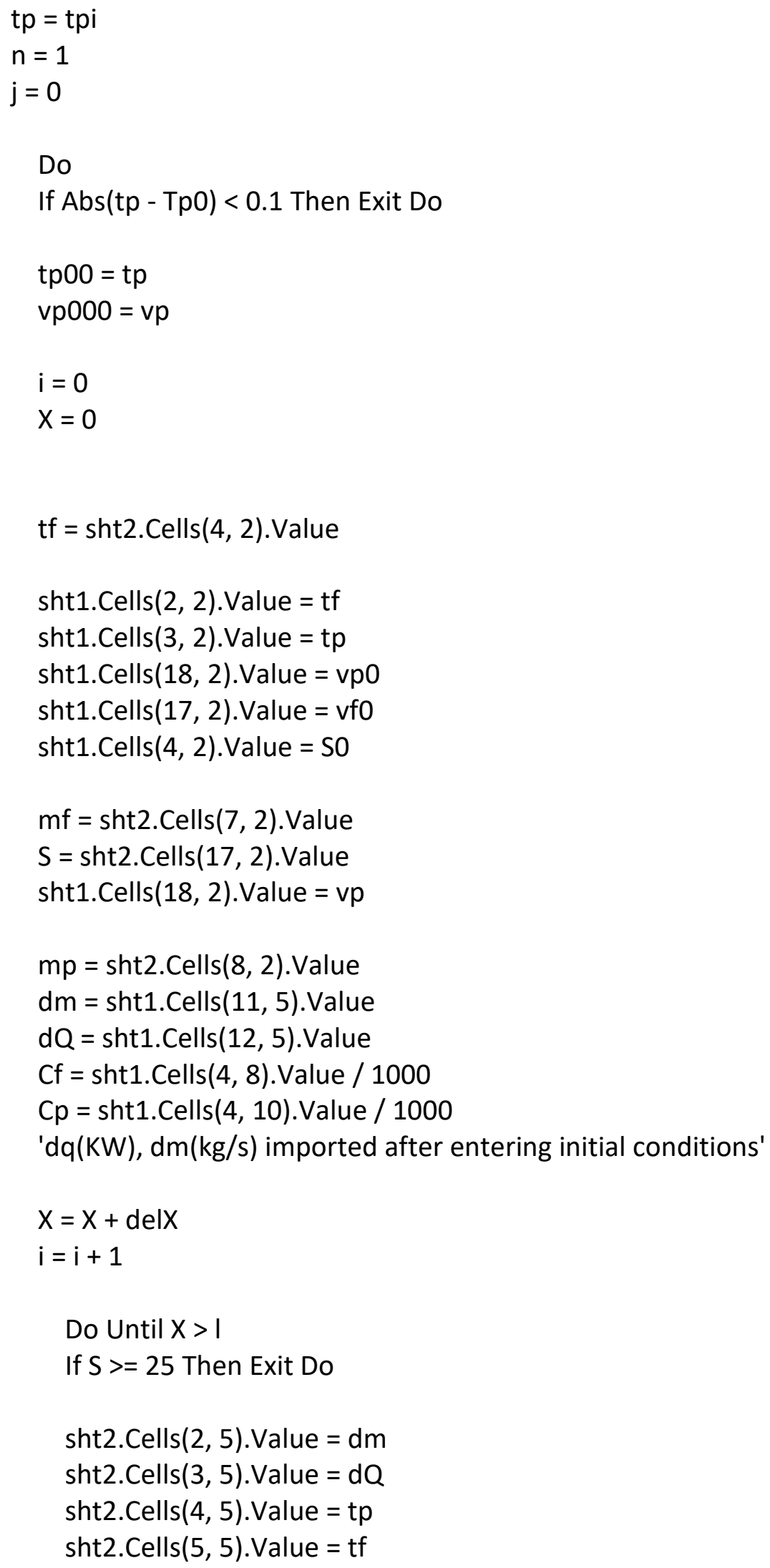




$$
\begin{aligned}
& \text { sht2.Cells }(7,5) \cdot \text { Value }=\mathrm{mf} \\
& \text { sht2.Cells }(8,5) \cdot \text { Value }=m p \\
& \text { sht2.Cells }(6,5) \cdot \text { Value }=\mathrm{S} \\
& \text { sht2.Cells }(10,5) \cdot \text { Value }=v p \\
& \text { sht2.Cells }(12,5) \cdot \text { Value }=\mathrm{Cf} \\
& \text { sht2.Cells }(13,5) \cdot \text { Value }=C p \\
& \mathrm{tf}=\text { sht2.Cells }(5,7) . \text { Value } \\
& \mathrm{tp}=\text { sht2.Cells }(4,7) \text {.Value } \\
& \mathrm{mf}=\text { sht2.Cells }(7,7) \text {.Value } \\
& \mathrm{mp}=\text { sht2.Cells }(8,7) \text {.Value } \\
& \mathrm{S}=\text { sht2.Cells(6, 7).Value } \\
& \mathrm{vp}=\text { sht2.Cells }(10,7) \cdot \text { Value } \\
& v f=\operatorname{sht2} . \text { Cells }(9,7) \cdot \text { Value } \\
& \text { sht1.Cells }(3,2) \cdot \text { Value }=\mathrm{tp} \\
& \text { sht1.Cells }(2,2) \cdot \text { Value }=t f \\
& \text { sht1.Cells }(4,2) \cdot \text { Value }=\mathrm{S} \\
& \text { sht1.Cells }(18,2) \cdot \text { Value }=v p \\
& \text { sht1.Cells }(17,2) \cdot \text { Value }=v f \\
& \mathrm{dm}=\text { sht1.Cells }(11,5) \cdot \text { Value } \\
& d Q=\text { sht1.Cells }(12,5) \cdot \text { Value } \\
& \mathrm{Cf}=\text { sht1.Cells }(4,8) \cdot \text { Value / } 1000 \\
& \mathrm{Cp}=\text { sht1.Cells }(4,10) \cdot \text { Value } / 1000 \\
& \mathrm{X}=\mathrm{X}+\text { del } \mathrm{X} \\
& i=i+1
\end{aligned}
$$

If $\mathrm{tp}<=$ Tp0 Then Exit Do

$$
\text { tp }=\text { tpi }- \text { tpi } * 0.005 * j
$$$$
j=j+1
$$

Loop

If $\mathrm{Abs}(\mathrm{mp}-\mathrm{mp00}) * 100 / \mathrm{mp}<0.5$ Then Exit Do 


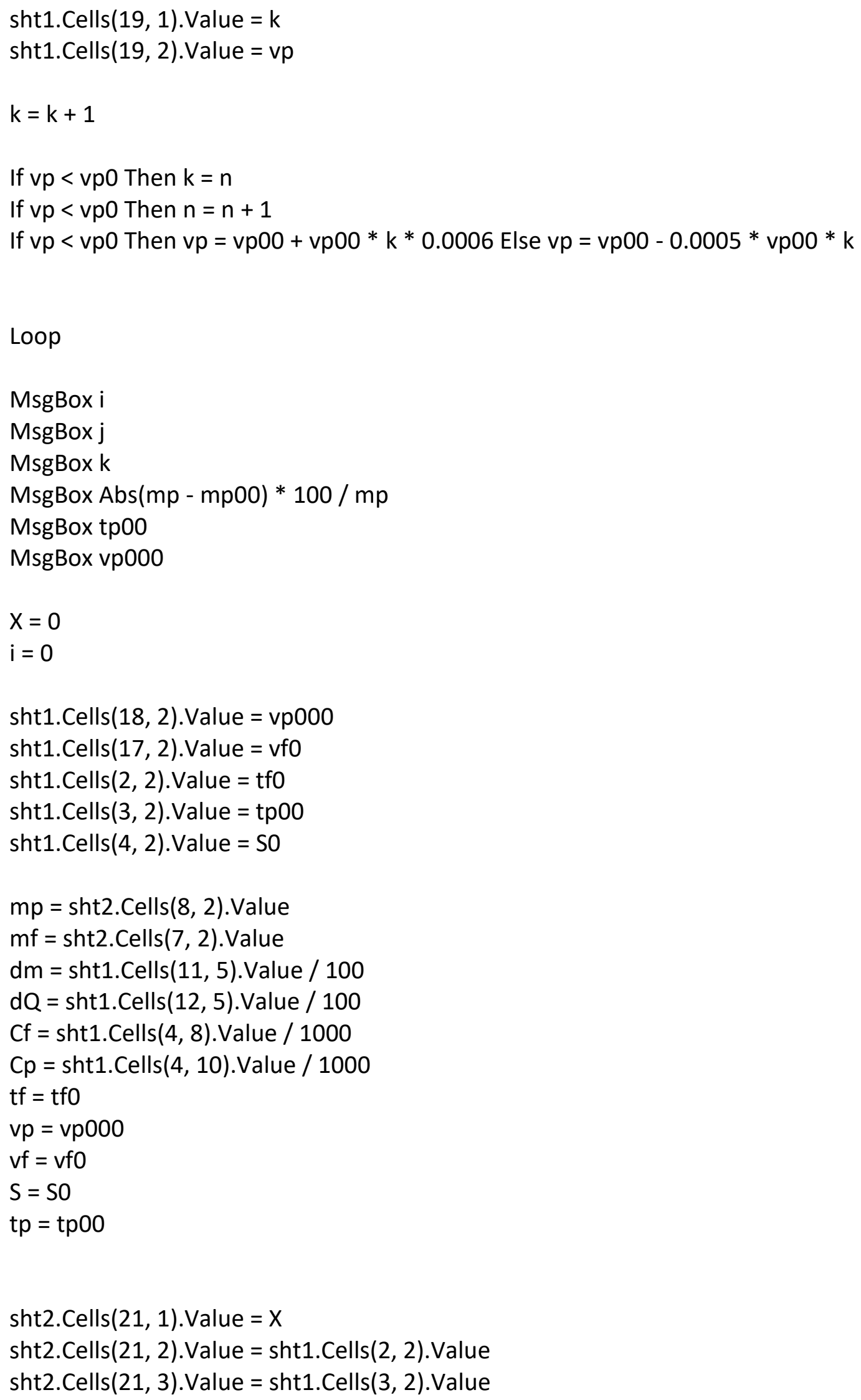




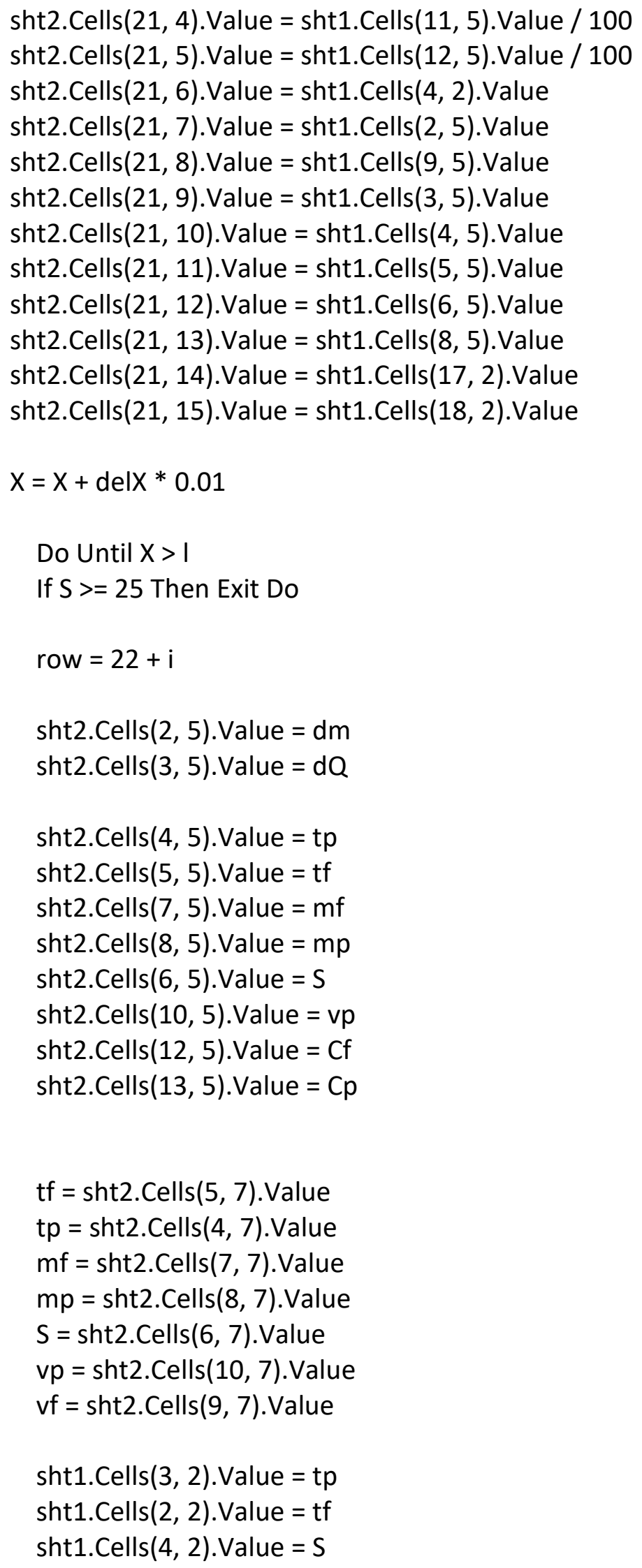




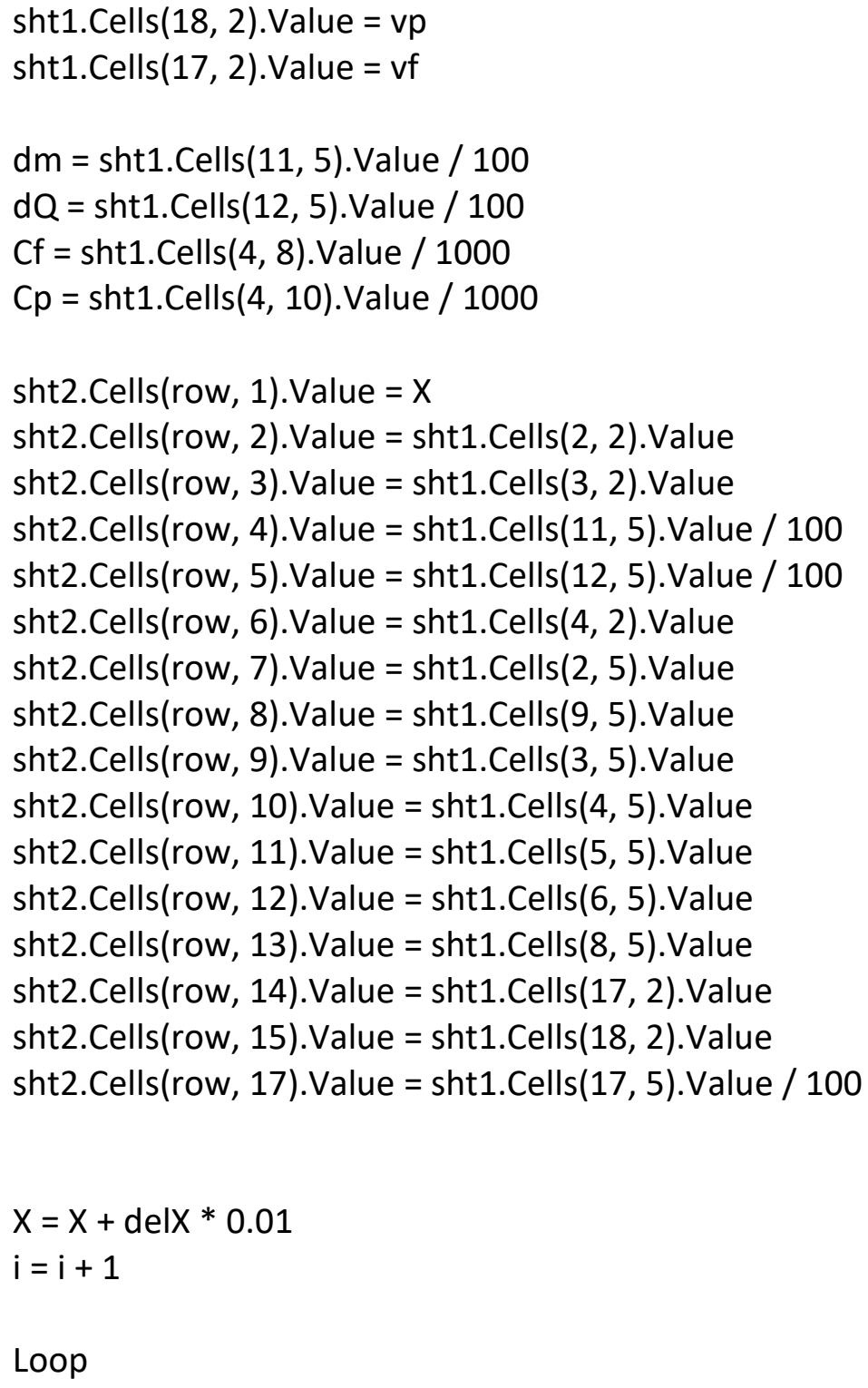

End Sub 
Sensitivity Analysis Code Example for Feed Temperature:

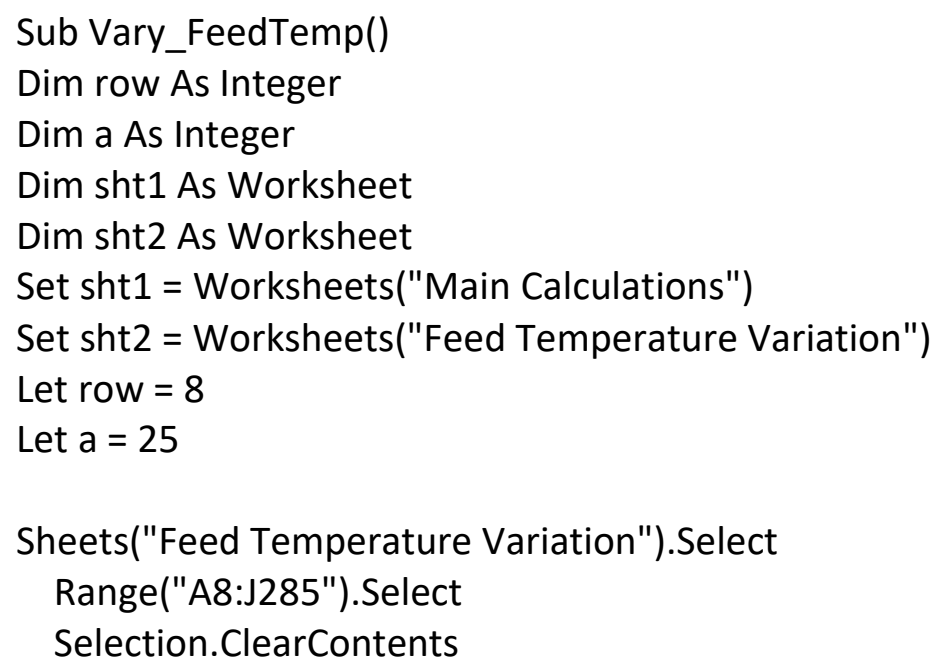

Do

If $\mathrm{a}>80$ Then Exit Do

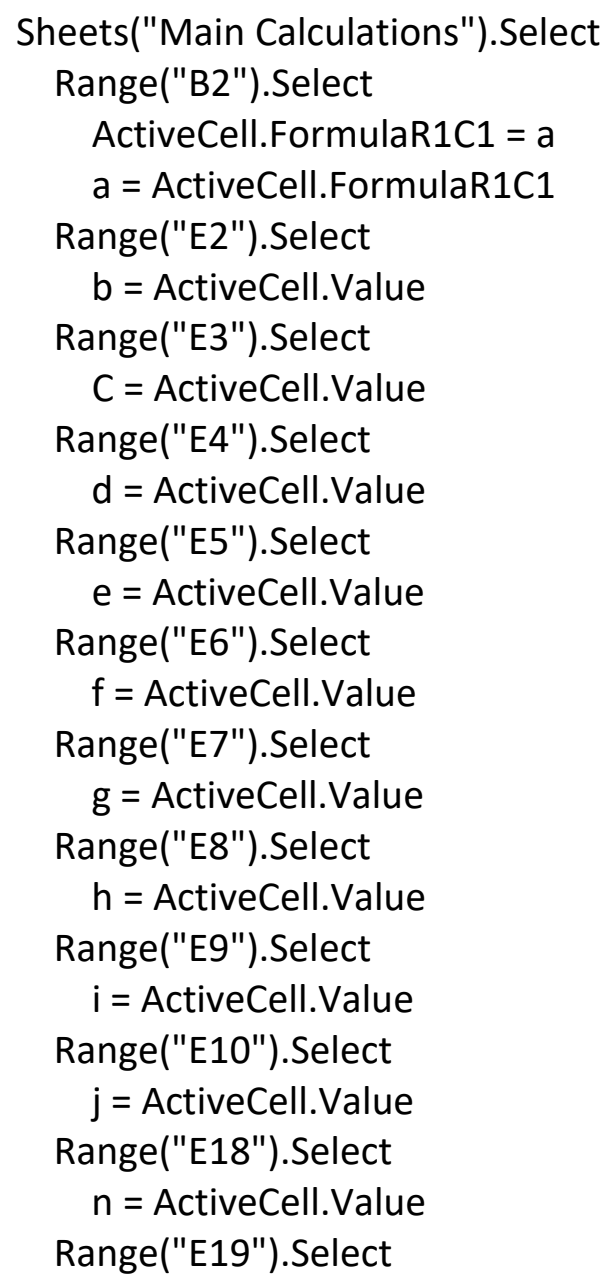




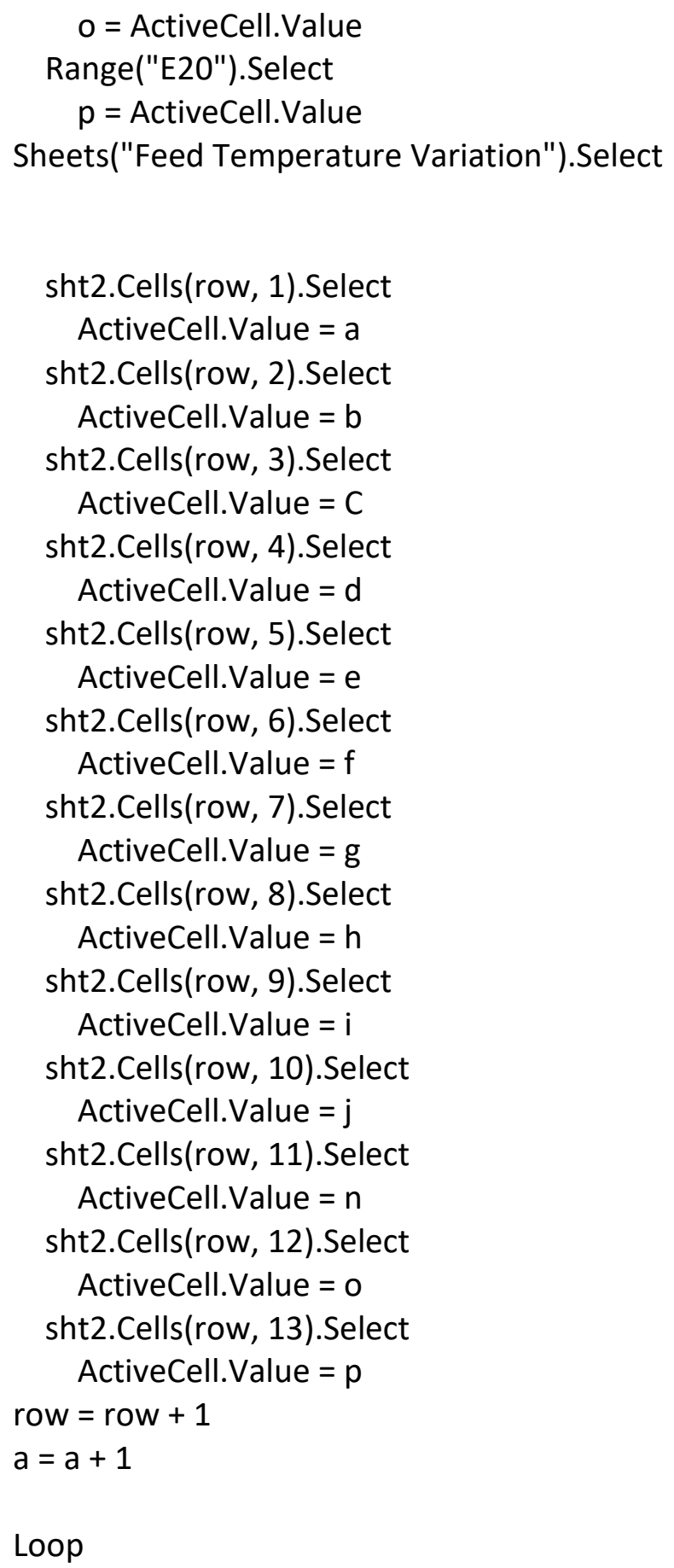

End Sub 


\section{Appendix C: Instantaneous Algorithm Spreadsheet}

Input Conditions, Output Conditions, and Property Calculator

\begin{tabular}{|c|c|}
\hline \multicolumn{2}{|l|}{ Inputs } \\
\hline Feed Bulk Temperature (Tf) & 60 \\
\hline $\begin{array}{l}\text { Permeate Bulk Temperature } \\
\qquad(\mathrm{Tp})\end{array}$ & 20 \\
\hline Feed NaCl Wt Fraction (\%) & 0.06 \\
\hline Hydraulic Diameter (m) & $9.94 \mathrm{E}-02$ \\
\hline Channel Height (m) & $5.96 \mathrm{E}-02$ \\
\hline Membrane Thickness ( $\mathrm{m}$ ) & $1.75 \mathrm{E}-04$ \\
\hline Pressure (bar) & 1.08 \\
\hline Membrane Porosity & 0.7 \\
\hline Membrane Material & PTFE \\
\hline Flat Plate Module Length (m) & 20 \\
\hline Flat Plate Module Width (m) & 2.98E-01 \\
\hline Pore size, $d_{p}(\mu m)$ & 0.45 \\
\hline Feed Flow Rate (m3/s) & 0 \\
\hline Permeate Flow Rate $(\mathrm{m} 3 / \mathrm{s})$ & 0 \\
\hline \multicolumn{2}{|c|}{ Or (Insert Zero for other) } \\
\hline Feed Cross-flow Velocity (m/s) & 1.75 \\
\hline $\begin{array}{l}\text { Permeate Cross-flow Velocity } \\
\qquad(\mathrm{m} / \mathrm{s})\end{array}$ & 1.75 \\
\hline
\end{tabular}

\begin{tabular}{|c|c|}
\hline \multicolumn{2}{|c|}{ Outputs } \\
\hline $\begin{array}{l}\text { Predicted Flux, N } \\
(\mathrm{kg} / \mathrm{m} 2-\mathrm{hr})\end{array}$ & 65.00228315 \\
\hline $\operatorname{Tmf}\left({ }^{\circ} \mathrm{C}\right)$ & 52.91 \\
\hline $\operatorname{Tmp}\left({ }^{\circ} \mathrm{C}\right)$ & 28.93 \\
\hline TPC & 0.600 \\
\hline CPC & 1.30830 \\
\hline $\begin{array}{c}\text { Total Heat } \\
\text { Transfer, Q(KW) }\end{array}$ & 50.4 \\
\hline Thermal Efficiency & $86 \%$ \\
\hline Convergence & Converges \\
\hline Knudsen Number & 0.288 \\
\hline $\mathrm{dm}(\mathrm{kg} / \mathrm{s})$ & $1.08 E-02$ \\
\hline dQ (KW) & $3.0 \mathrm{E}+01$ \\
\hline$\Delta \mathrm{H}_{\mathrm{vap}}$ & 2404.7 \\
\hline$h_{\text {boss },}(m)$ & 0.7 \\
\hline$h_{\text {losssfoed }}(m)$ & 0.3 \\
\hline$h_{\text {losspermeate }}(m)$ & 0.4 \\
\hline$h_{\text {losst, dx }}(m)$ & 0.1 \\
\hline $\begin{array}{l}\text { STEC Chantanious } \\
(\mathrm{KWh} / \mathrm{m} 3)\end{array}$ & 775 \\
\hline $\begin{array}{l}\text { Hydraulic Energy } \\
\text { Consumption } \\
\text { Instantanious } \\
\text { (KWh/m3) }\end{array}$ & 13 \\
\hline $\begin{array}{c}\mathrm{SEC}_{\text {Instantanious }} \\
(\mathrm{KWh} / \mathrm{m} 3)\end{array}$ & 788 \\
\hline
\end{tabular}

\begin{tabular}{|c|c|c|c|}
\hline \multicolumn{4}{|c|}{ Feed and Permeate Properties } \\
\hline Feed Density $(\mathrm{kg} / \mathrm{m} 3)$ & 983.608 & $\begin{array}{c}\text { Permeate Density } \\
(\mathrm{kg} / \mathrm{m} 3)\end{array}$ & 998.21 \\
\hline $\begin{array}{l}\text { Feed Fluid Thermal } \\
\text { Conductivity }(\mathrm{W} / \mathrm{mK})\end{array}$ & 0.65091 & $\begin{array}{c}\text { Permeate Fluid } \\
\text { Thermal Conductivity } \\
(\mathrm{W} / \mathrm{mK})\end{array}$ & 0.59803 \\
\hline $\begin{array}{l}\text { Feed Fluid Specific Heat } \\
\text { Capacity }(J / \mathrm{kgK})\end{array}$ & 4185.1 & $\begin{array}{c}\text { Permeate Fluid } \\
\text { Specific Heat Capacity } \\
(\mathrm{J} / \mathrm{kgK})\end{array}$ & 4184.4 \\
\hline Feed Viscosity & 4.67E-04 & Permeate Viscosity & $1.00 E-03$ \\
\hline Mean Initial Temperature & 40 & Mean Viscosity & 0.00065338 \\
\hline - & - & $\begin{array}{l}\text { Mean Fluid Specific } \\
\text { Heat Capacity }(J / \mathrm{kgK})\end{array}$ & 4179.6 \\
\hline - & - & $\begin{array}{l}\text { Mean Fluid Thermal } \\
\text { Conductivity }(\mathrm{W} / \mathrm{mK})\end{array}$ & 0.62856 \\
\hline
\end{tabular}


Heat Transfer Model Iteration Example

\begin{tabular}{|c|c|c|c|c|}
\hline \multirow{3}{*}{\multicolumn{2}{|c|}{ Heat Transfer Related Properties }} & \multirow{2}{*}{\multicolumn{3}{|c|}{ Heat Transfer Model }} \\
\hline & & & & \\
\hline & & \multicolumn{3}{|c|}{ Intermediates (Iteration 2) } \\
\hline Feed Mem Density & 993 & $\mathrm{Re}_{\mathrm{p}}$ & 366623 & \\
\hline $\begin{array}{l}\text { Feed Mem Thermal } \\
\text { Conductivity }\end{array}$ & 0.65 & $\mathrm{Re}_{\mathrm{p}}$ & 173315 & \\
\hline $\begin{array}{l}\text { Feed Mem Specific } \\
\text { Heat Capacity }\end{array}$ & 4184 & $\mathrm{Pr}_{f}$ & 3.0 & \\
\hline Feed Mem Viscosity & 0.000480 & $\mathrm{Pr}_{\mathrm{p}}$ & 7.0 & \\
\hline $\begin{array}{l}\text { Permeate Mem } \\
\text { Density }\end{array}$ & 998 & $T_{m p}$ & 22 & \\
\hline $\begin{array}{c}\text { Permeate Mem } \\
\text { Thermal } \\
\text { Conductivity }\end{array}$ & 0.60 & $T_{m t}$ & 58.4 & \\
\hline $\begin{array}{c}\text { Permeate Mem } \\
\text { Specific Heat } \\
\text { Capacity }\end{array}$ & 4183.8 & $\mathrm{Pr}_{\text {wal }, f}$ & 3.1 & \\
\hline $\begin{array}{l}\text { Permeate Mem } \\
\text { Viscosity }\end{array}$ & 0.00098 & $\mathrm{Pr}_{\text {wal }, p}$ & 7 & \\
\hline & & $\mathrm{Nu}_{\mathrm{p}}$ & 1067 & \\
\hline & & $\mathrm{Nu}_{\mathrm{p}}$ & 916.32 & \\
\hline & & $\mathrm{kg}_{\mathrm{g}}$ & 0.03 & \\
\hline & & $k_{5}$ & 0.27 & \\
\hline & & $\beta$ & 0.75 & \\
\hline & & $\mathrm{k}_{\mathrm{m}}$ & 0 & \\
\hline & & $\mathrm{h}_{\mathrm{m}}$ & 289 & \\
\hline & & $h_{r}$ & 6989 & \\
\hline & & $h_{p}$ & 5514.4 & \\
\hline & & $\Delta \mathrm{H}_{\text {vap }}$ & 43320 & \\
\hline & & $T_{m f}$ & 49.6 & \\
\hline & & $\mathrm{T}_{\mathrm{mp}}$ & 33.2 & \\
\hline & & $\mathrm{N}$ (From MT model) & 0.7 & \\
\hline & & $\begin{array}{l}\mathrm{T}_{\mathrm{mf}} \text { change from } \\
\text { previous iteration } \\
\mathrm{T}_{\mathrm{mp}} \text { change from } \\
\text { previous iteration }\end{array}$ & & $\begin{array}{r}8.842 \\
11.417\end{array}$ \\
\hline
\end{tabular}




\section{Mass Transfer Model Iteration Example}

\begin{tabular}{|c|c|}
\hline \multicolumn{2}{|c|}{ Mass Transfer Model } \\
\hline$T_{m}$ & 41.4 \\
\hline Prop (ossuming pure) & 9098 \\
\hline$P_{m \rightarrow 0}$ & 12083.7 \\
\hline $\begin{array}{l}\text { Mole Fraction of } \mathrm{NaCl} \\
\text { at membrane, } x \mathrm{NaCl}\end{array}$ & 0.0001849 \\
\hline $\begin{array}{l}\text { Mole Fraction of } \\
\text { Water, } x w\end{array}$ & 1 \\
\hline Activity Coefficient & 0.999907 \\
\hline $\begin{array}{l}\text { Actual Vapor } \\
\text { Pressure, } \mathrm{Pme}_{\mathrm{m}}(\mathrm{Ps})\end{array}$ & 12000.3 \\
\hline Pressure, $P[\mathrm{~Pa}]$ & 109000 \\
\hline Ges Constant & 8 \\
\hline Tortuosity. & 2.41 \\
\hline $\begin{array}{c}\text { Mesn Temperature of } \\
\text { Membrane, } T_{n}\end{array}$ & 41.4 \\
\hline Botzmsnn Constent & 0 \\
\hline Mesn Pressure, $P_{m}$ & 8589 \\
\hline $\begin{array}{l}\text { Mean Free Path of } \\
\text { Water Molecule, } \lambda\end{array}$ & 1.3E-01 \\
\hline Knudsen Number, $K_{n}$ & $2.9 E-01$ \\
\hline Transfer Mechanism & Difrusive/Knudsen Transition \\
\hline Pore Radius, $r(\mu m)$ & 0.2 \\
\hline Air Pressure, $P_{x}$ & 99411 \\
\hline $\begin{array}{l}\text { Pressure times } \\
\text { Diffusion Coefficient, } \\
\mathrm{PD}_{\mathrm{w}}(\mathrm{Ps}-\mathrm{m} 2 / \mathrm{s})\end{array}$ & 4.4 \\
\hline $\begin{array}{l}\text { Flux Prediction } \\
\text { (Fick's) (kg/m2-s) }\end{array}$ & 0.01225 \\
\hline Flux $x$, dale (molim2-6) & 1 \\
\hline Flux, dae (kg/m2-hr) & 4 \\
\hline Change in Flux & 57.96 \\
\hline Percent Change & 96.80 \\
\hline
\end{tabular}




\section{Concentration Polarization Model Iteration Example}

\begin{tabular}{|c|c|}
\hline \multicolumn{2}{|c|}{ Concentration Polarization Estimation } \\
\hline $\begin{array}{l}\text { Density at Feed side } \\
\text { of membrane, } \rho \\
(\mathrm{kg} / \mathrm{m} 3)\end{array}$ & 992 \\
\hline $\begin{array}{l}\text { Viscosity at Feed side } \\
\text { of membrane ( } \mathrm{Pa}-\mathrm{s})\end{array}$ & $5.52 \mathrm{E}-04$ \\
\hline $\mathrm{D}$ & $1.50 \mathrm{E}-09$ \\
\hline $\mathrm{Sc}$ & 322 \\
\hline Sh & 4373.445451 \\
\hline $\mathrm{K}$ & $6.60 \mathrm{E}-05$ \\
\hline $\begin{array}{l}\text { Concentration at the } \\
\text { feed side of the } \\
\text { membrane, Cmf ( } \% \text { by } \\
\text { Weight }\end{array}$ & 0.072336 \\
\hline $\begin{array}{l}\text { Feed Membrane } \mathrm{NaCl} \\
\text { Molality (mol } / \mathrm{kg} \text { ) }\end{array}$ & 0.012387 \\
\hline
\end{tabular}

